\title{
Gut
}

\section{Epigenetic mechanisms and metabolic reprogramming in fibrogenesis: Dual targeting of G9a and DNMT1 for the inhibition of liver fibrosis}

\begin{tabular}{|c|c|}
\hline Journal: & Gut \\
\hline Manuscript ID & gutjnl-2019-320205.R1 \\
\hline Article Type: & Original research \\
\hline $\begin{array}{r}\text { Date Submitted by the } \\
\text { Author: }\end{array}$ & $\mathrm{n} / \mathrm{a}$ \\
\hline Complete List of Authors: & $\begin{array}{l}\text { Barcena-Varela, Marina; CIMA-University of Navarra, IdiSNA, CIBEREHD, } \\
\text { Hepatology } \\
\text { Paish, Hannah; Newcastle University Faculty of Medical Sciences, } \\
\text { Institute of Cellular Medicine, Newcastle Fibrosis Research Group } \\
\text { Alvarez, Laura; CIMA-University of Navarra, Hepatology } \\
\text { Uriarte, Iker; CIMA-University of Navarra, IdiSNA, CIBEREHD, } \\
\text { Hepatology; CIBEREHD } \\
\text { Latasa, Maria; Cima. University of Navarra, Hepatology and Gene } \\
\text { Therapy } \\
\text { Santamaria, Eva; CIMA-University of Navarra, Hepatology; CIBEREHD } \\
\text { Recalde, Miriam; CIMA-University of Navarra, Hepatology } \\
\text { Garate, Maria; CIMA-University of Navarra, Hepatology } \\
\text { Claveria, Alex; CIMA-University of Navarra, Hepatology } \\
\text { Colyn, Leticia; CIMA-University of Navarra, Hepatology } \\
\text { Arechederra, Maria; Centro de Investigacion Medica Aplicada, } \\
\text { Iraburu, Maria; University of Navarra, Department of Biochemistry and } \\
\text { Genetics } \\
\text { Milkiewicz, Malgorzata ; Pomeranian Medical University, Department of } \\
\text { Medical Biology } \\
\text { Milkiewicz, Piotr; Warsaw Medical University, Department of General, } \\
\text { Transplant and Liver Surgery } \\
\text { Sangro, Bruno; Clinica Universitaria de Navarra, Liver Unit, Dept. of } \\
\text { Internal Medicine } \\
\text { Robinson, Stuart; Newcastle Upon Tyne Hospitals NHS Foundation Trust } \\
\text { French, Jeremy; Newcastle Upon Tyne Hospitals NHS Foundation Trust } \\
\text { Pardo-Saganta, Ana; Cima, University of Navarra, Cell Therapy Program } \\
\text { Oyarzabal, Julen; Cima, University of Navarra, Molecular Therapies } \\
\text { Program } \\
\text { Prosper, Felipe; University of Navarra, Hematology and Cell Therapy } \\
\text { Rombouts, Krista; University College London, UCL, Institute for Liver \& } \\
\text { Digestive Health, Royal Free } \\
\text { Oakley, Fiona ; Newcastle University Faculty of Medical Sciences, } \\
\text { Institute of Cellular Medicine, Newcastle Fibrosis Research Group } \\
\text { Mann, Jelena; Newcastle University Faculty of Medical Sciences, Institute } \\
\text { of Cellular Medicine, Newcastle Fibrosis Research Group } \\
\text { Berasain, Carmen; Cima. University of Navarra, Hepatology Program ; } \\
\text { CIBEREHD } \\
\text { Avila, Matias; CIMA-University of Navarra, Hepatology; CIBEREHD }\end{array}$ \\
\hline
\end{tabular}


G Fernandez-Barrena, Maite; Centro de Investigacion Medica Aplicada, Hepatology Program; CIBEREHD

Keywords: FIBROGENESIS, GLUCOSE METABOLISM, GENE REGULATION

\section{SCHOLARONE \\ Manuscripts}


I, the Submitting Author has the right to grant and does grant on behalf of all authors of the Work (as defined in the below author licence), an exclusive licence and/or a non-exclusive licence for contributions from authors who are: i) UK Crown employees; ii) where BMJ has agreed a CC-BY licence shall apply, and/or iii) in accordance with the terms applicable for US Federal Government officers or employees acting as part of their official duties; on a worldwide, perpetual, irrevocable, royalty-free basis to BMJ Publishing Group Ltd ("BMJ") its licensees and where the relevant Journal is co-owned by BMJ to the co-owners of the Journal, to publish the Work in this journal and any other BMJ products and to exploit all rights, as set out in our licence.

The Submitting Author accepts and understands that any supply made under these terms is made by BMJ to the Submitting Author unless you are acting as an employee on behalf of your employer or a postgraduate student of an affiliated institution which is paying any applicable article publishing charge ("APC") for Open Access articles. Where the Submitting Author wishes to make the Work available on an Open Access basis (and intends to pay the relevant APC), the terms of reuse of such Open Access shall be governed by a Creative Commons licence - details of these licences and which Creative Commons licence will apply to this Work are set out in our licence referred to above.

Other than as permitted in any relevant BMJ Author's Self Archiving Policies, I confirm this Work has not been accepted for publication elsewhere, is not being considered for publication elsewhere and does not duplicate material already published. I confirm all authors consent to publication of this Work and authorise the granting of this licence. 


\section{Epigenetic mechanisms and metabolic reprogramming in fibrogenesis: Dual targeting of G9a and DNMT1 for the inhibition of liver fibrosis}

Short title: Simultaneous inhibition of G9a/DNMT1 to inhibit liver fibrogenesis

Marina Bárcena-Varela ${ }^{1}$, Hannah L. Paish ${ }^{2}$, Laura Álvarez ${ }^{1}$, Iker Uriarte ${ }^{1,3}$, Maria U Latasa $^{1}$, Eva Santamaría ${ }^{1,3}$, Miriam Recalde ${ }^{1}$, María Gárate ${ }^{1}$, Alex Clavería ${ }^{1}$, Leticia Colyn$^{1}$, María Arechederra ${ }^{1,4}$, María J. Iraburu ${ }^{5}$, Malgorzata Milkiewitz ${ }^{6}$, Piotr Milkiewitz $^{7}$, Bruno Sangro ${ }^{3,4,8}$, Stuart M. Robinson ${ }^{9}$, Jeremy French ${ }^{9}$, Ana PardoSaganta $^{10}$, Julen Oyarzábal ${ }^{11}$, Felipe Prósper ${ }^{4,12}$, Krista Rombouts ${ }^{13}$, Fiona Oakley ${ }^{2}$,

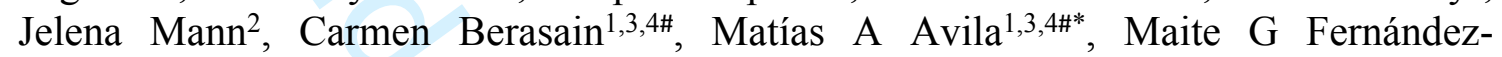
Barrena ${ }^{1,3,4 \#^{*}}$

1. Hepatology Program. Cima, University of Navarra, 31008 Pamplona, Spain.

2. Newcastle Fibrosis Research Group, Institute of Cellular Medicine, Faculty of Medical Sciences, Newcastle University, Newcastle upon Tyne, NE2 4HH, UK.

3. CIBERehd, Instituto de Salud Carlos III, 28029 Madrid, Spain.

4. Instituto de Investigaciones Sanitarias de Navarra-IdiSNA, 31008 Pamplona, Spain.

5. Department of Biochemistry and Genetics, University of Navarra, 31008 Pamplona, Spain

6. Department of Medical Biology, Pomeranian Medical University, 70-204 Szczecin, Poland.

7. Liver and Internal Medicine Unit, Department of General, Transplant and Liver Surgery, Medical University of Warsaw, 02-091 Warsaw, Poland.

8. Hepatology Unit, Navarra University Clinic, 31080 Pamplona, Spain.

9. Department of Gastroenterology and Hepatology, Newcastle upon Tyne Hospitals NHS Foundation Trust, Newcastle upon Tyne, NE2 4HH, UK.

10. Cell Therapy Program. Cima, University of Navarra, 31008 Pamplona, Spain. 11. Molecular Therapies Program. Cima, University of Navarra, 31008 Pamplona, Spain.

12. Oncohematology Program, Cima, University of Navarra, 31008 Pamplona, Spain.

13. Institute for Liver and Digestive Health, University College London NW3 2PF, UK.

\#Co-senior authors

\section{* Correspondence:}

Matias A Avila and Maite G Fernandez-Barrena.

Hepatology Program, CIMA, University of Navarra. Avda. Pio XII, n55, Pamplona, 31008

Spain. Tel: +34-948-194700. E-mail: maavila@unav.es, magarfer@unav.es.

Conflict of interest: F.O and J.M are directors of Fibrofind Ltd. H.P, F.O, and J.M are shareholders in Fibrofind Ltd.

Word count: 4374. 


\begin{abstract}
Abbreviations:
ECM: extracellular matrix; HSC: hepatic stellate cells; TGF $\beta 1$ : transforming growth factor- $\beta 1$; MeCP2: methyl-CpG binding protein; HMTs: histone methyltransferases; EZH2: enhancer of zeste homolog-2; ASH1: absent, small, or homeotic disc 1; DNMTs: DNA-methyltransferases; EHMT2: euchromatin histone-lysine methyltransferase 2; HCV: hepatitis C virus; HBV: hepatitis B virus; ALD: alcoholic cirrhosis; PSC: primary sclerosing cholangitis; BDL: bile duct ligation; PCLSs: precision cut liver slices; PDGF$\mathrm{BB}$ : platelet-derived growth factor-BB; Alk5i: activin receptor-like kinase 5 inhibitor; aSMA: $\alpha$-smooth muscle actin; UHRF1: ubiquitin-like with PHD and RING finger domains-1; 5meC: 5-methyl-cytosine; GFAP: glial fibrillary acidic protein; Lrat: lecithinretinol acyltransferase; GO: gene ontology; GSEA: gene set enrichment analysis; PPAR: peroxisome proliferator-activated receptor; PDGFR $\beta$ : platelet-derived growth factor receptor- $\beta$; HIF: hypoxia-inducible factor; TIMP1: tissue inhibitor of metalloproteases 1 ; LOX: lysyl oxidase; LDHA: lactate dehydrogenase A; OCR: oxygen consumption rate; ECAR: extracellular acidification rate; PGC-1 $\alpha$ : peroxisome proliferator activated receptor gamma coactivator-1 $\alpha$; HK-I: hexokinase-I; PFKFB3: 6-phosphofructo-2kinase/fructose-2,6-biphosphatase 3; ALDOA: aldolase-A; PGK-I: phosphoglycerate kinase-I; PKM2: pyruvate kinase M2; PHGDH: phosphoglycerate dehydrogenase; PSAT1: phosphoserine aminotransferase 1; PSPH: phosphoserine phosphatase; SHMT2: serine hydroxymethyl transferase 2; PEPCK: phosphoenolpyruvate-carboxykinase; FBP1: fructose-1,6-bisphosphatase-1; OXPHOS: oxidative phosphorylation; MSP: methylation-specific PCR; ColIa1: collagen type I- $\alpha-1$; LDH: lactate dehydrogenase.
\end{abstract}

\title{
Contributorship Statement
}

- Performed experiments and data interpretation: MBV, HLP, LA, IU, MUL, ES, MR, MG, AC, LC, MA, MJI, MM, APS

- Provided key biological samples and materials: PM, BS, SMR, JF, JO, FP, KR, FO, JM.

- Critical revision of the manuscript: JO, FP, KR, FO, JM, MJI, CB.

- Study design, data interpretation, manuscript writing and submission: $\mathrm{CB}, \mathrm{MGFB}$, MAA. 


\begin{abstract}
Objective. Hepatic stellate cells (HSC) transdifferentiation into myofibroblasts is central to fibrogenesis. Epigenetic mechanisms, including histone and DNA methylation, play a key role in this process. Concerted action between histone and DNA-mehyltransferases like G9a and DNMT1 is a common theme in gene expression regulation. We aimed to study the efficacy of CM272, a first-in-class dual and reversible G9a/DNMT1 inhibitor, in halting fibrogenesis.
\end{abstract}

Design. G9a and DNMT1 were analyzed in cirrhotic human livers, mouse models of liver fibrosis and cultured mouse HSC. G9a and DNMT1 expression was knocked-down or inhibited with CM272 in human HSC (hHSC), and transcriptomic responses to transforming growth factor- $\beta 1$ (TGF $\beta 1$ ) were examined. Glycolytic metabolism and mitochondrial function were analyzed with Seahorse-XF technology. Gene expression regulation was analyzed by chromatin immunoprecipitation and methylation-specific PCR. Antifibrogenic activity and safety of CM272 were studied in mouse chronic $\mathrm{CCl}_{4}$ administration and bile duct ligation (BDL), and in human precision-cut liver slices (PCLSs) in a new bioreactor technology.

Results. G9a and DNMT1 were detected in stromal cells in areas of active fibrosis in human and mouse livers. G9a and DNMT1 expression was induced during mouse HSC activation, and TGF $\beta 1$ triggered their chromatin recruitment in hHSC. G9a/DNMT1 knockdown and CM272 inhibited TGF $\beta 1$ fibrogenic responses in hHSC. TGF $\beta 1$ mediated profibrogenic metabolic reprogramming was abrogated by CM272, which restored gluconeogenic gene expression and mitochondrial function through on-target epigenetic effects. CM272 inhibited fibrogenesis in mice and PCLSs without toxicity.

Conclusions. Dual G9a/DNMT1 inhibition by compounds like CM272 may be a novel therapeutic strategy for treating liver fibrosis.

Keywords. Fibrogenesis, glucose metabolism, gene regulation. 


\section{What is already known on this subject?}

- The progression of liver fibrosis depends on the activation and transdifferentiation of hepatic stellate cells into a myofibroblastic phenotype.

- Epigenetic mechanisms have been shown to control many aspects of fibrogenesis in the liver.

- Metabolic reprogramming is emerging as a key process in the activation of fibrogenic cells in different organs.

\section{What are the new findings?}

- Together with DNMT1, the histone methyltransferase G9a is expressed in fibrogenic cells in cirrhotic human liver, in chronically injured mouse liver and upon activation of cultured mouse HSC.

- G9a and DNMT1 expression is required for fibrogenic activation of HSC by TGF $\beta 1$.

- Pharmacological targeting of DNMT1 and G9a with the novel first-in-class dual G9a/DNMT1 inhibitor CM272 counteracts the pro-fibrogenic responses and metabolic reprogramming of HSC elicited by TGF $\beta 1$.

- CM272 administration shows antifibrogenic activity in clinically relevant mouse models of liver fibrosis and in human precision-cut liver slices without causing toxic effects.

\section{How might it impact on clinical practice in the foreseeable future?}

- The development of effective antifibrotic therapies is much needed not only for chronic liver disease but also for other organs like the lung and kidney. Targeting the complex epigenetic mechanisms involved in fibrogenesis with innovative molecules like CM272 may pave the way for better therapies. 


\section{INTRODUCTION}

The fibrogenic response is part of the natural reparative reaction in different tissues and organs. This process leads to the formation of a temporary extracellular matrix (ECM) which after wound repair is degraded and tissue architecture is restored. However, when damage persists, as occurs in liver chronic viral infection, alcohol abuse or in nonalcoholic fatty liver disease, the equilibrium between ECM production and removal is ultimately lost resulting in excessive accumulation of a dense ECM rich in fibrillar collagens.[1] This ECM is a physical barrier that perturbs organ's perfusion, contributes to loss of liver function, progression to cirrhosis and hepatocellular carcinoma development.[1,2] The pathological relevance of liver fibrogenesis has driven very active research over the past decades. One major finding was the realization of the highly dynamic nature of the process, including clinical findings showing fibrosis reversion upon removal of the causative agent.[1] The major cellular source of collagen are the liver myofibroblasts, mesenchymal cells mainly derived from hepatic stellate cells (HSC) and periportal fibroblasts.[3] In the normal liver HSC show a quiescent and differentiated phenotype which upon hepatic injury is substantially altered. A plethora of cytokines, small molecules and growth factors, with transforming growth factor- $\beta 1$ (TGF $\beta 1$ ) playing a central role, contribute to HSC activation and conversion into proliferative and inflammatory collagen-secreting myofibroblasts.[3] A profound metabolic reprogramming, including a shift towards aerobic glycolysis, was recently identified as an essential mechanism in HSC activation.[4,5] Earlier evidence indicated that during fibrosis regression myofibroblasts were removed by apoptosis or entered a senescent profibrolytic state prone to immune-mediated clearance.[1] However, later studies demonstrated that upon cessation of injury a significant proportion of myofibroblasts also undergo reversion to a deactivated phenotype.[6,7] Together, these findings attest to the 
plasticity of HSC and provide valuable insights for the development of much needed antifibrogenic strategies.[8]

Extensive changes in the HSC's transcriptome occur during their transition into hepatic myofibroblasts and upon cessation of injury their reversion to quiescence.[1,7] In this context epigenetic mechanisms are increasingly recognized to play a central role.[9] DNA hypomethylation has been associated with fibrogenic gene activation, while repression of genes that maintain HSC differentiation and quiescence was linked to increased methylCpGs abundance in their regulatory regions.[10][11] Mechanistically, to control gene expression DNA methylation works in concert with other epigenetic modifications such acetylation and methylation of lysine residues in histones H3 and H4.[9] The methyl-CpG binding protein $\mathrm{MeCP} 2$ plays a key function in this process, orchestrating the activity of the histone methyltransferases (HMTs) enhancer of zeste homolog-2 (EZH2) and absent, small, or homeotic disc 1 (ASH1) during the reprogramming of HSC transcriptome to the myofibroblast phenotype.[12,13] From a translational perspective, it is important to consider that epigenetic modifications are reversible and amenable to pharmacological intervention. Indeed, the antifibrogenic effects of histone deacetylase inhibitors were already reported twenty years ago.[14] More recently it was demonstrated that targeting DNA-methyltransferases (DNMTs) with 5-azadeoxycytidine prevents HSC fibrogenic activation, while inhibition of HMTs halts hepatic fibrosis progression in mice.[15-17] Similarly, pharmacological inhibition of the H3K9 methyltransferase G9a, also known as euchromatic histone-lysine methyltransferase 2 (EHMT2), has been recently shown to reduce kidney and lung fibrosis, although the underlying mechanisms are not fully understood.[18,19] Concerted action between DNMTs and HMTs appears a common theme in physiological transcriptional control, of tissue homeostasis. However, when dysregulated this crosstalk can cause disease, including tumorigenesis.[20,21] This has 
been demonstrated for G9a, which physically and functionally interacts with DNMT1 driving tumor cell proliferation and adaptation to hypoxia, among other cancer traits.[22,23] Therefore, the simultaneous targeting of G9a and DNMT methyltransferase activities could be a more effective therapeutic strategy. With this in mind, we recently developed a new series of potent first-in-class, selective and reversible dual small molecule inhibitors against G9a and DNMT activity with an excellent in vivo safety profile.[24,25] These compounds are very effective against hematological malignancies,[24] and also in HCC models, particularly on HSC-driven HCC growth.[26] Here we demonstrate the therapeutic potential of dual G9a/DNMT targeting in experimental liver fibrosis and show how this epigenetic mechanism can control TGF $\beta 1$ mediated pro-fibrogenic metabolic reprogramming and HSC activation. 


\section{MATERIALS AND METHODS}

\section{Human samples}

Liver tissue samples and patients' data were provided by the Biobank of the University of Navarra (Pamplona, Spain) or by the Medical University of Warsaw (Warsaw, Poland). Samples were from patients with hepatitis C virus $(\mathrm{HCV})(\mathrm{n}=10)$ and HBV $(n=10)$ infection and alcoholic cirrhosis (ALD) $(n=10)$. All of them presented cirrhosis and underwent liver transplantation. Control liver tissue samples $(n=5)$ were obtained from large-margin liver resections of colorectal metastases showing no pathologist-identified microscopic changes of liver disease. Liver tissue specimens were paraffin embedded and stored at $-75^{\circ} \mathrm{C}$ until use. Written informed consent was obtained from each patient and samples were processed following standard operating procedures approved by the Ethical and Scientific Committees of the University of Navarra and the Medical University of Warsaw.

\section{Mouse models}

C57BL/6J male mice 6-8 weeks old ( $\mathrm{n}=6-8$ mice per group) were used. For acute $\mathrm{CCl}_{4}$ treatment mice received a 1:1 mixture of $\mathrm{CCl}_{4}$ and olive oil $\left(1 \mu \mathrm{L} \mathrm{CCl}_{4} / \mathrm{g}\right.$ body weight, i.p), 24h later mice received one injection of CM272 (5mg/Kg, i.p.) or vehicle (PBS), and 24h later were humanely killed. For chronic $\mathrm{CCl}_{4}$ treatment, mice received a 1:3 mixture of $\mathrm{CCl}_{4}$ and olive oil $\left(0.67 \mu \mathrm{L} \mathrm{CCl} \mathrm{Cl}_{4} / \mathrm{g}\right.$ body weight, i.p. $)$ twice per week for 6 weeks to induce fibrosis. For the last two weeks animals received daily injections of CM272 $\left(5 \mathrm{mg} / \mathrm{Kg}\right.$, i.p) or PBS. Mice were humanely killed at day 1 and 4 after the last $\mathrm{CCl}_{4}$ injection. Bile duct ligation (BDL) was performed as described.[12] [27] From day 2 postsurgery animals received daily injections of CM272 (2.5mg/Kg) or PBS (i.p.) and were humanely killed after 11 days. Animal care and procedures were approved by the Animal 
Care Committee of the University of Navarra or the Newcastle Animal Welfare and Ethical Review Board and performed under a UK Home Office license.

\section{Precision cut liver slices (PCLSs) experiments}

Human liver tissue was obtained from normal resection margins surrounding colorectal metastases from adult patients undergoing surgical resection at the Freeman Hospital (Newcastle-upon-Tyne, UK). Informed consent was obtained from all patients and study was approved by the Newcastle \& North Tyneside Research Ethics Committee. PCLSs were obtained from agarose embedded tissues cut with a Leica VT1200S vibratome and cultured in a rocking bioreactor platform as previously described.[28] PCLSs were rested for $24 \mathrm{~h}$ and were then treated with TGF $\beta 1(3 \mathrm{ng} / \mathrm{mL})$ and platelet-derived growth factorBB (PDGF-BB) (50ng/mL) from Peprotech (London, UK), activin receptor-like kinase-

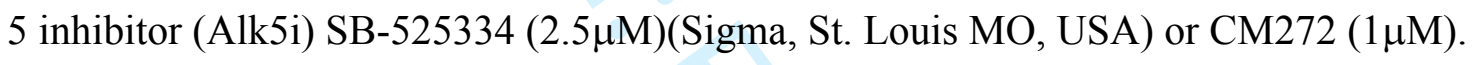
Additional methods are provided in Supplementary Methods. 


\section{RESULTS}

\section{Expression of G9a and DNMT1 in activated HSC.}

We performed immunohistochemical staining of liver tissue samples from patients with viral cirrhosis and ALD. We detected the presence of G9a and DNMT1 in activated myofibroblasts ( $\alpha$-smooth muscle actin, $\alpha$-SMA-expressing cells) (Fig. 1A, Supporting Fig. S1 and S2). G9a and DNMT1 were also detected in mouse liver myofibroblasts after chronic $\mathrm{CCl}_{4}$ injury or BDL (Fig. 1B, Supporting Fig. S3). Next, we examined the expression of G9a and DNMT1 in quiescent and culture-activated mouse HSC. We found that G9a and DNMT1 protein levels were significantly induced between day 1 and day 4 of culture in parallel with $\alpha$-SMA, a marker of HSC myofibroblastic transdifferentiation (Fig. 2A).[3] The expression of ubiquitin-like with PHD and RING finger domains-1 (UHRF1), a key coordinator of DNA methylation during DNA replication and a functional adaptor between DNMT1 and G9a,[29] was also increased in culture-activated HSC (Fig. 2A). The mRNA levels of these three genes also increased upon HSC activation (Fig. 2A). Interestingly, in LX2 cells, a well-characterized model of human HSC,[30] TGF $\beta 1$ stimulation induced the rapid recruitment of the three proteins to the nuclear chromatin subfraction, without significantly changing their expression (Fig. 2B). Combined, these observations suggested a role for G9a and DNMT1, together with UHRF1, in HSC activation. To directly address this point, we examined TGF $\beta 1$ responses in LX2 cells after siRNA-mediated knockdown of these genes (Supporting Fig. S4). We found an overall impairment of TGF $\beta 1$-activated profibrogenic gene expression, an effect that was particularly strong upon $G 9 a$ downregulation (Fig. 2C). 


\section{Dual targeting of G9a and DNMT1 inhibits hypoxia- and TGF $\beta 1$-driven activation of HSC.}

These observations and our previous findings, [26] suggested that interference with G9a/DNMT1 activities may counteract HSC activation. Therefore, we tested the effects of CM272, our lead G9a/DNMT dual inhibitory compound,[24] on LX2 cells. We demonstrated that CM272 decreased global DNA methylation (5-methyl-cytosine [5meC]) and H3K9me2 levels without affecting other histone marks (Supporting Fig. S5A and B). Next we observed a marked impairment of TGF $\beta 1$ effects on key fibrogenic genes expression, including COL1 $\alpha 1$ and TGF $\beta 1$ itself (Fig. 3A and Supporting Fig. S5C), while glial fibrillary acidic protein $(G F A P)$, a marker of quiescent $\mathrm{HSC},[3,31]$ was upregulated (Fig. 3A). These effects were reproduced in primary human HSC (Supporting Fig. S5D). Interestingly, culture-activation of primary mouse HSC was also reduced by CM272 treatment, as indicated by the expression of Colla1, Timp1 and lecithin-retinol acyltransferase (Lrat) (Supporting Fig. S5E). In agreement with the impaired response to TGF $\beta 1$ stimulation when G9a and DNMT1 were knocked-down in LX2 cells (Fig. 2C) we found that combined treatment with the DNMT1 inhibitor decitabine and the G9a inhibitor BIX01294 also dampened the pro-fibrogenic responses to this growth factor (Supporting Fig. S5F). Together with TGF $\beta 1$, hypoxia is considered a major driver of liver fibrogenesis.[32,33] Consistently, we found that hypoxia stimulated LX2 cells growth and that CM272 inhibited this response as well as basal cell growth under normoxia (Fig. 3B). Moreover, fibrogenic gene expression induction by hypoxia was also blunted by CM272 (Fig. 3B). To better understand the effects of CM272 on fibrogenic cells activation, we performed a microarray analysis of gene expression in LX2 cells treated with TGF $\beta 1$ in the presence or absence of the drug. CM272 markedly affected TGF $\beta 1$-mediated gene expression regulation, with 1930 upregulated and 1442 
downregulated genes $(P<0.01)$ compared to cells treated with TGF $\beta 1$ alone (Fig. 3C). Gene ontology (GO) functional classification fundamentally identified categories related to cell growth, differentiation, signalling, metabolism, chromatin regulation and response to hypoxia (Fig. 3C). Accordingly, when we applied gene set enrichment analysis (GSEA), a significant positive enrichment in genes of the KEGG peroxisome proliferatoractivated receptor (PPAR) signaling pathway, as well as the reactome "metabolism of steroid hormones and vitamins A and D”, was detected in cells treated with CM272 (Fig. 3D). Also consistent with our GO analyses and with the effects of CM272 on TGF $\beta 1$ and hypoxia-mediated fibrogenic activation, we found significant negative enrichments in gene sets involved in TGF $\beta 1$, platelet derived growth factor receptor- $\beta$ (PDGFR $\beta$ ) and hypoxia-inducible factor (HIF) pathways (Fig. 3D). Interestingly, a negative enrichment was also observed in the KEGG glycolysis/gluconeogenesis gene set (Fig. 3D). Collectively, these findings indicate that G9a/DNMT1 targeting with CM272 profoundly affects the fibrogenic activation of liver myofibroblasts and the involved metabolic adaptations.

\section{Mechanisms of the inhibitory effects of CM272 on hepatic myofibroblasts activation.}

In view of the antagonism of CM272 on TGF $\beta 1$ cellular responses we first checked wether TGF $\beta 1$ signaling could be affected. We found that CM272 treatment attenuated SMAD3 phosphorylation in response to TGF $\beta 1$ in LX2 cells (Supporting Fig. S6A). Different mechanisms have been involved in the regulation of TGF $\beta 1$ signaling, among them is the expression of the TGF $\beta$ pseudoreceptor bone morphogenic protein and activin membrane-bound inhibitor (BAMBI) in different cell types but also in liver myofibroblasts.[34] Interestingly, we observed that CM272 treatment increased the expression of this negative regulator of TGF $\beta 1$ signaling in LX2 cells (Supporting Fig. S6B). However, the antifibrogenic effects of CM272 may extend beyond the direct 
inhibition of TGF $\beta 1$ signaling. As previosuly shown in Fig. 3A, the basal expression of several genes including $T G F \beta 1, P D G F R \beta, P A I 1, L O X$ and $G F A P$ was regulated by CM272 in LX2 cells in the absence of TGF $\beta 1$. Interestingly, we found that these responses were also observed in the presence of the TGF $\beta 1$ receptor-1 inhibitor (Alk5i) SB-525334 regardless of TGF $\beta 1$ stimulation (Supporting Fig. S6C).

Metabolic reprogramming is emerging as a critical event in fibrogenic activation across different tissue types.[4,5,35,36] Therefore, we examined the effects of CM272 on oxygen consumption rate (OCR; a representation of mitochondrial activity) and the extracellular acidification rate (ECAR; a surrogate for glycolytic rate) in LX2 cells treated with TGF $\beta 1$. As recently reported we found that TGF $\beta 1$ reduced OCR and increased ECAR,[36] however these effects were attenuated by CM272 (Fig. 4A). Consistently, the relative contribution to ATP production of glycolysis $v s$ oxidative phosphorylation, which was increased by TGF $\beta 1$, was mitigated by CM272 treatment (Fig. 4B). TGF $\beta 1$-triggered lactate production, a hallmark of the glycolytic phenotype contributing to fibrogenesis,[4] was also attenuated by CM272 (Fig. 4C). Changes in the expression of key glycolytic and gluconeogenic genes have been mechanistically linked to metabolic reprogramming and activation of fibrogenic cells.[3,35,37,38] Consistently, when glycolysis was inhibited using the glucose analog 2-deoxy-D-glucose (2DG) (Supporting Fig. S7A) we found that TGF $\beta 1$-mediated fibrogenic gene expression in LX2 cells was impaired (Supporting Fig. S7B). Next, we tested the expression of the glycolytic genes hexokinase-I $(H K-I), 6-$ phosphofructo-2-kinase/fructose-2,6-biphosphatase 3 (PFKFB3), aldolase-A (ALDOA), phosphoglycerate kinase-I (PGK-I), pyruvate kinase M2 (PKM2) and lactate dehydrogenase A $(L D H A)$ in LX2 cells treated with TGF $\beta 1$ and CM272. CM272 reduced the basal expression of these genes and/or markedly counteracted the stimulatory effect of TGF $\beta 1$ on most of them (Fig. 4D). Recent studies in lung fibroblasts demonstrated that 
besides glycolytic activation TGF $\beta 1$ also triggers the expression of enzymes of the serineglycine biosynthetic pathway, a key source of glycine critically needed for collagen synthesis.[38-40] The serine-glycine biosynthetic pathway diverges from glycolysis via 3-phosphoglycerate, which in four consecutive steps is converted into glycine by the action of phosphoglycerate dehydrogenase (PHGDH), phosphoserine aminotransferase1 (PSAT1), phosphoserine phosphatase (PSPH) and finally serine hydroxymethyl transferase-2 (SHMT2) (Fig. 4D).[38,40] TGF $\beta 1$ induced the expression of the serineglycine pathway genes, and this effect was blunted by CM272 (Fig. 4D), which also reduced the basal expression of $P H G D H$ and the levels of $\mathrm{H} 3 \mathrm{~K} 9$ monomethylation (Fig. 4D and Supporting Fig. S7C), a transcriptional activating epigenetic modification mediated by G9a.[41] Moreover, hypoxia-triggered expression of these genes in LX2 cells was also reduced by CM272 (Supporting Fig. S8A). Noteworthy, the serine-glycine metabolic pathway is indeed important for the activation of LX2 cells, as indicated by the inhibitory effects of NCT503, a PHGDH enzymatic inhibitor,[42] on hypoxia-elicited growth and TGF $\beta 1$-induced collagen synthesis in these cells (Supporting Fig. S8B). Very interestingly, the expression of the rate-limiting gluconeogenic enzymes phosphoenolpyruvate-carboxykinase $(P E P C K)$ and fructose-1,6-bisphosphatase-1 (FBP1), repressed during fibrogenic activation,[4] was also inhibited by TGF $\beta 1$, but restored under CM272 treatment (Fig. 4D). Moreover, the expression of the transcription factor and metabolic regulator peroxisome proliferator activated receptor gamma coactivator-1 $\alpha(P G C-1 \alpha)$, recently identified as a key guardian of lung fibroblasts quiescence, $[19,37]$ was also repressed by TGF $\beta 1$ and was potently reactivated upon CM272 treatment (Fig. 4D). These responses to CM272 were reproduced in human primary HSC (Supporting Fig. S9A). Importantly, the upregulation of FBP1 and PGC$1 \alpha$ expression by CM272 (Fig. 4E) was related to the on-target pharmacological actions 
of this molecule. By qChIP analyses we found that CM272 reduced the levels of the repressive $\mathrm{H} 3 \mathrm{~K} 9 \mathrm{me} 2$ mark in the proximal promoters of $F B P 1$ and $P G C-1 \alpha$ (Fig. 4F). At the DNA level, FBPI promoter was found hypermethylated in a region previously associated with its transcriptional repression in cancer,[26] and DNA methylation was reduced upon CM272 or decitabine treatment (Fig. 4G). Regarding $P G C$ - $1 \alpha$, we did not find significant levels of DNA methylation (Fig. 4G), suggesting that its transcriptional repression could be mainly mediated by G9a-H3K9 dimethylation, which indeed was reversed by CM272 treatment (Fig. 4F). In support of these notions we observed that FBP1 expression was upregulated by decitabine or BIX01294, and together both agents had an additive effect, while PGC-1 $\alpha$ expression was induced only by BIX01294 (Supporting Fig. S9B).

\section{CM272 inhibits hepatic fibrogenesis in vivo.}

Next, we examined the antifibrogenic potential of CM272 in different mouse models. First, we tested the effects of CM272 on the acute activation of $\mathrm{HSC}$ upon single $\mathrm{CCl}_{4}$ injection. We found that CM272 administration $24 \mathrm{~h}$ after $\mathrm{CCl}_{4}$ markedly inhibited $\mathrm{HSC}$ activation as indicated by $\alpha$-SMA expression (Supporting Fig. S10A). The antifibrogenic activity of CM272 was also evident in chronic liver injury. Mice received $\mathrm{CCl}_{4}$ twice a week for 6 weeks, and for the last two weeks were treated with CM272 or its vehicle (Fig. 5A). $\alpha$-SMA and Sirius red staining for collagen deposition demonstrated reduced liver fibrosis in CM272-treated mice (Fig. 5A), corroborated by decreased expression of collagen-I $\alpha 1$ (Coll $\alpha 1$ ), $\alpha$-Sma and Tgf $\beta 1$ (Fig. 5B). Interestingly, expression of Pkm2, previously identified as a marker of glycolytic activation in liver myofibroblasts and a key regulator of glycolysis and the serine-glycine pathway,[4,43] was induced by $\mathrm{CCl}_{4}$ administration. Noteworthy, $P k m 2$ expression was significantly attenuated by CM272 treatment, as was that of Phgdh (Fig. 5A and 5B). The antifibrotic effects of CM272 were 
reproduced in a model of cholestatic liver injury induced by BDL, as demonstrated by reduced $\alpha$-SMA immunostaining, collagen deposition and expression of fibrogenesis-and glycolysis-related genes (Fig. $5 \mathrm{C}$ and D). As in the $\mathrm{CCl}_{4}$ model, $P \mathrm{~km} 2$ expression was also increased in areas of active fibrosis and was downregulated by CM272 (Fig. 5C). No significant differences in serum transaminases and creatinine levels nor body weight were found between vehicle and CM272 treated mice in either model, while a decrease in the hepatic expression of pro-inflammatory cytokines was noticed (Supporting Fig. S10B and C). Together these findings demonstrate that in vivo targeting of G9a/DNMT1 with CM272 during ongoing liver injury has antifibrotic potential and is exempt of overt toxicity.

\section{CM272 has antifibrotic activity in human precision-cut liver slices (PCLSs).}

To further validate the antifibrotic effects of CM272 we used human PCLSs cultured in a newly designed bioreactor that allows modeling active fibrogenesis induced by pathophysiological stimuli; TGF $\beta 1$ and PDGF-BB.[28] First, we observed that $G 9 a$, DNMT1 and UHRF1 expression was significantly increased after $96 \mathrm{~h}$ in culture compared to freshly isolated tissues, and TGF $\beta 1+$ PDGF-BB enhanced this response (Fig. 6A). Immunohistochemical analyses of PCLSs detected G9a and DNMT1 proteins in regions of the parenchyma enriched in $\alpha$-SMA positive cells (Fig. 6B). Next, we tested the effects of CM272 treatment on TGF $\beta 1+$ PDGF-BB-mediated fibrogenic activation of PCLSs (Fig. 6A). PCLSs were incubated with TGF $\beta 1+P D G F-B B$ in the absence or presence of CM272 or the TGF $\beta 1$ receptor-1 inhibitor (Alk5i) SB-525334.[28] As shown in Fig. 6C, the upregulation of fibrogenic gene expression elicited by TGF $\beta 1+$ PDGF-BB was significantly attenuated by CM272. Consistently, soluble collagen secretion into the culture media, its deposition in the fibrotic matrix, and $\alpha$-SMA staining were also markedly inhibited (Fig. 6D and E). Interestingly, lactate accumulation in the culture 
medium, indicative of metabolic glycolytic reprogramming, was inhibited not only by SB-525334 but also very efficiently by CM272 (Fig. 6F). Accordingly, FBP1 expression was downregulated by TGF $\beta 1+$ PDGF-BB treatment while that of $P K M 2$ and $P H G D H$ was induced (Fig. 6G). These changes were also reversed by SB-525334 and CM272 (Fig. 6G). Immunohistochemical staining of PCLSs detected PKM2 expression in fibrogenic cells, validating the activation of glycolysis in human liver tissues by fibrogenic stimuli, and its inhibition by CM272 (Fig. 6H). Our PCLSs model may also provide valuable information on potential hepatotoxic effects of experimental therapies in a human liver tissue environment.[28] We measured a series of parameters, including albumin and urea levels, and lactate dehydrogenase (LDH), AST and ALT activities in conditioned media from control and CM272 treated PCLSs. We found no significant differences on these markers of hepatocellular function and injury in comparison with controls (Fig. 7A), and no major histological alterations upon H\&E staining were observed either (Fig. 7B). 


\section{DISCUSSION}

Accumulating evidence shows the involvement of epigenetic mechanisms in the activation of quiescent hepatic ECM-producing cells and the maintenance of their fibrogenic phenotype. $[9,11]$ Here we confirmed the overexpression of DNMT1 in human and mouse fibrotic liver,[44] and report the concomitant upregulation of the HMT G9a. Our novel findings indicate that these epigenetic effectors, together with their functional adaptor UHRF1,[29] contribute to HSC fibrogenic activation. Besides their marked induction during primary mouse HSC activation in culture, we observed that TGF $\beta 1$ stimulation led to their fast recruitment to the chromatin-bound nuclear subfraction in LX2 cells. This response has been observed for other transcriptional regulators involved in TGF $\beta 1$ control of gene expression such as activating transcription factor-4.[40] Here we extend this dynamic effect of TGF $\beta 1$ to epigenetic factors. However, compelling evidence on the involvement of G9a, DNMT1 and UHRF1 in liver fibrogenic cell activation was obtained when their expression was inhibited (siRNAs) in LX2 cells and we observed that the pro-fibrogenic transcriptomic response to TGF $\beta 1$ was abrogated. This genetic evidence, together with the extensive functional crosstalk between different chromatin regulatory mechanisms, such as DNA and H3K9 methylation,[21] prompted us to characterize in detail the antifibrogenic potential of a novel dual G9a/DNMT inhibitor CM272.[24] We observed that CM272 markedly inhibited TGF $\beta 1$-stimulated pro-fibrogenic gene expression in LX2 and human primary HSC. Interestingly, these effects of CM272 were not restricted to TGF $\beta 1$ action, as they were also observed under hypoxia, another key proliferative and fibrogenic stimulus for HSC.[32,33] To elucidate the mechanisms underlying CM272 activity we performed transcriptomic studies in LX2 cells treated with TGF $\beta 1$ in the absence or presence of the drug. Consistent with the inhibition of TGF $\beta 1$-triggered fibrogenic activation, our GSEA found negative 
enrichment in categories associated with TGF $\beta 1$ and PDGFRB signaling pathways. Interestingly, the HIF pathway, which critically participates in TGF $\beta 1$-mediated kidney fibrogenesis,[45] was also negatively affected by CM272. Notwithstanding the mechanistic relevance of these responses, it was the effect of CM272 on the expression of metabolism-related genes that captured our attention. Incipient, but nonetheless robust evidence on the importance of metabolic reprogramming for fibrogenic cell activation is steadily accumulating. Similar to the Warburg effect in cancer cells, glycolytic activation along with mitochondrial dysfunction have been shown to contribute to fibrogenesis in different tissues.[5,35-37] Early evidence obtained in liver myofibroblasts showed how reciprocal changes in glycolytic and gluconeogenic enzymes triggered by hedgehog signaling were mechanistically linked to HSC activation.[4] Here we found that TGF $\beta 1$ elicited very similar responses, inducing the expression of most genes coding for glycolytic enzymes and repressing that of the rate-limiting gluconeogenic genes FBP1 and $P E P C K$, as well as the metabolic regulator $P G C-1 \alpha$, which downregulation in lung fibroblasts markedly contributes to their activation.[37] These transcriptional effects of TGF $\beta 1$ translated into metabolic alterations, including enhanced glycolytic rate and decreased mitochondrial activity. Consequently, ATP production shifted from a preferentially mitochondrial origin (OXPHOS) to a glycolytic one. In agreement with recent findings in lung myofibroblasts,[38] we found that in human HSC TGF $\beta 1$ markedly stimulated the expression of genes in the serine-glycine pathway. This pathway is not only essential for the supply of glycine for collagen synthesis, [38,39] it also connects glycolysis with one-carbon metabolism and nucleotide synthesis, required for cell proliferation.[42] We found that CM272 treatment effectively reversed the transcriptional program triggered by TGF $\beta 1$ and its impact on glycolytic activity and mitochondrial function. The molecular mechanisms underlying these effects are likely 
complex, but to a great extent may be attributed to specific pharmacological activities of CM272. We believe that one central target gene in the antifibrogenic effects of CM272 would be FBP1. As we showed, the expression of $F B P 1$ is downregulated in activated liver myofibroblasts through epigenetic mechanisms involving increased DNA and H3K9 methylation in its promoter, modifications that were reversed by CM272. FBP1 is not only a key gluconeogenic enzyme, it is also able to suppress HIF-1 $\alpha$ activity by direct binding and acting as a transcriptional corepressor of HIF-1 $\alpha$ target genes, which include most of glycolytic enzymes.[46] Moreover, FBP1-mediated suppression of HIF-1 $\alpha$ activity may also be involved in the antagonistic effects of CM272 on TGF $\beta 1$ responses, as the HIF-1 $\alpha$ pathway is co-opted by TGF $\beta 1$ for its pro-fibrogenic activity even under normoxia.[45,47] Regarding the normalization of mitochondrial function, together with FBP1 reactivation[48] the enhanced expression of PGC-1 $\alpha$ by CM272 treatment may also be relevant. PGC- $1 \alpha$ is a master metabolic regulator, with roles including the preservation of mitochondrial function and the regulation of gluconeogenic gene expression (e.g. PEPCK).[49] Recently, transcriptional repression of $P G C-1 \alpha$ has been critically involved in lung myofibroblast metabolic reprogramming and activation.[37] Interestingly, G9a-mediated $\mathrm{H} 3 \mathrm{~K} 9$ methylation was also shown to participate in $P G C-1 \alpha$ repression during lung myofibroblast activation. [19] Concomitantly, CM272 inhibition of G9a activity might also be involved in the repression of serine-glycine pathway genes, as G9a-mediated $\mathrm{H} 3 \mathrm{~K} 9$ monomethylation has been reported to mediate the transcriptional activation of these genes.[41]

Our in vitro observations were validated in two etiologically distinct mouse models of liver fibrogenesis. Indeed, the expression of G9a and DNMT1 was detected in stromal fibrogenic cells also stained with $\alpha$-SMA, and CM272 reduced myofibroblast activation and ECM accumulation. Mechanistically, the inhibitory effects of CM272 on fibrogenic 
metabolic reprogramming could also be taking place in vivo, as indicated by decreased accumulation of PKM2-expressing stromal cells. Importantly, these findings were extended to the human setting. Cirrhotic human liver tissues also showed increased levels of G9a and DNMT1 in areas of active fibrosis, and the expression of these epigenetic effectors was induced in cultured PCLSs concomitantly with their fibrogenic activation. PCLSs are a very useful tool to test antifibrotic drugs due to being a close surrogate of the human liver microenvironment.[28] Here we reproduced the antifibrogenic effects of CM272 observed in cultured cells and mouse models, including key aspects of HSC activation and metabolic reprogramming. One fundamental feature of any drug candidate is the absence of toxic reactions, particularly when intended to be administered to patients with liver injury. Consistent with our previous reports,[24,26] we did not observe any signs of hepatic or systemic toxicity in mice treated with CM272. Most importantly, this lack of toxicity was also evident in human PCLS, where parameters of hepatocellular function (e.g. albumin production) and cell integrity were not negatively affected by the drug. Nevertheless, as some of us recently showed, there are emerging technologies allowing myofibroblast-selective drug delivery in vivo which may further enhance drug efficacy and safety in the context of liver injury.[16]

In summary, we have identified novel epigenetic targets involved in liver fibrosis and demonstrated that their dual targeting with an innovative "epi-drug" can inhibit progression of liver fibrosis even in the absence of treating the underlying disease. We have also provided extended evidence on the role of metabolic reprogramming in liver fibrogenesis, and how this can be manipulated at the epigenetic level to halt or reverse the process. CM272 might be also considered for the treatment of fibrotic processes in other organs like the lung and kidneys, in which this condition has devastating effects. 
Acknowledgments. We particularly acknowledge the patients for their participation and the Biobank of the University of Navarra for its collaboration. We thank Mr. Roberto Barbero and Mrs. Sara Arcelus for their technical support.

Competing Interests. The authors declare no competing interests.

Funding. We thank the financial support of: CIBERehd; grant PI16/01126 from Instituto de Salud Carlos III (ISCIII) co-financed by "Fondo Europeo de Desarrollo Regional" (FEDER) “Una manera de hacer Europa"; grant 58/17 from Gobierno de Navarra; grants SAF2014-54191-R, SAF2017-88933-R and SAF2019-104878RB-100 from FEDER/Ministerio de Ciencia, Innovación y Universidades-Agencia Estatal de Investigación; grant BIO15/CA/011 from Bio-Eusko Fundazioa (Eitb maratoia); grant from Asociación Española Contra el Cáncer (AECC) Scientific Foundation Rare Cancers grant 2017; HEPACARE Project from Fundación La Caixa; Fundación Eugenio Rodríguez Pascual; Fundación Echébano; Fundación Mario Losantos and Fundación M Torres. We thank Mr. Eduardo Ávila and Mr. Sergio Durá for their generous contribution. FPI fellowships from Ministerio de Educación, Cultura y Deporte to MBV, MG and MR; FIMA-CIMA fellowship to AC; Gobierno de Navarra fellowship to LC; AECC postdoctoral fellowship to MA and Ramón y Cajal Program contract to MGFB. This work was also funded by a UK Medical Research Council program grants to J.M, FO and others (MR/K10019494/1, MK/K001949/1, MR/R023026/1); National Institute on Alcohol Abuse and Alcoholism (NIAAA) (grant UO1AA018663). The research was further supported by the National Institute for Health Research Newcastle Biomedical Research Centre based at Newcastle Hospitals NHS Foundation Trust and Newcastle University. 


\section{REFERENCES}

1 Hernandez-Gea V, Friedman SL. Pathogenesis of Liver Fibrosis. Annu Rev Pathol Mech Dis 2011;6:425-56. doi:10.1146/annurev-pathol-011110-130246

2 Hernandez-Gea V, Toffanin S, Friedman SL, et al. Role of the Microenvironment in the Pathogenesis and Treatment of Hepatocellular Carcinoma.

Gastroenterology 2013;144:512-27. doi:10.1053/j.gastro.2013.01.002

3 Tsuchida T, Friedman SL. Mechanisms of hepatic stellate cell activation. Nat Rev Gastroenterol Hepatol 2017;14:397-411. doi:10.1038/nrgastro.2017.38

4 Chen Y, Choi SS, Michelotti GA, et al. Hedgehog Controls Hepatic Stellate Cell Fate by Regulating Metabolism. Gastroenterology 2012;143:1319-1329.e11. doi:10.1053/j.gastro.2012.07.115

5 Hou W, Syn W-K. Role of Metabolism in Hepatic Stellate Cell Activation and Fibrogenesis. Front Cell Dev Biol 2018;6:150. doi:10.3389/fcell.2018.00150

$6 \quad$ Kisseleva $\mathrm{T}$, Cong $\mathrm{M}$, Paik $\mathrm{Y}$, et al. Myofibroblasts revert to an inactive phenotype during regression of liver fibrosis. Proc Natl Acad Sci U S A 2012;109:9448-53. doi:10.1073/pnas.1201840109

7 Troeger JS, Mederacke I, Gwak G-Y, et al. Deactivation of hepatic stellate cells during liver fibrosis resolution in mice. Gastroenterology 2012;143:1073-83.e22. doi:10.1053/j.gastro.2012.06.036

8 Lee YA, Wallace MC, Friedman SL. Pathobiology of liver fibrosis: a translational success story. Gut 2015;64:830-41. doi:10.1136/gutjnl-2014-306842

9 Moran-Salvador E, Mann J. Epigenetics and Liver Fibrosis. Cell Mol Gastroenterol Hepatol 2017;4:125-34. doi:10.1016/j.jcmgh.2017.04.007

10 Barcena-Varela M, Colyn L, Fernandez-Barrena MG. Epigenetic Mechanisms in 
Hepatic Stellate Cell Activation During Liver Fibrosis and Carcinogenesis. Int J Mol Sci 2019;20:2507. doi:10.3390/ijms20102507

11 Wilson CL, Mann DA, Borthwick LA. Epigenetic reprogramming in liver fibrosis and cancer. Adv Drug Deliv Rev 2017;121:124-32.

doi:10.1016/j.addr.2017.10.011

12 Mann J, Chu DCK, Maxwell A, et al. MeCP2 controls an epigenetic pathway that promotes myofibroblast transdifferentiation and fibrosis. Gastroenterology 2010;138:705-14, 714.e1-4. doi:10.1053/j.gastro.2009.10.002

13 Perugorria MJ, Wilson CL, Zeybel M, et al. Histone methyltransferase ASH1 orchestrates fibrogenic gene transcription during myofibroblast transdifferentiation. Hepatology 2012;56:1129-39. doi:10.1002/hep.25754

14 Niki T, Rombouts K, De Bleser P, et al. A histone deacetylase inhibitor, trichostatin A, suppresses myofibroblastic differentiation of rat hepatic stellate cells in primary culture. Hepatology 1999;29:858-67. doi:10.1002/hep.510290328

15 Mann J, Oakley F, Akiboye F, et al. Regulation of myofibroblast transdifferentiation by DNA methylation and MeCP2: implications for wound healing and fibrogenesis. Cell Death Differ 2007;14:275-85. doi:10.1038/sj.cdd.4401979

16 Zeybel M, Luli S, Sabater L, et al. A Proof-of-Concept for Epigenetic Therapy of Tissue Fibrosis: Inhibition of Liver Fibrosis Progression by 3-Deazaneplanocin A. Mol Ther 2017;25:218-31. doi:10.1016/j.ymthe.2016.10.004

17 Martin-Mateos R, De Assuncao TM, Arab JP, et al. Enhancer of Zeste Homologue 2 Inhibition Attenuates TGF- $\beta$ Dependent Hepatic Stellate Cell Activation and 
Liver Fibrosis. Cell Mol Gastroenterol Hepatol 2019;7:197-209.

doi:10.1016/j.jcmgh.2018.09.005

18 Irifuku T, Doi S, Sasaki K, et al. Inhibition of H3K9 histone methyltransferase G9a attenuates renal fibrosis and retains klotho expression. Kidney Int 2016;89:14757. doi:10.1038/ki.2015.291

19 Ligresti G, Caporarello N, Meridew JA, et al. CBX5/G9a/H3K9me-mediated gene repression is essential to fibroblast activation during lung fibrosis. JCI Insight 2019;4:e127111. doi:10.1172/jci.insight.127111

20 Tachibana M, Matsumura Y, Fukuda M, et al. G9a/GLP complexes independently mediate $\mathrm{H} 3 \mathrm{~K} 9$ and DNA methylation to silence transcription. EMBO J 2008;27:2681-90. doi:10.1038/emboj.2008.192

21 Du J, Johnson LM, Jacobsen SE, et al. DNA methylation pathways and their crosstalk with histone methylation. Nat Rev Mol Cell Biol 2015;16:519-32. doi:10.1038/nrm4043

22 Wozniak RJ, Klimecki WT, Lau SS, et al. 5-Aza-2'-deoxycytidine-mediated reductions in G9A histone methyltransferase and histone H3 K9 di-methylation levels are linked to tumor suppressor gene reactivation. Oncogene 2007;26:7790. doi:10.1038/sj.onc.1209763

23 Casciello F, Windloch K, Gannon F, et al. Functional Role of G9a Histone Methyltransferase in Cancer. Front Immunol 2015;6. doi:10.3389/fimmu.2015.00487

24 San José-Enériz E, Agirre X, Rabal O, et al. Discovery of first-in-class reversible dual small molecule inhibitors against G9a and DNMTs in hematological malignancies. Nat Commun 2017;8:15424. doi:10.1038/ncomms15424 
25 Rabal O, José-Enériz ES, Agirre $X$, et al. Discovery of Reversible DNA Methyltransferase and Lysine Methyltransferase G9a Inhibitors with Antitumoral in Vivo Efficacy. J Med Chem 2018;61:6518-45. doi:10.1021/acs.jmedchem.7b01926

26 Bárcena-Varela M, Caruso S, Llerena S, et al. Dual Targeting of Histone Methyltransferase G9a and DNA-Methyltransferase 1 for the Treatment of Experimental Hepatocellular Carcinoma. Hepatology 2019;69:587-603. doi:10.1002/hep.30168

27 Garcia-Irigoyen O, Carotti S, Latasa MU, et al. Matrix metalloproteinase-10 expression is induced during hepatic injury and plays a fundamental role in liver tissue repair. Liver Int 2014;34:e257-70. doi:10.1111/liv.12337

28 Paish HL, Reed LH, Brown H, et al. A Bioreactor Technology for Modeling Fibrosis in Human and Rodent Precision-Cut Liver Slices. Hepatology 2019;:'hep.30651. doi:10.1002/hep.30651

29 Ferry L, Fournier A, Tsusaka T, et al. Methylation of DNA Ligase 1 by G9a/GLP Recruits UHRF1 to Replicating DNA and Regulates DNA Methylation. Mol Cell 2017;67:550-565.e5. doi:10.1016/j.molcel.2017.07.012

30 Xu L, Hui AY, Albanis E, et al. Human hepatic stellate cell lines, LX-1 and LX-2: new tools for analysis of hepatic fibrosis. Gut 2005;54:142-51. doi:10.1136/gut.2004.042127

31 Yang L, Jung Y, Omenetti A, et al. Fate-Mapping Evidence That Hepatic Stellate Cells Are Epithelial Progenitors in Adult Mouse Livers. Stem Cells 2008;26:210413. doi:10.1634/stemcells.2008-0115

32 Nath B, Szabo G. Hypoxia and hypoxia inducible factors: Diverse roles in liver 
diseases. Hepatology 2012;55:622-33. doi:10.1002/hep.25497

33 Roth KJ, Copple BL. Role of Hypoxia-Inducible Factors in the Development of Liver Fibrosis. Cell Mol Gastroenterol Hepatol 2015;1:589-97. doi:10.1016/j.jcmgh.2015.09.005

34 Seki E, De Minicis S, Osterreicher CH, et al. TLR4 enhances TGF-beta signaling and hepatic fibrosis. Nat Med 2007;13:1324-32. doi:10.1038/nm1663

35 Xie N, Tan Z, Banerjee S, et al. Glycolytic Reprogramming in Myofibroblast Differentiation and Lung Fibrosis. Am J Respir Crit Care Med 2015;192:1462-74. doi:10.1164/rccm.201504-07800C

36 Si M, Wang Q, Li Y, et al. Inhibition of hyperglycolysis in mesothelial cells prevents peritoneal fibrosis. Sci Transl Med 2019;11:eaav5341. doi:10.1126/scitranslmed.aav5341

37 Caporarello N, Meridew JA, Jones DL, et al. PGC1 $\alpha$ repression in IPF fibroblasts drives a pathologic metabolic, secretory and fibrogenic state. Thorax 2019;74:749-60. doi:10.1136/thoraxjnl-2019-213064

38 Nigdelioglu R, Hamanaka RB, Meliton AY, et al. Transforming Growth Factor (TGF)- $\beta$ Promotes de Novo Serine Synthesis for Collagen Production. J Biol Chem 2016;291:27239-51. doi:10.1074/jbc.M116.756247

39 Hamanaka RB, Nigdelioglu R, Meliton AY, et al. Inhibition of Phosphoglycerate Dehydrogenase Attenuates Bleomycin-induced Pulmonary Fibrosis. Am J Respir Cell Mol Biol 2018;58:585-93. doi:10.1165/rcmb.2017-01860C

40 Selvarajah B, Azuelos I, Platé M, et al. mTORC1 amplifies the ATF4-dependent de novo serine-glycine pathway to supply glycine during TGF- $\beta_{1}$-induced collagen biosynthesis. Sci Signal 2019;12:eaav3048. doi:10.1126/scisignal.aav3048 
41 Ding J, Li T, Wang X, et al. The histone H3 methyltransferase G9A epigenetically activates the serine-glycine synthesis pathway to sustain cancer cell survival and proliferation. Cell Metab 2013;18:896-907. doi:10.1016/j.cmet.2013.11.004

42 Pacold ME, Brimacombe KR, Chan SH, et al. A PHGDH inhibitor reveals coordination of serine synthesis and one-carbon unit fate. Nat Chem Biol 2016;12:452-8. doi:10.1038/nchembio.2070

43 Ye J, Mancuso A, Tong X, et al. Pyruvate kinase M2 promotes de novo serine synthesis to sustain mTORC1 activity and cell proliferation. Proc Natl Acad Sci U S A 2012;109:6904-9. doi:10.1073/pnas.1204176109

44 Page A, Paoli P, Moran Salvador E, et al. Hepatic stellate cell transdifferentiation involves genome-wide remodeling of the DNA methylation landscape. J Hepatol 2016;64:661-73. doi:10.1016/j.jhep.2015.11.024

45 Hanna C, Hubchak SC, Liang X, et al. Hypoxia-inducible factor-2 $\alpha$ and TGF- $\beta$ signaling interact to promote normoxic glomerular fibrogenesis. Am J Physiol Renal Physiol 2013;305:F1323-31. doi:10.1152/ajprenal.00155.2013

46 Li B, Qiu B, Lee DSM, et al. Fructose-1,6-bisphosphatase opposes renal carcinoma progression. Nature 2014;513:251-5. doi:10.1038/nature13557

47 Rozen-Zvi B, Hayashida T, Hubchak SC, et al. TGF- $\beta / S m a d 3$ activates mammalian target of rapamycin complex-1 to promote collagen production by increasing HIF-1 $\alpha$ expression. Am J Physiol Renal Physiol 2013;305:F485-94. doi:10.1152/ajprenal.00215.2013

48 Dong $\mathrm{C}$, Yuan T, Wu Y, et al. Loss of FBP1 by Snail-mediated repression provides metabolic advantages in basal-like breast cancer. Cancer Cell 2013;23:316-31. doi:10.1016/j.ccr.2013.01.022 
49 Liang H, Ward WF. PGC-1alpha: a key regulator of energy metabolism. Adv Physiol Educ 2006;30:145-51. doi:10.1152/advan.00052.2006 


\section{Figure legends}

Figure 1. G9a, DNMT1 and $\alpha$-SMA immunostaining on sections from normal and diseased human and mouse liver tissues. (A) Representative immunostainings showing G9a and DNMT1 detection (arrows) in fibrotic lesions in livers from cirrhotic patients with chronic hepatitis $\mathrm{C}$ virus (HCV) or hepatitis B virus (HVB) infection, or alcoholic liver disease (ALD). $\alpha$-SMA staining identifies myofibroblasts in association with fibrotic lesions. Images are representative of at least ten patients per condition. (B) Representative immunostainings showing G9a and DNMT1 detection (arrows) in liver sections from control mice and from animals chronically treated with $\mathrm{CCl}_{4}$ (six weeks) or eleven days after bile duct ligation (BDL). $\alpha$-SMA staining identifies myofibroblasts in association with fibrotic lesions. Images are representative of at least six mice per condition.

Figure 2. Expression and role of G9a, DNMT1 and UHRF1 in liver fibrogenic cells activation. (A) Expression of G9a, DNMT1 and UHRF1 in primary mouse HSC during culture activation. Left panel shows a representative western blot including $\alpha$-SMA protein levels denoting HSC activation kinetics and Ponceau staining to show equal loading. Right panel shows qPCR analyses of mRNA levels for the indicated genes in the early phase of HSC culture activation. (B) Representative western blot analyses of G9a, DNMT1 and UHRF1 proteins in the chromatin fraction from nuclear extracts, or total cell lysates, obtained from LX2 cells treated with TGF $\beta 1$ for 3 h. Histone H3 and $\alpha$ TUBULIN levels are shown to demonstrate equal loading. (C) Influence of $G 9 a, D N M T 1$ and UHRF1 expression on TGF $\beta 1$ mediated fibrosis-related gene expression in LX2 cells. Cells were transfected with $G 9 a, D N M T 1$ or $U H R F 1$-specific siRNAs, or control siRNAS (siC) and 24h later were treated with TGF $\beta 1$ for another $24 \mathrm{~h}$. Graph shows the qPCR analysis of mRNA levels for the indicated genes. 
Figure 3. Dual targeting of G9a and DNMT1 inhibits hypoxia- and TGF $\beta 1$-driven activation of HSC. (A) LX2 cells were treated with CM272 (400nM) for 24h and then stimulated with TGF $\beta 1(5 \mathrm{ng} / \mathrm{mL})$ for another $24 \mathrm{~h}$. Expression of fibrogenic activationrelated genes and GFAP was evaluated by qPCR. (B) Effect of CM272 on the growth (left panel) and fibrogenic gene expression (right panel) elicited by hypoxia, including transforming growth factor- $\beta 1$ (TGF $\beta 1)$, platelet derived growth factor receptor $\beta$ $(P D G F R \beta)$, tissue inhibitor of metalloproteases 1 (TIMP1), lysyl oxidase $(L O X)$ and lactate dehydrogenase A ( $L D H A)$. LX2 cells were treated with CM272 (400nM) for 24h and then grown under normoxic $\left(20 \% \mathrm{O}_{2}\right)$ or hypoxic $\left(1 \% \mathrm{O}_{2}\right)$ conditions for a further 24h. (C) Left panel shows the most relevant GO categories of genes undergoing changes in expression identified by microarray analysis in LX2 cells treated or not with CM272 $(400 \mathrm{nM})$ and then stimulated with TGF $\beta 1(5 \mathrm{ng} / \mathrm{mL})$ for another $24 \mathrm{~h}$. Right panel shows a volcano plot displaying differentially expressed genes between LX2 cells treated with TGF $\beta 1$ in the presence or absence of CM272. Red dots represent upregulated transcripts and green dots represent transcripts with downregulated expression. (D) GSEA of microarray gene expression data revealed positive enrichment in gene expression by CM272 in categories related to PPAR signaling and steroid hormone and liposoluble vitamins metabolism, and negative enrichment of related to glucose metabolism, hypoxia and fibrogenic activation (TGF $\beta 1$ and PDGFR $\beta$ pathways).

Figure 4. Dual targeting of G9a and DNMT1 counteracts the pro-fibrogenic metabolic reprogramming of HSC elicited by TGF $\beta 1$. (A) Left panel, oxygen consumption rate (OCR) in LX2 cells treated or not with CM272 (400nM) for $24 \mathrm{~h}$ and then stimulated or not with TGF $\beta 1(5 \mathrm{ng} / \mathrm{mL})$ for $3 \mathrm{~h}$. Right panel, extracellular acidification rate (ECAR) in 
LX2 cells treated as indicated above. (B) Relative ATP production from oxidative phosphorylation (OXPHOS) and glycolysis in LX2 cells treated as indicated above. (C) Lactate production (i.e. lactate release to culture medium) by LX2 cells pre-treated or not with CM272 (400nM) for $24 \mathrm{~h}$ and then stimulated with TGF $\beta 1(5 \mathrm{ng} / \mathrm{mL})$ for up to $24 \mathrm{~h}$ more. (D) CM272 counteracts the reprogramming of metabolic gene expression elicited by TGF $\beta 1$ in LX2 cells. Cells were treated with CM272 (400nM) for $24 \mathrm{~h}$ and then stimulated with TGF $\beta 1(5 \mathrm{ng} / \mathrm{mL})$ for another $24 \mathrm{~h}$ as indicated. The expression of genes involved in glycolysis (red letters), the serine-glycine pathway (green letters) and gluconeogenesis (blue letters) was measured by qPCR. (E) Western blot analysis of FBP1 and PGC-1 $\alpha$ protein levels in LX2 cells treated with CM272 (200nM) for $48 \mathrm{~h}$. Representative blots are shown. (F) analysis of H3K9me2 levels by qChIP assay in the proximal promoter regions of $F B P 1$ and $P G C-1 \alpha$ genes in $\mathrm{LX} 2$ cells treated with $\mathrm{CM} 272$ (200nM) for 48h. (G) Methylation-specific PCR (MSP) assays of DNA methylation in FBP1 and PGC-1 $\alpha$ promoters in control and CM272 (100nM, 96h) treated LX2 cells. Cells were also treated with decitabine $(5 \mu \mathrm{M})$ as a control for a DNA demethylating agent. Bands in lanes labeled " $\mathrm{U}$ " and "M" are PCR products amplified with unmethylation- and methylation-specific primers. Images are representative of three experiments performed in duplicates.

Figure 5. CM272 inhibits liver fibrogenesis in vivo. (A) As shown in the diagram, mice received $\mathrm{CCl}_{4}$ or vehicle (oil) for six weeks, and for the last two weeks were treated with CM272 $(2.5 \mathrm{mg} / \mathrm{kg}$ body weight $)$ or PBS. Animals were humanely killed $24 \mathrm{~h}$ or 4 days after the last $\mathrm{CCl}_{4}$ injection and liver tissues were immunostained for $\alpha$-SMA and PKM2, or stained with Sirius Red for collagen detection. Representative images are shown. (B) Expression of key genes involved in hepatic fibrogenesis and metabolic reprogramming in the livers of mice treated as described in panel A. (C) Mice underwent BDL and were 
treated with CM272 $(2.5 \mathrm{mg} / \mathrm{kg}$ body weight $)$ or PBS as indicated in the diagram. At day 11 after surgery animals were sacrificed and liver tissue sections were immunostained for $\alpha$-SMA and PKM2 or stained with Sirius Red for collagen detection. (D) Expression of key genes involved in hepatic fibrogenesis and metabolic reprogramming in the livers of mice treated as described in the graph. Liver samples from sham operated mice were used as controls.

Figure 6. CM272 has antifibrotic effects in human PCLSs. (A) Human precision cut liver slices were isolated and placed in the bioreactor chambers. After 24h PCLSs were treated with a fibrogenic stimulus (TGF $\beta 1+$ PDGF-BB), its vehicle, CM272 $(1 \mu \mathrm{M})$ or the activin receptor-like kinase 5 inhibitor (Alk5i) SB-525334 as shown in the graph. G9a, DNMT1 and UHRF1 expression levels were measured by qPCR (B) Immunohistochemical analyses of G9a, DNMT1 and $\alpha$-SMA performed in tissue sections from PCLSs treated as indicated. Representative images are shown. (C) qPCR analysis of the expression of key genes involved in hepatic fibrogenesis in PCLSs treated as indicated. (D) Soluble collagen (COLIA1) levels in media of bioreactor cultured PCLSs after 72 and $96 \mathrm{~h}$ incubation under the indicated conditions. Grey bars: vehicle; black bars: TGF $\beta 1+$ PDGFBB. (E) Representative images of $\alpha$-SMA and picrosirius-red-stained tissue sections from PCLSs at $\mathrm{t}=0$ and after $96 \mathrm{~h}$ treatment as indicated. (F) Quantification of lactate accumulation in media of bioreactor cultured PCLSs after 72 and $96 \mathrm{~h}$ incubation under the indicated conditions. Grey bars: vehicle; black bars: TGF $\beta 1+P D G F-B B$. (G) qPCR analysis of the expression of key genes associated with the reprogramming of glucose metabolism in PCLSs. (H) Immunohistochemical analysis of PKM2 performed in tissue sections from PCLSs at $\mathrm{t}=0$ and after $96 \mathrm{~h}$ of treatment as indicated. Representative images are shown. PCLSs from four different patients were used in four independent experiments. For each time-point and condition two PCLSs were used. 
Figure 7. CM272 does not cause toxicity in bioreactor cultured human PCLSs. (A) Average levels of albumin, urea, lactate dehydrogenase (LDH), aspartate aminotransferase (AST) and alanine aminotransferase (ALT) released into the culture media by PCLSs treated with vehicle (control) or CM272 $(1 \mu \mathrm{M})$ as indicated. (B) Representative H\&E images of tissue sections from PCLSs treated with vehicle (control) or CM272 $(1 \mu \mathrm{M})$ for $96 \mathrm{~h}$. 


\section{Epigenetic mechanisms and metabolic reprogramming in fibrogenesis: Dual targeting of G9a and DNMT1 for the inhibition of liver fibrosis}

Short title: Simultaneous inhibition of G9a/DNMT1 to inhibit liver fibrogenesis

Marina Bárcena-Varela ${ }^{1}$, Hannah L. Paish ${ }^{2}$, Laura Álvarez ${ }^{1}$, Iker Uriarte ${ }^{1,3}$, Maria U Latasa $^{1}$, Eva Santamaría ${ }^{1,3}$, Miriam Recalde ${ }^{1}$, María Gárate ${ }^{1}$, Alex Clavería ${ }^{1}$, Leticia Colyn$^{1}$, María Arechederra ${ }^{1,4}$, María J. Iraburu ${ }^{5}$, Malgorzata Milkiewitz ${ }^{6}$, Piotr Milkiewitz $^{7}$, Bruno Sangro ${ }^{3,4,8}$, Stuart M. Robinson', Jeremy French ${ }^{9}$, Ana Pardo$\underline{\text { Saganta }}^{10}$, Julen Oyarzábal ${ }^{11}$, Felipe Prósper ${ }^{4,12}$, Krista Rombouts ${ }^{13}$, Fiona Oakley ${ }^{2}$,

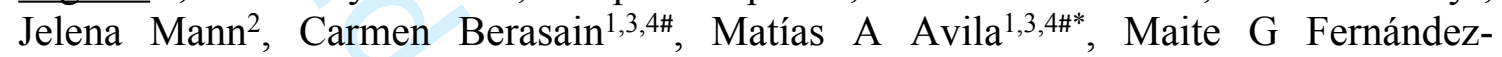
Barrena ${ }^{1,3,4 \#^{*}}$

1. Hepatology Program. Cima, University of Navarra, 31008 Pamplona, Spain.

2. Newcastle Fibrosis Research Group, Institute of Cellular Medicine, Faculty of

Medical Sciences, Newcastle University, Newcastle upon Tyne, NE2 4HH, UK.

3. CIBERehd, Instituto de Salud Carlos III, 28029 Madrid, Spain.

4. Instituto de Investigaciones Sanitarias de Navarra-IdiSNA, 31008 Pamplona, Spain.

5. Department of Biochemistry and Genetics, University of Navarra, 31008 Pamplona, Spain

6. Department of Medical Biology, Pomeranian Medical University, 70-204 Szczecin, Poland.

7. Liver and Internal Medicine Unit, Department of General, Transplant and Liver Surgery, Medical University of Warsaw, 02-091 Warsaw, Poland.

8. Hepatology Unit, Navarra University Clinic, 31080 Pamplona, Spain.

9. Department of Gastroenterology and Hepatology, Newcastle upon Tyne Hospitals

NHS Foundation Trust, Newcastle upon Tyne, NE2 4HH, UK.

10. Cell Therapy Program. Cima, University of Navarra, 31008 Pamplona, Spain.

11. Molecular Therapies Program. Cima, University of Navarra, 31008 Pamplona,

Spain.

12. Oncohematology Program, Cima, University of Navarra, 31008 Pamplona, Spain.

13. Institute for Liver and Digestive Health, University College London NW3 2PF, UK.

\#Co-senior authors

* Correspondence:

Matias A Avila and Maite G Fernandez-Barrena.

Hepatology Program, CIMA, University of Navarra. Avda. Pio XII, n55, Pamplona, 31008

Spain. Tel: +34-948-194700. E-mail: maavila@unav.es, magarfer@unav.es.

Conflict of interest: F.O and J.M are directors of Fibrofind Ltd. H.P, F.O, and J.M are shareholders in Fibrofind Ltd.

Word count: 4374. 
Abbreviations:

ECM: extracellular matrix; HSC: hepatic stellate cells; TGF $\beta 1$ : transforming growth factor- $\beta 1$; MeCP2: methyl-CpG binding protein; HMTs: histone methyltransferases; EZH2: enhancer of zeste homolog-2; ASH1: absent, small, or homeotic disc 1; DNMTs: DNA-methyltransferases; EHMT2: euchromatin histone-lysine methyltransferase 2; HCV: hepatitis C virus; HBV: hepatitis B virus; ALD: alcoholic cirrhosis; PSC: primary sclerosing cholangitis; BDL: bile duct ligation; PCLSs: precision cut liver slices; PDGF$\mathrm{BB}$ : platelet-derived growth factor-BB; Alk5i: activin receptor-like kinase 5 inhibitor; $\alpha$ SMA: $\alpha$-smooth muscle actin; UHRF1: ubiquitin-like with PHD and RING finger domains-1; 5meC: 5-methyl-cytosine; GFAP: glial fibrillary acidic protein; Lrat: lecithinretinol acyltransferase; GO: gene ontology; GSEA: gene set enrichment analysis; PPAR: peroxisome proliferator-activated receptor; PDGFR $\beta$ : platelet-derived growth factor receptor- $\beta$; HIF: hypoxia-inducible factor; TIMP1: tissue inhibitor of metalloproteases 1 ; LOX: lysyl oxidase; LDHA: lactate dehydrogenase A; OCR: oxygen consumption rate; ECAR: extracellular acidification rate; PGC-1 $\alpha$ : peroxisome proliferator activated receptor gamma coactivator-1 $\alpha$; HK-I: hexokinase-I; PFKFB3: 6-phosphofructo-2kinase/fructose-2,6-biphosphatase 3; ALDOA: aldolase-A; PGK-I: phosphoglycerate kinase-I; PKM2: pyruvate kinase M2; PHGDH: phosphoglycerate dehydrogenase; PSAT1: phosphoserine aminotransferase 1; PSPH: phosphoserine phosphatase; SHMT2: serine hydroxymethyl transferase 2; PEPCK: phosphoenolpyruvate-carboxykinase; FBP1: fructose-1,6-bisphosphatase-1; OXPHOS: oxidative phosphorylation; MSP: methylation-specific PCR; ColIa1: collagen type I- $\alpha-1$; LDH: lactate dehydrogenase.

\section{Contributorship Statement}

- Performed experiments and data interpretation: MBV, HLP, LA, IU, MUL, ES, MR, MG, AC, LC, MA, MJI, MM, APS

- Provided key biological samples and materials: PM, BS, SMR, JF, JO, FP, KR, FO, JM.

- Critical revision of the manuscript: JO, FP, KR, FO, JM, MJI, CB.

- Study design, data interpretation, manuscript writing and submission: $\mathrm{CB}, \mathrm{MGFB}$, MAA. 


\begin{abstract}
Objective. Hepatic stellate cells (HSC) transdifferentiation into myofibroblasts is central to fibrogenesis. Epigenetic mechanisms, including histone and DNA methylation, play a key role in this process. Concerted action between histone and DNA-mehyltransferases like G9a and DNMT1 is a common theme in gene expression regulation. We aimed to study the efficacy of CM272, a first-in-class dual and reversible G9a/DNMT1 inhibitor, in halting fibrogenesis.

Design. G9a and DNMT1 were analyzed in cirrhotic human livers, mouse models of liver fibrosis and cultured mouse HSC. G9a and DNMT1 expression was knocked-down or inhibited with CM272 in human HSC (hHSC), and transcriptomic responses to transforming growth factor- $\beta 1$ (TGF $\beta 1$ ) were examined. Glycolytic metabolism and mitochondrial function were analyzed with Seahorse-XF technology. Gene expression regulation was analyzed by chromatin immunoprecipitation and methylation-specific PCR. Antifibrogenic activity and safety of CM272 were studied in mouse chronic $\mathrm{CCl}_{4}$ administration and bile duct ligation (BDL), and in human precision-cut liver slices (PCLSs) in a new bioreactor technology.

Results. G9a and DNMT1 were detected in stromal cells in areas of active fibrosis in human and mouse livers. G9a and DNMT1 expression was induced during mouse HSC activation, and TGF $\beta 1$ triggered their chromatin recruitment in hHSC. G9a/DNMT1 knockdown and CM272 inhibited TGF $\beta 1$ fibrogenic responses in hHSC. TGF $\beta 1$ mediated profibrogenic metabolic reprogramming was abrogated by CM272, which restored gluconeogenic gene expression and mitochondrial function through on-target epigenetic effects. CM272 inhibited fibrogenesis in mice and PCLSs without toxicity.
\end{abstract}

Conclusions. Dual G9a/DNMT1 inhibition by compounds like CM272 may be a novel therapeutic strategy for treating liver fibrosis.

Keywords. Fibrogenesis, glucose metabolism, gene regulation. 


\section{What is already known on this subject?}

- The progression of liver fibrosis depends on the activation and transdifferentiation of hepatic stellate cells into a myofibroblastic phenotype.

- Epigenetic mechanisms have been shown to control many aspects of fibrogenesis in the liver.

- Metabolic reprogramming is emerging as a key process in the activation of fibrogenic cells in different organs.

\section{What are the new findings?}

- Together with DNMT1, the histone methyltransferase G9a is expressed in fibrogenic cells in cirrhotic human liver, in chronically injured mouse liver and upon activation of cultured mouse HSC.

- G9a and DNMT1 expression is required for fibrogenic activation of HSC by TGF $\beta 1$.

- Pharmacological targeting of DNMT1 and G9a with the novel first-in-class dual G9a/DNMT1 inhibitor CM272 counteracts the pro-fibrogenic responses and metabolic reprogramming of HSC elicited by TGF $\beta 1$.

- CM272 administration shows antifibrogenic activity in clinically relevant mouse models of liver fibrosis and in human precision-cut liver slices without causing toxic effects.

\section{How might it impact on clinical practice in the foreseeable future?}

- The development of effective antifibrotic therapies is much needed not only for chronic liver disease but also for other organs like the lung and kidney. Targeting the complex epigenetic mechanisms involved in fibrogenesis with innovative molecules like CM272 may pave the way for better therapies. 


\section{INTRODUCTION}

The fibrogenic response is part of the natural reparative reaction in different tissues and organs. This process leads to the formation of a temporary extracellular matrix (ECM) which after wound repair is degraded and tissue architecture is restored. However, when damage persists, as occurs in liver chronic viral infection, alcohol abuse or in nonalcoholic fatty liver disease, the equilibrium between ECM production and removal is ultimately lost resulting in excessive accumulation of a dense ECM rich in fibrillar collagens.[1] This ECM is a physical barrier that perturbs organ's perfusion, contributes to loss of liver function, progression to cirrhosis and hepatocellular carcinoma development.[1,2] The pathological relevance of liver fibrogenesis has driven very active research over the past decades. One major finding was the realization of the highly dynamic nature of the process, including clinical findings showing fibrosis reversion upon removal of the causative agent.[1] The major cellular source of collagen are the liver myofibroblasts, mesenchymal cells mainly derived from hepatic stellate cells (HSC) and periportal fibroblasts.[3] In the normal liver HSC show a quiescent and differentiated phenotype which upon hepatic injury is substantially altered. A plethora of cytokines, small molecules and growth factors, with transforming growth factor- $\beta 1$ (TGF $\beta 1$ ) playing a central role, contribute to HSC activation and conversion into proliferative and inflammatory collagen-secreting myofibroblasts.[3] A profound metabolic reprogramming, including a shift towards aerobic glycolysis, was recently identified as an essential mechanism in HSC activation.[4,5] Earlier evidence indicated that during fibrosis regression myofibroblasts were removed by apoptosis or entered a senescent profibrolytic state prone to immune-mediated clearance.[1] However, later studies demonstrated that upon cessation of injury a significant proportion of myofibroblasts also undergo reversion to a deactivated phenotype.[6,7] Together, these findings attest to the 
plasticity of HSC and provide valuable insights for the development of much needed antifibrogenic strategies.[8]

Extensive changes in the HSC's transcriptome occur during their transition into hepatic myofibroblasts and upon cessation of injury their reversion to quiescence.[1,7] In this context epigenetic mechanisms are increasingly recognized to play a central role.[9] DNA hypomethylation has been associated with fibrogenic gene activation, while repression of genes that maintain HSC differentiation and quiescence was linked to increased methylCpGs abundance in their regulatory regions.[10][11] Mechanistically, to control gene expression DNA methylation works in concert with other epigenetic modifications such acetylation and methylation of lysine residues in histones H3 and H4.[9] The methyl-CpG binding protein $\mathrm{MeCP} 2$ plays a key function in this process, orchestrating the activity of the histone methyltransferases (HMTs) enhancer of zeste homolog-2 (EZH2) and absent, small, or homeotic disc 1 (ASH1) during the reprogramming of HSC transcriptome to the myofibroblast phenotype.[12,13] From a translational perspective, it is important to consider that epigenetic modifications are reversible and amenable to pharmacological intervention. Indeed, the antifibrogenic effects of histone deacetylase inhibitors were already reported twenty years ago.[14] More recently it was demonstrated that targeting DNA-methyltransferases (DNMTs) with 5-azadeoxycytidine prevents HSC fibrogenic activation, while inhibition of HMTs halts hepatic fibrosis progression in mice.[15-17] Similarly, pharmacological inhibition of the H3K9 methyltransferase G9a, also known as euchromatic histone-lysine methyltransferase 2 (EHMT2), has been recently shown to reduce kidney and lung fibrosis, although the underlying mechanisms are not fully understood.[18,19] Concerted action between DNMTs and HMTs appears a common theme in physiological transcriptional control, of tissue homeostasis. However, when dysregulated this crosstalk can cause disease, including tumorigenesis.[20,21] This has 
been demonstrated for G9a, which physically and functionally interacts with DNMT1 driving tumor cell proliferation and adaptation to hypoxia, among other cancer traits.[22,23] Therefore, the simultaneous targeting of G9a and DNMT methyltransferase activities could be a more effective therapeutic strategy. With this in mind, we recently developed a new series of potent first-in-class, selective and reversible dual small molecule inhibitors against G9a and DNMT activity with an excellent in vivo safety profile.[24,25] These compounds are very effective against hematological malignancies,[24] and also in HCC models, particularly on HSC-driven HCC growth.[26] Here we demonstrate the therapeutic potential of dual G9a/DNMT targeting in experimental liver fibrosis and show how this epigenetic mechanism can control TGF $\beta 1$ mediated pro-fibrogenic metabolic reprogramming and HSC activation. 


\section{MATERIALS AND METHODS}

\section{Human samples}

Liver tissue samples and patients' data were provided by the Biobank of the University of Navarra (Pamplona, Spain) or by the Medical University of Warsaw (Warsaw, Poland). Samples were from patients with hepatitis C virus $(\mathrm{HCV})(\mathrm{n}=10)$ and HBV $(n=10)$ infection and alcoholic cirrhosis (ALD) $(n=10)$. All of them presented cirrhosis and underwent liver transplantation. Control liver tissue samples $(n=5)$ were obtained from large-margin liver resections of colorectal metastases showing no pathologist-identified microscopic changes of liver disease. Liver tissue specimens were paraffin embedded and stored at $-75^{\circ} \mathrm{C}$ until use. Written informed consent was obtained from each patient and samples were processed following standard operating procedures approved by the Ethical and Scientific Committees of the University of Navarra and the Medical University of Warsaw.

\section{Mouse models}

C57BL/6J male mice 6-8 weeks old ( $\mathrm{n}=6-8$ mice per group) were used. For acute $\mathrm{CCl}_{4}$ treatment mice received a 1:1 mixture of $\mathrm{CCl}_{4}$ and olive oil $\left(1 \mu \mathrm{L} \mathrm{CCl}_{4} / \mathrm{g}\right.$ body weight, i.p), 24h later mice received one injection of CM272 (5mg/Kg, i.p.) or vehicle (PBS), and 24h later were humanely killed. For chronic $\mathrm{CCl}_{4}$ treatment, mice received a 1:3 mixture of $\mathrm{CCl}_{4}$ and olive oil $\left(0.67 \mu \mathrm{L} \mathrm{CCl} \mathrm{Cl}_{4} / \mathrm{g}\right.$ body weight, i.p. $)$ twice per week for 6 weeks to induce fibrosis. For the last two weeks animals received daily injections of CM272 $\left(5 \mathrm{mg} / \mathrm{Kg}\right.$, i.p) or PBS. Mice were humanely killed at day 1 and 4 after the last $\mathrm{CCl}_{4}$ injection. Bile duct ligation (BDL) was performed as described.[12] [27] From day 2 postsurgery animals received daily injections of CM272 (2.5mg/Kg) or PBS (i.p.) and were humanely killed after 11 days. Animal care and procedures were approved by the Animal 
Care Committee of the University of Navarra or the Newcastle Animal Welfare and Ethical Review Board and performed under a UK Home Office license.

\section{Precision cut liver slices (PCLSs) experiments}

Human liver tissue was obtained from normal resection margins surrounding colorectal metastases from adult patients undergoing surgical resection at the Freeman Hospital (Newcastle-upon-Tyne, UK). Informed consent was obtained from all patients and study was approved by the Newcastle \& North Tyneside Research Ethics Committee. PCLSs were obtained from agarose embedded tissues cut with a Leica VT1200S vibratome and cultured in a rocking bioreactor platform as previously described.[28] PCLSs were rested for $24 \mathrm{~h}$ and were then treated with TGF $\beta 1(3 \mathrm{ng} / \mathrm{mL})$ and platelet-derived growth factorBB (PDGF-BB) (50ng/mL) from Peprotech (London, UK), activin receptor-like kinase-

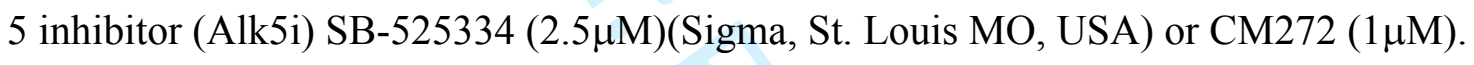
Additional methods are provided in Supplementary Methods. 


\section{RESULTS}

\section{Expression of G9a and DNMT1 in activated HSC.}

We performed immunohistochemical staining of liver tissue samples from patients with viral cirrhosis and ALD. We detected the presence of G9a and DNMT1 in activated myofibroblasts ( $\alpha$-smooth muscle actin, $\alpha$-SMA-expressing cells) (Fig. 1A, Supporting Fig. S1 and S2). G9a and DNMT1 were also detected in mouse liver myofibroblasts after chronic $\mathrm{CCl}_{4}$ injury or BDL (Fig. 1B, Supporting Fig. S3). Next, we examined the expression of G9a and DNMT1 in quiescent and culture-activated mouse HSC. We found that G9a and DNMT1 protein levels were significantly induced between day 1 and day 4 of culture in parallel with $\alpha$-SMA, a marker of HSC myofibroblastic transdifferentiation (Fig. 2A).[3] The expression of ubiquitin-like with PHD and RING finger domains-1 (UHRF1), a key coordinator of DNA methylation during DNA replication and a functional adaptor between DNMT1 and G9a,[29] was also increased in culture-activated HSC (Fig. 2A). The mRNA levels of these three genes also increased upon HSC activation (Fig. 2A). Interestingly, in LX2 cells, a well-characterized model of human HSC,[30] TGF $\beta 1$ stimulation induced the rapid recruitment of the three proteins to the nuclear chromatin subfraction, without significantly changing their expression (Fig. 2B). Combined, these observations suggested a role for G9a and DNMT1, together with UHRF1, in HSC activation. To directly address this point, we examined TGF $\beta 1$ responses in LX2 cells after siRNA-mediated knockdown of these genes (Supporting Fig. S4). We found an overall impairment of TGF $\beta 1$-activated profibrogenic gene expression, an effect that was particularly strong upon $G 9 a$ downregulation (Fig. 2C). 


\section{Dual targeting of G9a and DNMT1 inhibits hypoxia- and TGF $\beta 1$-driven activation of HSC.}

These observations and our previous findings,[26] suggested that interference with G9a/DNMT1 activities may counteract HSC activation. Therefore, we tested the effects of CM272, our lead G9a/DNMT dual inhibitory compound,[24] on LX2 cells. We demonstrated that CM272 decreased global DNA methylation (5-methyl-cytosine [5meC]) and H3K9me2 levels without affecting other histone marks (Supporting Fig. S5A and B). Next we observed a marked impairment of TGF $\beta 1$ effects on key fibrogenic

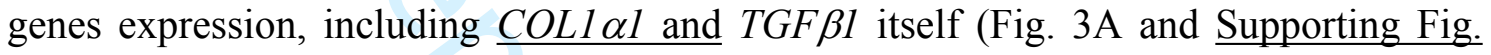

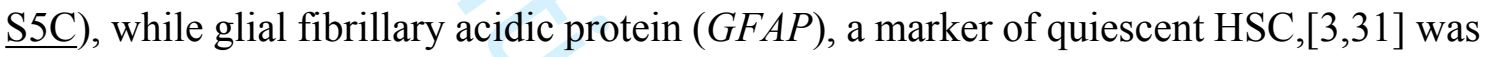
upregulated (Fig. 3A). These effects were reproduced in primary human HSC (Supporting Fig. S5D). Interestingly, culture-activation of primary mouse HSC was also reduced by $\underline{\mathrm{CM} 272 \text { treatment, as indicated by the expression of Colla1, Timp1 and lecithin-retinol }}$ acyltransferase (Lrat) (Supporting Fig. S5E). In agreement with the impaired response to TGF $\beta 1$ stimulation when $G 9 a$ and DNMT1 were knocked-down in LX2 cells (Fig. 2C) we found that combined treatment with the DNMT1 inhibitor decitabine and the G9a inhibitor BIX01294 also dampened the pro-fibrogenic responses to this growth factor (Supporting Fig. S5F). Together with TGF $\beta 1$, hypoxia is considered a major driver of liver fibrogenesis.[32,33] Consistently, we found that hypoxia stimulated LX2 cells growth and that CM272 inhibited this response as well as basal cell growth under normoxia (Fig. 3B). Moreover, fibrogenic gene expression induction by hypoxia was also blunted by CM272 (Fig. 3B). To better understand the effects of CM272 on fibrogenic cells activation, we performed a microarray analysis of gene expression in LX2 cells treated with TGF $\beta 1$ in the presence or absence of the drug. CM272 markedly affected TGF $\beta 1$-mediated gene expression regulation, with 1930 upregulated and 1442 
downregulated genes $(P<0.01)$ compared to cells treated with TGF $\beta 1$ alone (Fig. 3C). Gene ontology (GO) functional classification fundamentally identified categories related to cell growth, differentiation, signalling, metabolism, chromatin regulation and response to hypoxia (Fig. 3C). Accordingly, when we applied gene set enrichment analysis (GSEA), a significant positive enrichment in genes of the KEGG peroxisome proliferatoractivated receptor (PPAR) signaling pathway, as well as the reactome "metabolism of steroid hormones and vitamins A and D”, was detected in cells treated with CM272 (Fig. 3D). Also consistent with our GO analyses and with the effects of CM272 on TGF $\beta 1$ and hypoxia-mediated fibrogenic activation, we found significant negative enrichments in gene sets involved in TGF $\beta 1$, platelet derived growth factor receptor- $\beta$ (PDGFR $\beta$ ) and hypoxia-inducible factor (HIF) pathways (Fig. 3D). Interestingly, a negative enrichment was also observed in the KEGG glycolysis/gluconeogenesis gene set (Fig. 3D). Collectively, these findings indicate that G9a/DNMT1 targeting with CM272 profoundly affects the fibrogenic activation of liver myofibroblasts and the involved metabolic adaptations.

\section{Mechanisms of the inhibitory effects of CM272 on hepatic myofibroblasts activation.}

$\underline{\text { In view of the antagonism of CM272 on TGF } \beta 1 \text { cellular responses we first checked }}$ wether TGF $\beta 1$ signaling could be affected. We found that CM272 treatment attenuated SMAD3 phosphorylation in response to TGF $\beta 1$ in LX2 cells (Supporting Fig. S6A). Different mechanisms have been involved in the regulation of TGF $\beta 1$ signaling, among them is the expression of the TGF $\beta$ pseudoreceptor bone morphogenic protein and activin membrane-bound inhibitor (BAMBI) in different cell types but also in liver myofibroblasts.[34] Interestingly, we observed that CM272 treatment increased the expression of this negative regulator of TGF $\beta 1$ signaling in LX2 cells (Supporting Fig. S6B). However, the antifibrogenic effects of CM272 may extend beyond the direct 
inhibition of TGF $\beta 1$ signaling. As previosuly shown in Fig. 3A, the basal expression of several genes including $T G F \beta 1, P D G F R \beta, P A I 1, L O X$ and $G F A P$ was regulated by CM272 in LX2 cells in the absence of TGF $\beta 1$. Interestingly, we found that these responses were also observed in the presence of the TGF $\beta 1$ receptor-1 inhibitor (Alk5i)

\section{$\underline{\text { SB-525334 regardless of TGF } \beta 1 \text { stimulation (Supporting Fig. S6C). }}$}

Metabolic reprogramming is emerging as a critical event in fibrogenic activation across different tissue types.[4,5,35,36] Therefore, we examined the effects of CM272 on oxygen consumption rate (OCR; a representation of mitochondrial activity) and the extracellular acidification rate (ECAR; a surrogate for glycolytic rate) in LX2 cells treated with TGF $\beta 1$. As recently reported we found that TGF $\beta 1$ reduced OCR and increased ECAR,[36] however these effects were attenuated by CM272 (Fig. 4A). Consistently, the relative contribution to ATP production of glycolysis $v s$ oxidative phosphorylation, which was increased by TGF $\beta 1$, was mitigated by CM272 treatment (Fig. 4B). TGF $\beta 1$-triggered lactate production, a hallmark of the glycolytic phenotype contributing to fibrogenesis,[4] was also attenuated by CM272 (Fig. 4C). Changes in the expression of key glycolytic and gluconeogenic genes have been mechanistically linked to metabolic reprogramming and activation of fibrogenic cells. $[3,35,37,38]$ Consistently, when glycolysis was inhibited using the glucose analog 2-deoxy-D-glucose (2DG) (Supporting Fig. S7A) we found that TGF $\beta 1$-mediated fibrogenic gene expression in LX2 cells was impaired (Supporting Fig. $\underline{\mathrm{S} 7 \mathrm{~B})}$. Next, we tested the expression of the glycolytic genes hexokinase-I $(H K-I), 6-$ phosphofructo-2-kinase/fructose-2,6-biphosphatase 3 (PFKFB3), aldolase-A (ALDOA), phosphoglycerate kinase-I (PGK-I), pyruvate kinase M2 (PKM2) and lactate dehydrogenase A $(L D H A)$ in LX2 cells treated with TGF $\beta 1$ and CM272. CM272 reduced the basal expression of these genes and/or markedly counteracted the stimulatory effect of TGF $\beta 1$ on most of them (Fig. 4D). Recent studies in lung fibroblasts demonstrated that 
besides glycolytic activation TGF $\beta 1$ also triggers the expression of enzymes of the serineglycine biosynthetic pathway, a key source of glycine critically needed for collagen synthesis.[38-40] The serine-glycine biosynthetic pathway diverges from glycolysis via 3-phosphoglycerate, which in four consecutive steps is converted into glycine by the action of phosphoglycerate dehydrogenase (PHGDH), phosphoserine aminotransferase1 (PSAT1), phosphoserine phosphatase (PSPH) and finally serine hydroxymethyl transferase-2 (SHMT2) (Fig. 4D).[38,40] TGF $\beta 1$ induced the expression of the serineglycine pathway genes, and this effect was blunted by CM272 (Fig. 4D), which also reduced the basal expression of $P H G D H$ and the levels of H3K9 monomethylation (Fig. $\underline{4 \mathrm{D} \text { and Supporting Fig. S7C), a transcriptional activating epigenetic modification }}$ mediated by G9a.[41] Moreover, hypoxia-triggered expression of these genes in LX2 cells was also reduced by CM272 (Supporting Fig. S8A). Noteworthy, the serine-glycine metabolic pathway is indeed important for the activation of LX2 cells, as indicated by the inhibitory effects of NCT503, a PHGDH enzymatic inhibitor,[42] on hypoxia-elicited growth and TGF $\beta 1$-induced collagen synthesis in these cells (Supporting Fig. S8B). Very interestingly, the expression of the rate-limiting gluconeogenic enzymes phosphoenolpyruvate-carboxykinase $(P E P C K)$ and fructose-1,6-bisphosphatase-1 (FBP1), repressed during fibrogenic activation,[4] was also inhibited by TGF $\beta 1$, but restored under CM272 treatment (Fig. 4D). Moreover, the expression of the transcription factor and metabolic regulator peroxisome proliferator activated receptor gamma coactivator-1 $\alpha(P G C-1 \alpha)$, recently identified as a key guardian of lung fibroblasts quiescence, $[19,37]$ was also repressed by TGF $\beta 1$ and was potently reactivated upon CM272 treatment (Fig. 4D). These responses to CM272 were reproduced in human primary HSC ( Supporting Fig. S9A $)$. Importantly, the upregulation of FBP1 and PGC$1 \alpha$ expression by CM272 (Fig. 4E) was related to the on-target pharmacological actions 
of this molecule. By qChIP analyses we found that CM272 reduced the levels of the repressive $\mathrm{H} 3 \mathrm{~K} 9 \mathrm{me} 2$ mark in the proximal promoters of $F B P 1$ and $P G C-1 \alpha$ (Fig. 4F). At the DNA level, FBP1 promoter was found hypermethylated in a region previously associated with its transcriptional repression in cancer,[26] and DNA methylation was reduced upon CM272 or decitabine treatment (Fig. 4G). Regarding $P G C$ - $1 \alpha$, we did not find significant levels of DNA methylation (Fig. 4G), suggesting that its transcriptional repression could be mainly mediated by G9a-H3K9 dimethylation, which indeed was reversed by CM272 treatment (Fig. 4F). In support of these notions we observed that FBP1 expression was upregulated by decitabine or BIX01294, and together both agents had an additive effect, while PGC-1 $\alpha$ expression was induced only by BIX01294 (Supporting Fig. S9B).

\section{CM272 inhibits hepatic fibrogenesis in vivo.}

Next, we examined the antifibrogenic potential of CM272 in different mouse models. First, we tested the effects of CM272 on the acute activation of $\mathrm{HSC}$ upon single $\mathrm{CCl}_{4}$ injection. We found that CM272 administration $24 \mathrm{~h}$ after $\mathrm{CCl}_{4}$ markedly inhibited $\mathrm{HSC}$ activation as indicated by $\alpha$-SMA expression (Supporting Fig. S10A). The antifibrogenic activity of CM272 was also evident in chronic liver injury. Mice received $\mathrm{CCl}_{4}$ twice a week for 6 weeks, and for the last two weeks were treated with CM272 or its vehicle (Fig. 5A). $\alpha$-SMA and Sirius red staining for collagen deposition demonstrated reduced liver fibrosis in CM272-treated mice (Fig. 5A), corroborated by decreased expression of collagen-I $\alpha 1$ (Coll $\alpha 1$ ), $\alpha$-Sma and Tgf $\beta 1$ (Fig. 5B). Interestingly, expression of Pkm2, previously identified as a marker of glycolytic activation in liver myofibroblasts and a key regulator of glycolysis and the serine-glycine pathway,[4,43] was induced by $\mathrm{CCl}_{4}$ administration. Noteworthy, $P k m 2$ expression was significantly attenuated by CM272 treatment, as was that of Phgdh (Fig. 5A and 5B). The antifibrotic effects of CM272 were 
reproduced in a model of cholestatic liver injury induced by BDL, as demonstrated by reduced $\alpha$-SMA immunostaining, collagen deposition and expression of fibrogenesis-and glycolysis-related genes (Fig. $5 \mathrm{C}$ and D). As in the $\mathrm{CCl}_{4}$ model, $P \mathrm{~km} 2$ expression was also increased in areas of active fibrosis and was downregulated by CM272 (Fig. 5C). No significant differences in serum transaminases and creatinine levels nor body weight were found between vehicle and CM272 treated mice in either model, while a decrease in the hepatic expression of pro-inflammatory cytokines was noticed (Supporting Fig. S10B and C). Together these findings demonstrate that in vivo targeting of G9a/DNMT1 with CM272 during ongoing liver injury has antifibrotic potential and is exempt of overt toxicity.

\section{CM272 has antifibrotic activity in human precision-cut liver slices (PCLSs).}

To further validate the antifibrotic effects of CM272 we used human PCLSs cultured in a newly designed bioreactor that allows modeling active fibrogenesis induced by pathophysiological stimuli; TGF $\beta 1$ and PDGF-BB.[28] First, we observed that $G 9 a$, DNMT1 and UHRF1 expression was significantly increased after $96 \mathrm{~h}$ in culture compared to freshly isolated tissues, and TGF $\beta 1+$ PDGF-BB enhanced this response (Fig. 6A). Immunohistochemical analyses of PCLSs detected G9a and DNMT1 proteins in regions of the parenchyma enriched in $\alpha$-SMA positive cells (Fig. 6B). Next, we tested the effects of CM272 treatment on TGF $\beta 1+$ PDGF-BB-mediated fibrogenic activation of PCLSs (Fig. 6A). PCLSs were incubated with TGF $\beta 1+P D G F-B B$ in the absence or presence of CM272 or the TGF $\beta 1$ receptor-1 inhibitor (Alk5i) SB-525334.[28] As shown in Fig. 6C, the upregulation of fibrogenic gene expression elicited by TGF $\beta 1+$ PDGF-BB was significantly attenuated by CM272. Consistently, soluble collagen secretion into the culture media, its deposition in the fibrotic matrix, and $\alpha$-SMA staining were also markedly inhibited (Fig. 6D and E). Interestingly, lactate accumulation in the culture 
medium, indicative of metabolic glycolytic reprogramming, was inhibited not only by SB-525334 but also very efficiently by CM272 (Fig. 6F). Accordingly, FBP1 expression was downregulated by TGF $\beta 1+$ PDGF-BB treatment while that of $P K M 2$ and $P H G D H$ was induced (Fig. 6G). These changes were also reversed by SB-525334 and CM272 (Fig. 6G). Immunohistochemical staining of PCLSs detected PKM2 expression in fibrogenic cells, validating the activation of glycolysis in human liver tissues by fibrogenic stimuli, and its inhibition by CM272 (Fig. 6H). Our PCLSs model may also provide valuable information on potential hepatotoxic effects of experimental therapies in a human liver tissue environment.[28] We measured a series of parameters, including albumin and urea levels, and lactate dehydrogenase (LDH), AST and ALT activities in conditioned media from control and CM272 treated PCLSs. We found no significant differences on these markers of hepatocellular function and injury in comparison with controls (Fig. 7A), and no major histological alterations upon H\&E staining were observed either (Fig. 7B). 


\section{DISCUSSION}

Accumulating evidence shows the involvement of epigenetic mechanisms in the activation of quiescent hepatic ECM-producing cells and the maintenance of their fibrogenic phenotype. $[9,11]$ Here we confirmed the overexpression of DNMT1 in human and mouse fibrotic liver,[44] and report the concomitant upregulation of the HMT G9a. Our novel findings indicate that these epigenetic effectors, together with their functional adaptor UHRF1,[29] contribute to HSC fibrogenic activation. Besides their marked induction during primary mouse HSC activation in culture, we observed that TGF $\beta 1$ stimulation led to their fast recruitment to the chromatin-bound nuclear subfraction in LX2 cells. This response has been observed for other transcriptional regulators involved in TGF $\beta 1$ control of gene expression such as activating transcription factor-4.[40] Here we extend this dynamic effect of TGF $\beta 1$ to epigenetic factors. However, compelling evidence on the involvement of G9a, DNMT1 and UHRF1 in liver fibrogenic cell activation was obtained when their expression was inhibited (siRNAs) in LX2 cells and we observed that the pro-fibrogenic transcriptomic response to TGF $\beta 1$ was abrogated. This genetic evidence, together with the extensive functional crosstalk between different chromatin regulatory mechanisms, such as DNA and H3K9 methylation,[21] prompted us to characterize in detail the antifibrogenic potential of a novel dual G9a/DNMT inhibitor CM272.[24] We observed that CM272 markedly inhibited TGF $\beta 1$-stimulated pro-fibrogenic gene expression in LX2 and human primary HSC. Interestingly, these effects of CM272 were not restricted to TGF $\beta 1$ action, as they were also observed under hypoxia, another key proliferative and fibrogenic stimulus for HSC.[32,33] To elucidate the mechanisms underlying CM272 activity we performed transcriptomic studies in LX2 cells treated with TGF $\beta 1$ in the absence or presence of the drug. Consistent with the inhibition of TGF $\beta 1$-triggered fibrogenic activation, our GSEA found negative 
enrichment in categories associated with TGF $\beta 1$ and PDGFRB signaling pathways. Interestingly, the HIF pathway, which critically participates in TGF $\beta 1$-mediated kidney fibrogenesis,[45] was also negatively affected by CM272. Notwithstanding the mechanistic relevance of these responses, it was the effect of CM272 on the expression of metabolism-related genes that captured our attention. Incipient, but nonetheless robust evidence on the importance of metabolic reprogramming for fibrogenic cell activation is steadily accumulating. Similar to the Warburg effect in cancer cells, glycolytic activation along with mitochondrial dysfunction have been shown to contribute to fibrogenesis in different tissues.[5,35-37] Early evidence obtained in liver myofibroblasts showed how reciprocal changes in glycolytic and gluconeogenic enzymes triggered by hedgehog signaling were mechanistically linked to HSC activation.[4] Here we found that TGF $\beta 1$ elicited very similar responses, inducing the expression of most genes coding for glycolytic enzymes and repressing that of the rate-limiting gluconeogenic genes FBP1 and $P E P C K$, as well as the metabolic regulator $P G C-1 \alpha$, which downregulation in lung fibroblasts markedly contributes to their activation.[37] These transcriptional effects of TGF $\beta 1$ translated into metabolic alterations, including enhanced glycolytic rate and decreased mitochondrial activity. Consequently, ATP production shifted from a preferentially mitochondrial origin (OXPHOS) to a glycolytic one. In agreement with recent findings in lung myofibroblasts,[38] we found that in human HSC TGF $\beta 1$ markedly stimulated the expression of genes in the serine-glycine pathway. This pathway is not only essential for the supply of glycine for collagen synthesis, [38,39] it also connects glycolysis with one-carbon metabolism and nucleotide synthesis, required for cell proliferation.[42] We found that CM272 treatment effectively reversed the transcriptional program triggered by TGF $\beta 1$ and its impact on glycolytic activity and mitochondrial function. The molecular mechanisms underlying these effects are likely 
complex, but to a great extent may be attributed to specific pharmacological activities of CM272. We believe that one central target gene in the antifibrogenic effects of CM272 would be FBP1. As we showed, the expression of $F B P 1$ is downregulated in activated liver myofibroblasts through epigenetic mechanisms involving increased DNA and H3K9 methylation in its promoter, modifications that were reversed by CM272. FBP1 is not only a key gluconeogenic enzyme, it is also able to suppress HIF-1 $\alpha$ activity by direct binding and acting as a transcriptional corepressor of HIF-1 $\alpha$ target genes, which include most of glycolytic enzymes.[46] Moreover, FBP1-mediated suppression of HIF-1 $\alpha$ activity may also be involved in the antagonistic effects of CM272 on TGF $\beta 1$ responses, as the HIF-1 $\alpha$ pathway is co-opted by TGF $\beta 1$ for its pro-fibrogenic activity even under normoxia.[45,47] Regarding the normalization of mitochondrial function, together with FBP1 reactivation[48] the enhanced expression of PGC-1 $\alpha$ by $\mathrm{CM} 272$ treatment may also be relevant. PGC- $1 \alpha$ is a master metabolic regulator, with roles including the preservation of mitochondrial function and the regulation of gluconeogenic gene expression (e.g. PEPCK).[49] Recently, transcriptional repression of $P G C-1 \alpha$ has been critically involved in lung myofibroblast metabolic reprogramming and activation.[37] Interestingly, G9a-mediated $\mathrm{H} 3 \mathrm{~K} 9$ methylation was also shown to participate in $P G C-1 \alpha$ repression during lung myofibroblast activation. [19] Concomitantly, CM272 inhibition of G9a activity might also be involved in the repression of serine-glycine pathway genes, as G9a-mediated $\mathrm{H} 3 \mathrm{~K} 9$ monomethylation has been reported to mediate the transcriptional activation of these genes.[41]

Our in vitro observations were validated in two etiologically distinct mouse models of liver fibrogenesis. Indeed, the expression of G9a and DNMT1 was detected in stromal fibrogenic cells also stained with $\alpha$-SMA, and CM272 reduced myofibroblast activation and ECM accumulation. Mechanistically, the inhibitory effects of CM272 on fibrogenic 
metabolic reprogramming could also be taking place in vivo, as indicated by decreased accumulation of PKM2-expressing stromal cells. Importantly, these findings were extended to the human setting. Cirrhotic human liver tissues also showed increased levels of G9a and DNMT1 in areas of active fibrosis, and the expression of these epigenetic effectors was induced in cultured PCLSs concomitantly with their fibrogenic activation. PCLSs are a very useful tool to test antifibrotic drugs due to being a close surrogate of the human liver microenvironment.[28] Here we reproduced the antifibrogenic effects of CM272 observed in cultured cells and mouse models, including key aspects of HSC activation and metabolic reprogramming. One fundamental feature of any drug candidate is the absence of toxic reactions, particularly when intended to be administered to patients with liver injury. Consistent with our previous reports,[24,26] we did not observe any signs of hepatic or systemic toxicity in mice treated with CM272. Most importantly, this lack of toxicity was also evident in human PCLS, where parameters of hepatocellular function (e.g. albumin production) and cell integrity were not negatively affected by the drug. Nevertheless, as some of us recently showed, there are emerging technologies allowing myofibroblast-selective drug delivery in vivo which may further enhance drug efficacy and safety in the context of liver injury.[16]

In summary, we have identified novel epigenetic targets involved in liver fibrosis and demonstrated that their dual targeting with an innovative "epi-drug" can inhibit progression of liver fibrosis even in the absence of treating the underlying disease. We have also provided extended evidence on the role of metabolic reprogramming in liver fibrogenesis, and how this can be manipulated at the epigenetic level to halt or reverse the process. CM272 might be also considered for the treatment of fibrotic processes in other organs like the lung and kidneys, in which this condition has devastating effects. 
Acknowledgments. We particularly acknowledge the patients for their participation and the Biobank of the University of Navarra for its collaboration. We thank Mr. Roberto Barbero and Mrs. Sara Arcelus for their technical support.

Competing Interests. The authors declare no competing interests.

Funding. We thank the financial support of: CIBERehd; grant PI16/01126 from Instituto de Salud Carlos III (ISCIII) co-financed by "Fondo Europeo de Desarrollo Regional" (FEDER) “Una manera de hacer Europa"; grant 58/17 from Gobierno de Navarra; grants SAF2014-54191-R, SAF2017-88933-R and SAF2019-104878RB-100 from FEDER/Ministerio de Ciencia, Innovación y Universidades-Agencia Estatal de Investigación; grant BIO15/CA/011 from Bio-Eusko Fundazioa (Eitb maratoia); grant from Asociación Española Contra el Cáncer (AECC) Scientific Foundation Rare Cancers grant 2017; HEPACARE Project from Fundación La Caixa; Fundación Eugenio Rodríguez Pascual; Fundación Echébano; Fundación Mario Losantos and Fundación M Torres. We thank Mr. Eduardo Ávila and Mr. Sergio Durá for their generous contribution. FPI fellowships from Ministerio de Educación, Cultura y Deporte to MBV, MG and MR; FIMA-CIMA fellowship to AC; Gobierno de Navarra fellowship to LC; AECC postdoctoral fellowship to MA and Ramón y Cajal Program contract to MGFB. This work was also funded by a UK Medical Research Council program grants to J.M, FO and others $(\underline{\mathrm{MR} / \mathrm{K} 10019494 / 1, \mathrm{MK} / \mathrm{K} 001949 / 1}, \mathrm{MR} / \mathrm{R} 023026 / 1)$; National Institute on Alcohol Abuse and Alcoholism (NIAAA) (grant UO1AA018663). The research was further supported by the National Institute for Health Research Newcastle Biomedical Research Centre based at Newcastle Hospitals NHS Foundation Trust and Newcastle University. 


\section{REFERENCES}

1 Hernandez-Gea V, Friedman SL. Pathogenesis of Liver Fibrosis. Annu Rev Pathol Mech Dis 2011;6:425-56. doi:10.1146/annurev-pathol-011110-130246

2 Hernandez-Gea V, Toffanin S, Friedman SL, et al. Role of the Microenvironment in the Pathogenesis and Treatment of Hepatocellular Carcinoma.

Gastroenterology 2013;144:512-27. doi:10.1053/j.gastro.2013.01.002

3 Tsuchida T, Friedman SL. Mechanisms of hepatic stellate cell activation. Nat Rev Gastroenterol Hepatol 2017;14:397-411. doi:10.1038/nrgastro.2017.38

4 Chen Y, Choi SS, Michelotti GA, et al. Hedgehog Controls Hepatic Stellate Cell Fate by Regulating Metabolism. Gastroenterology 2012;143:1319-1329.e11. doi:10.1053/j.gastro.2012.07.115

5 Hou W, Syn W-K. Role of Metabolism in Hepatic Stellate Cell Activation and Fibrogenesis. Front Cell Dev Biol 2018;6:150. doi:10.3389/fcell.2018.00150

$6 \quad$ Kisseleva $\mathrm{T}$, Cong $\mathrm{M}$, Paik $\mathrm{Y}$, et al. Myofibroblasts revert to an inactive phenotype during regression of liver fibrosis. Proc Natl Acad Sci U S A 2012;109:9448-53. doi:10.1073/pnas.1201840109

7 Troeger JS, Mederacke I, Gwak G-Y, et al. Deactivation of hepatic stellate cells during liver fibrosis resolution in mice. Gastroenterology 2012;143:1073-83.e22. doi:10.1053/j.gastro.2012.06.036

8 Lee YA, Wallace MC, Friedman SL. Pathobiology of liver fibrosis: a translational success story. Gut 2015;64:830-41. doi:10.1136/gutjnl-2014-306842

9 Moran-Salvador E, Mann J. Epigenetics and Liver Fibrosis. Cell Mol Gastroenterol Hepatol 2017;4:125-34. doi:10.1016/j.jcmgh.2017.04.007

10 Barcena-Varela M, Colyn L, Fernandez-Barrena MG. Epigenetic Mechanisms in 
Hepatic Stellate Cell Activation During Liver Fibrosis and Carcinogenesis. Int J Mol Sci 2019;20:2507. doi:10.3390/ijms20102507

11 Wilson CL, Mann DA, Borthwick LA. Epigenetic reprogramming in liver fibrosis and cancer. Adv Drug Deliv Rev 2017;121:124-32.

doi:10.1016/j.addr.2017.10.011

12 Mann J, Chu DCK, Maxwell A, et al. MeCP2 controls an epigenetic pathway that promotes myofibroblast transdifferentiation and fibrosis. Gastroenterology 2010;138:705-14, 714.e1-4. doi:10.1053/j.gastro.2009.10.002

13 Perugorria MJ, Wilson CL, Zeybel M, et al. Histone methyltransferase ASH1 orchestrates fibrogenic gene transcription during myofibroblast transdifferentiation. Hepatology 2012;56:1129-39. doi:10.1002/hep.25754

14 Niki T, Rombouts K, De Bleser P, et al. A histone deacetylase inhibitor, trichostatin A, suppresses myofibroblastic differentiation of rat hepatic stellate cells in primary culture. Hepatology 1999;29:858-67. doi:10.1002/hep.510290328

15 Mann J, Oakley F, Akiboye F, et al. Regulation of myofibroblast transdifferentiation by DNA methylation and MeCP2: implications for wound healing and fibrogenesis. Cell Death Differ 2007;14:275-85. doi:10.1038/sj.cdd.4401979

16 Zeybel M, Luli S, Sabater L, et al. A Proof-of-Concept for Epigenetic Therapy of Tissue Fibrosis: Inhibition of Liver Fibrosis Progression by 3-Deazaneplanocin A. Mol Ther 2017;25:218-31. doi:10.1016/j.ymthe.2016.10.004

17 Martin-Mateos R, De Assuncao TM, Arab JP, et al. Enhancer of Zeste Homologue 2 Inhibition Attenuates TGF- $\beta$ Dependent Hepatic Stellate Cell Activation and 
Liver Fibrosis. Cell Mol Gastroenterol Hepatol 2019;7:197-209.

doi:10.1016/j.jcmgh.2018.09.005

18 Irifuku T, Doi S, Sasaki K, et al. Inhibition of H3K9 histone methyltransferase G9a attenuates renal fibrosis and retains klotho expression. Kidney Int 2016;89:14757. doi:10.1038/ki.2015.291

19 Ligresti G, Caporarello N, Meridew JA, et al. CBX5/G9a/H3K9me-mediated gene repression is essential to fibroblast activation during lung fibrosis. JCI Insight 2019;4:e127111. doi:10.1172/jci.insight.127111

20 Tachibana M, Matsumura Y, Fukuda M, et al. G9a/GLP complexes independently mediate $\mathrm{H} 3 \mathrm{~K} 9$ and DNA methylation to silence transcription. EMBO J 2008;27:2681-90. doi:10.1038/emboj.2008.192

21 Du J, Johnson LM, Jacobsen SE, et al. DNA methylation pathways and their crosstalk with histone methylation. Nat Rev Mol Cell Biol 2015;16:519-32. doi:10.1038/nrm4043

22 Wozniak RJ, Klimecki WT, Lau SS, et al. 5-Aza-2'-deoxycytidine-mediated reductions in G9A histone methyltransferase and histone H3 K9 di-methylation levels are linked to tumor suppressor gene reactivation. Oncogene 2007;26:7790. doi:10.1038/sj.onc.1209763

23 Casciello F, Windloch K, Gannon F, et al. Functional Role of G9a Histone Methyltransferase in Cancer. Front Immunol 2015;6. doi:10.3389/fimmu.2015.00487

24 San José-Enériz E, Agirre X, Rabal O, et al. Discovery of first-in-class reversible dual small molecule inhibitors against G9a and DNMTs in hematological malignancies. Nat Commun 2017;8:15424. doi:10.1038/ncomms15424 
25 Rabal O, José-Enériz ES, Agirre $X$, et al. Discovery of Reversible DNA Methyltransferase and Lysine Methyltransferase G9a Inhibitors with Antitumoral in Vivo Efficacy. J Med Chem 2018;61:6518-45. doi:10.1021/acs.jmedchem.7b01926

26 Bárcena-Varela M, Caruso S, Llerena S, et al. Dual Targeting of Histone Methyltransferase G9a and DNA-Methyltransferase 1 for the Treatment of Experimental Hepatocellular Carcinoma. Hepatology 2019;69:587-603. doi:10.1002/hep.30168

27 Garcia-Irigoyen O, Carotti S, Latasa MU, et al. Matrix metalloproteinase-10 expression is induced during hepatic injury and plays a fundamental role in liver tissue repair. Liver Int 2014;34:e257-70. doi:10.1111/liv.12337

28 Paish HL, Reed LH, Brown H, et al. A Bioreactor Technology for Modeling Fibrosis in Human and Rodent Precision-Cut Liver Slices. Hepatology 2019;:'hep.30651. doi:10.1002/hep.30651

29 Ferry L, Fournier A, Tsusaka T, et al. Methylation of DNA Ligase 1 by G9a/GLP Recruits UHRF1 to Replicating DNA and Regulates DNA Methylation. Mol Cell 2017;67:550-565.e5. doi:10.1016/j.molcel.2017.07.012

$30 \mathrm{Xu} \mathrm{L,} \mathrm{Hui} \mathrm{AY,} \mathrm{Albanis} \mathrm{E,} \mathrm{et} \mathrm{al.} \mathrm{Human} \mathrm{hepatic} \mathrm{stellate} \mathrm{cell} \mathrm{lines,} \mathrm{LX-1} \mathrm{and} \mathrm{LX-2:}$ new tools for analysis of hepatic fibrosis. Gut 2005;54:142-51. doi:10.1136/gut.2004.042127

31 Yang L, Jung Y, Omenetti A, et al. Fate-Mapping Evidence That Hepatic Stellate Cells Are Epithelial Progenitors in Adult Mouse Livers. Stem Cells 2008;26:210413. doi:10.1634/stemcells.2008-0115

32 Nath B, Szabo G. Hypoxia and hypoxia inducible factors: Diverse roles in liver 
diseases. Hepatology 2012;55:622-33. doi:10.1002/hep.25497

33 Roth KJ, Copple BL. Role of Hypoxia-Inducible Factors in the Development of Liver Fibrosis. Cell Mol Gastroenterol Hepatol 2015;1:589-97. doi:10.1016/j.jcmgh.2015.09.005

34 Seki E, De Minicis S, Osterreicher CH, et al. TLR4 enhances TGF-beta signaling and hepatic fibrosis. Nat Med 2007;13:1324-32. doi:10.1038/nm1663

35 Xie N, Tan Z, Banerjee S, et al. Glycolytic Reprogramming in Myofibroblast Differentiation and Lung Fibrosis. Am J Respir Crit Care Med 2015;192:1462-74. doi:10.1164/rccm.201504-07800C

36 Si M, Wang Q, Li Y, et al. Inhibition of hyperglycolysis in mesothelial cells prevents peritoneal fibrosis. Sci Transl Med 2019;11:eaav5341. doi:10.1126/scitranslmed.aav5341

37 Caporarello N, Meridew JA, Jones DL, et al. PGC1 $\alpha$ repression in IPF fibroblasts drives a pathologic metabolic, secretory and fibrogenic state. Thorax 2019;74:749-60. doi:10.1136/thoraxjnl-2019-213064

38 Nigdelioglu R, Hamanaka RB, Meliton AY, et al. Transforming Growth Factor (TGF)- $\beta$ Promotes de Novo Serine Synthesis for Collagen Production. J Biol Chem 2016;291:27239-51. doi:10.1074/jbc.M116.756247

39 Hamanaka RB, Nigdelioglu R, Meliton AY, et al. Inhibition of Phosphoglycerate Dehydrogenase Attenuates Bleomycin-induced Pulmonary Fibrosis. Am J Respir Cell Mol Biol 2018;58:585-93. doi:10.1165/rcmb.2017-01860C

40 Selvarajah B, Azuelos I, Platé M, et al. mTORC1 amplifies the ATF4-dependent de novo serine-glycine pathway to supply glycine during TGF- $\beta_{1}$-induced collagen biosynthesis. Sci Signal 2019;12:eaav3048. doi:10.1126/scisignal.aav3048 
41 Ding J, Li T, Wang X, et al. The histone H3 methyltransferase G9A epigenetically activates the serine-glycine synthesis pathway to sustain cancer cell survival and proliferation. Cell Metab 2013;18:896-907. doi:10.1016/j.cmet.2013.11.004

42 Pacold ME, Brimacombe KR, Chan SH, et al. A PHGDH inhibitor reveals coordination of serine synthesis and one-carbon unit fate. Nat Chem Biol 2016;12:452-8. doi:10.1038/nchembio.2070

43 Ye J, Mancuso A, Tong X, et al. Pyruvate kinase M2 promotes de novo serine synthesis to sustain mTORC1 activity and cell proliferation. Proc Natl Acad Sci U S A 2012;109:6904-9. doi:10.1073/pnas.1204176109

44 Page A, Paoli P, Moran Salvador E, et al. Hepatic stellate cell transdifferentiation involves genome-wide remodeling of the DNA methylation landscape. J Hepatol 2016;64:661-73. doi:10.1016/j.jhep.2015.11.024

45 Hanna C, Hubchak SC, Liang X, et al. Hypoxia-inducible factor-2 $\alpha$ and TGF- $\beta$ signaling interact to promote normoxic glomerular fibrogenesis. Am J Physiol Renal Physiol 2013;305:F1323-31. doi:10.1152/ajprenal.00155.2013

46 Li B, Qiu B, Lee DSM, et al. Fructose-1,6-bisphosphatase opposes renal carcinoma progression. Nature 2014;513:251-5. doi:10.1038/nature13557

47 Rozen-Zvi B, Hayashida T, Hubchak SC, et al. TGF- $\beta / S m a d 3$ activates mammalian target of rapamycin complex-1 to promote collagen production by increasing HIF-1 $\alpha$ expression. Am J Physiol Renal Physiol 2013;305:F485-94. doi:10.1152/ajprenal.00215.2013

48 Dong $\mathrm{C}$, Yuan T, Wu Y, et al. Loss of FBP1 by Snail-mediated repression provides metabolic advantages in basal-like breast cancer. Cancer Cell 2013;23:316-31. doi:10.1016/j.ccr.2013.01.022 
49 Liang H, Ward WF. PGC-1alpha: a key regulator of energy metabolism. Adv Physiol Educ 2006;30:145-51. doi:10.1152/advan.00052.2006 


\section{Figure legends}

Figure 1. G9a, DNMT1 and $\alpha$-SMA immunostaining on sections from normal and diseased human and mouse liver tissues. (A) Representative immunostainings showing G9a and DNMT1 detection (arrows) in fibrotic lesions in livers from cirrhotic patients with chronic hepatitis $\mathrm{C}$ virus (HCV) or hepatitis B virus (HVB) infection, or alcoholic liver disease (ALD). $\alpha$-SMA staining identifies myofibroblasts in association with fibrotic lesions. Images are representative of at least ten patients per condition. (B) Representative immunostainings showing G9a and DNMT1 detection (arrows) in liver sections from control mice and from animals chronically treated with $\mathrm{CCl}_{4}$ (six weeks) or eleven days after bile duct ligation (BDL). $\alpha$-SMA staining identifies myofibroblasts in association with fibrotic lesions. Images are representative of at least six mice per condition.

Figure 2. Expression and role of G9a, DNMT1 and UHRF1 in liver fibrogenic cells activation. (A) Expression of G9a, DNMT1 and UHRF1 in primary mouse HSC during culture activation. Left panel shows a representative western blot including $\alpha$-SMA protein levels denoting HSC activation kinetics and Ponceau staining to show equal loading. Right panel shows qPCR analyses of mRNA levels for the indicated genes in the early phase of HSC culture activation. (B) Representative western blot analyses of G9a, DNMT1 and UHRF1 proteins in the chromatin fraction from nuclear extracts, or total cell lysates, obtained from LX2 cells treated with TGF $\beta 1$ for 3 h. Histone H3 and $\alpha$ TUBULIN levels are shown to demonstrate equal loading. (C) Influence of $G 9 a, D N M T 1$ and UHRF1 expression on TGF $\beta 1$ mediated fibrosis-related gene expression in LX2 cells. Cells were transfected with $G 9 a, D N M T 1$ or $U H R F 1$-specific siRNAs, or control siRNAS (siC) and 24h later were treated with TGF $\beta 1$ for another $24 \mathrm{~h}$. Graph shows the qPCR analysis of mRNA levels for the indicated genes. 
Figure 3. Dual targeting of G9a and DNMT1 inhibits hypoxia- and TGF $\beta 1$-driven activation of HSC. (A) LX2 cells were treated with CM272 (400nM) for 24h and then stimulated with TGF $\beta 1(5 \mathrm{ng} / \mathrm{mL})$ for another $24 \mathrm{~h}$. Expression of fibrogenic activationrelated genes and GFAP was evaluated by qPCR. (B) Effect of CM272 on the growth (left panel) and fibrogenic gene expression (right panel) elicited by hypoxia, including transforming growth factor- $\beta 1$ (TGF $\beta 1)$, platelet derived growth factor receptor $\beta$ $(P D G F R \beta)$, tissue inhibitor of metalloproteases 1 (TIMP1), lysyl oxidase $(L O X)$ and lactate dehydrogenase A ( $L D H A)$. LX2 cells were treated with CM272 (400nM) for 24h and then grown under normoxic $\left(20 \% \mathrm{O}_{2}\right)$ or hypoxic $\left(1 \% \mathrm{O}_{2}\right)$ conditions for a further 24h. (C) Left panel shows the most relevant GO categories of genes undergoing changes in expression identified by microarray analysis in LX2 cells treated or not with CM272 $(400 \mathrm{nM})$ and then stimulated with TGF $\beta 1(5 \mathrm{ng} / \mathrm{mL})$ for another $24 \mathrm{~h}$. Right panel shows a volcano plot displaying differentially expressed genes between LX2 cells treated with TGF $\beta 1$ in the presence or absence of CM272. Red dots represent upregulated transcripts and green dots represent transcripts with downregulated expression. (D) GSEA of microarray gene expression data revealed positive enrichment in gene expression by CM272 in categories related to PPAR signaling and steroid hormone and liposoluble vitamins metabolism, and negative enrichment of related to glucose metabolism, hypoxia and fibrogenic activation (TGF $\beta 1$ and PDGFR $\beta$ pathways).

Figure 4. Dual targeting of G9a and DNMT1 counteracts the pro-fibrogenic metabolic reprogramming of HSC elicited by TGF $\beta 1$. (A) Left panel, oxygen consumption rate (OCR) in LX2 cells treated or not with CM272 (400nM) for $24 \mathrm{~h}$ and then stimulated or not with TGF $\beta 1(5 \mathrm{ng} / \mathrm{mL})$ for $3 \mathrm{~h}$. Right panel, extracellular acidification rate (ECAR) in 
LX2 cells treated as indicated above. (B) Relative ATP production from oxidative phosphorylation (OXPHOS) and glycolysis in LX2 cells treated as indicated above. (C) Lactate production (i.e. lactate release to culture medium) by LX2 cells pre-treated or not with CM272 (400nM) for $24 \mathrm{~h}$ and then stimulated with TGF $\beta 1(5 \mathrm{ng} / \mathrm{mL})$ for up to $24 \mathrm{~h}$ more. (D) CM272 counteracts the reprogramming of metabolic gene expression elicited by TGF $\beta 1$ in LX2 cells. Cells were treated with CM272 (400nM) for $24 \mathrm{~h}$ and then stimulated with TGF $\beta 1(5 \mathrm{ng} / \mathrm{mL})$ for another $24 \mathrm{~h}$ as indicated. The expression of genes involved in glycolysis (red letters), the serine-glycine pathway (green letters) and gluconeogenesis (blue letters) was measured by qPCR. (E) Western blot analysis of FBP1 and PGC-1 $\alpha$ protein levels in LX2 cells treated with CM272 (200nM) for $48 \mathrm{~h}$. Representative blots are shown. (F) analysis of H3K9me2 levels by qChIP assay in the proximal promoter regions of $F B P 1$ and $P G C-1 \alpha$ genes in $\mathrm{LX} 2$ cells treated with $\mathrm{CM} 272$ (200nM) for 48h. (G) Methylation-specific PCR (MSP) assays of DNA methylation in FBP1 and PGC-1 $\alpha$ promoters in control and CM272 (100nM, 96h) treated LX2 cells. Cells were also treated with decitabine $(5 \mu \mathrm{M})$ as a control for a DNA demethylating agent. Bands in lanes labeled " $\mathrm{U}$ " and "M" are PCR products amplified with unmethylation- and methylation-specific primers. Images are representative of three experiments performed in duplicates.

Figure 5. CM272 inhibits liver fibrogenesis in vivo. (A) As shown in the diagram, mice received $\mathrm{CCl}_{4}$ or vehicle (oil) for six weeks, and for the last two weeks were treated with CM272 $(2.5 \mathrm{mg} / \mathrm{kg}$ body weight $)$ or PBS. Animals were humanely killed $24 \mathrm{~h}$ or 4 days after the last $\mathrm{CCl}_{4}$ injection and liver tissues were immunostained for $\alpha$-SMA and PKM2, or stained with Sirius Red for collagen detection. Representative images are shown. (B) Expression of key genes involved in hepatic fibrogenesis and metabolic reprogramming in the livers of mice treated as described in panel A. (C) Mice underwent BDL and were 
treated with CM272 $(2.5 \mathrm{mg} / \mathrm{kg}$ body weight $)$ or PBS as indicated in the diagram. At day 11 after surgery animals were sacrificed and liver tissue sections were immunostained for $\alpha$-SMA and PKM2 or stained with Sirius Red for collagen detection. (D) Expression of key genes involved in hepatic fibrogenesis and metabolic reprogramming in the livers of mice treated as described in the graph. Liver samples from sham operated mice were used as controls.

Figure 6. CM272 has antifibrotic effects in human PCLSs. (A) Human precision cut liver slices were isolated and placed in the bioreactor chambers. After 24h PCLSs were treated with a fibrogenic stimulus (TGF $\beta 1+$ PDGF-BB), its vehicle, CM272 $(1 \mu \mathrm{M})$ or the activin receptor-like kinase 5 inhibitor (Alk5i) SB-525334 as shown in the graph. G9a, DNMT1 and UHRF1 expression levels were measured by qPCR (B) Immunohistochemical analyses of G9a, DNMT1 and $\alpha$-SMA performed in tissue sections from PCLSs treated as indicated. Representative images are shown. (C) qPCR analysis of the expression of key genes involved in hepatic fibrogenesis in PCLSs treated as indicated. (D) Soluble collagen (COLIA1) levels in media of bioreactor cultured PCLSs after 72 and $96 \mathrm{~h}$ incubation under the indicated conditions. Grey bars: vehicle; black bars: TGF $\beta 1+$ PDGFBB. (E) Representative images of $\alpha$-SMA and picrosirius-red-stained tissue sections from PCLSs at $\mathrm{t}=0$ and after $96 \mathrm{~h}$ treatment as indicated. (F) Quantification of lactate accumulation in media of bioreactor cultured PCLSs after 72 and $96 \mathrm{~h}$ incubation under the indicated conditions. Grey bars: vehicle; black bars: TGF $\beta 1+P D G F-B B$. (G) qPCR analysis of the expression of key genes associated with the reprogramming of glucose metabolism in PCLSs. (H) Immunohistochemical analysis of PKM2 performed in tissue sections from PCLSs at $\mathrm{t}=0$ and after $96 \mathrm{~h}$ of treatment as indicated. Representative images are shown. PCLSs from four different patients were used in four independent experiments. For each time-point and condition two PCLSs were used. 
Figure 7. CM272 does not cause toxicity in bioreactor cultured human PCLSs. (A) Average levels of albumin, urea, lactate dehydrogenase (LDH), aspartate aminotransferase (AST) and alanine aminotransferase (ALT) released into the culture media by PCLSs treated with vehicle (control) or CM272 $(1 \mu \mathrm{M})$ as indicated. (B) Representative H\&E images of tissue sections from PCLSs treated with vehicle (control) or CM272 $(1 \mu \mathrm{M})$ for $96 \mathrm{~h}$. 
A
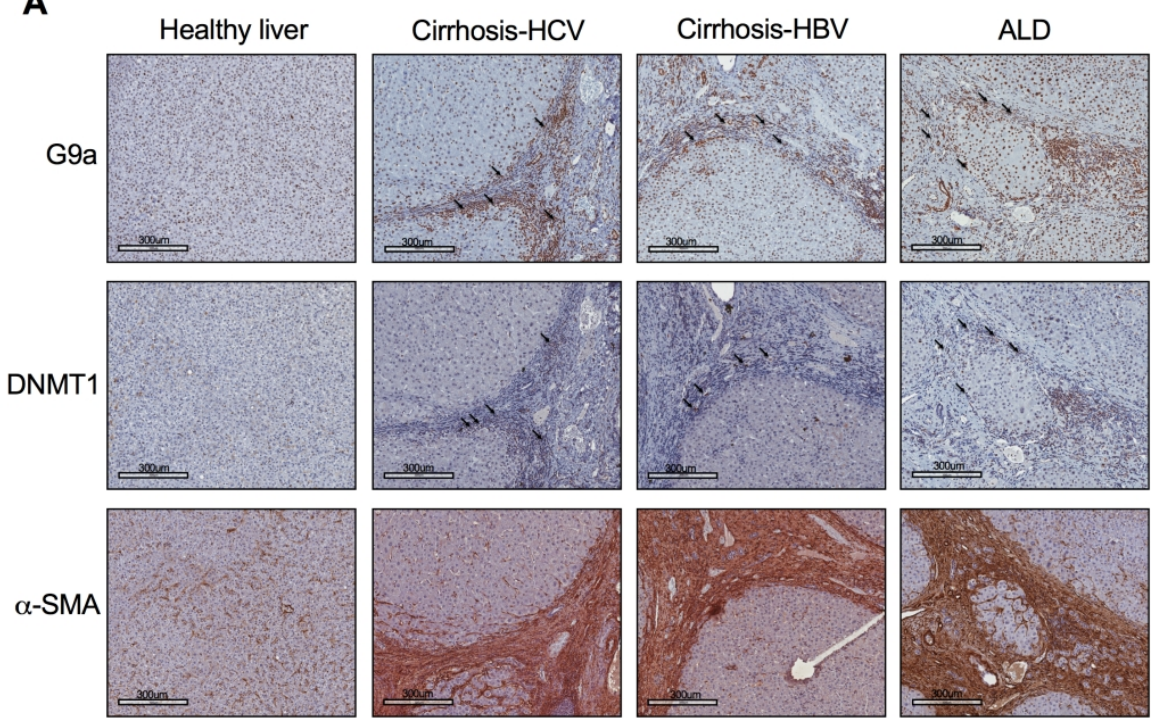

B

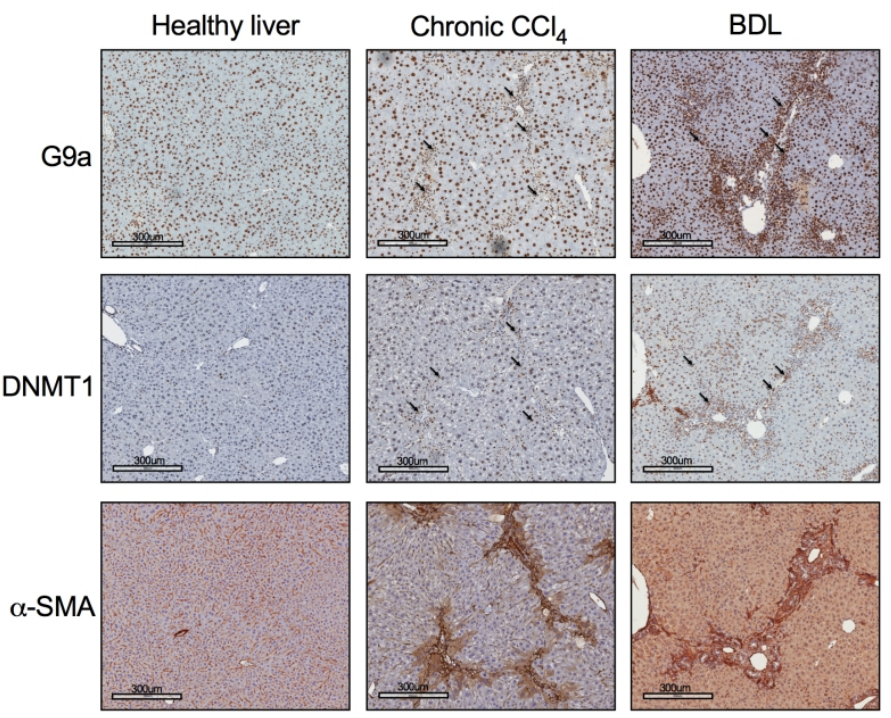

Figure 1

Figure 1

$189 \times 256 \mathrm{~mm}(300 \times 300$ DPI $)$ 
A
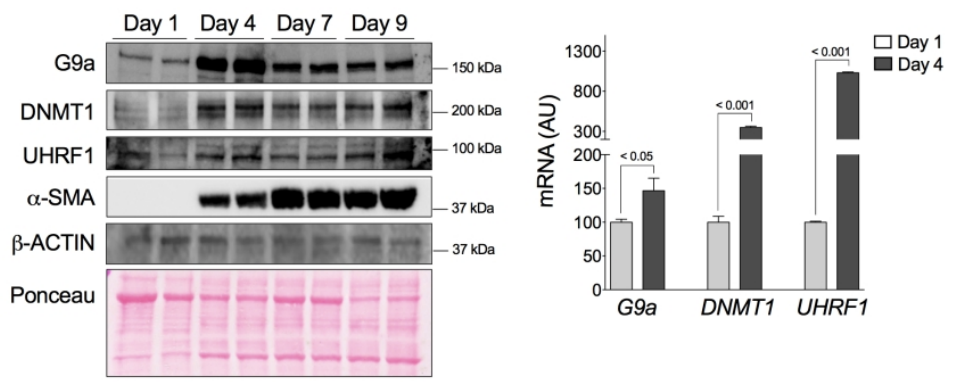

B

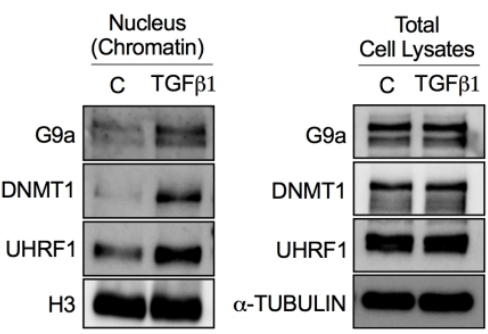

C
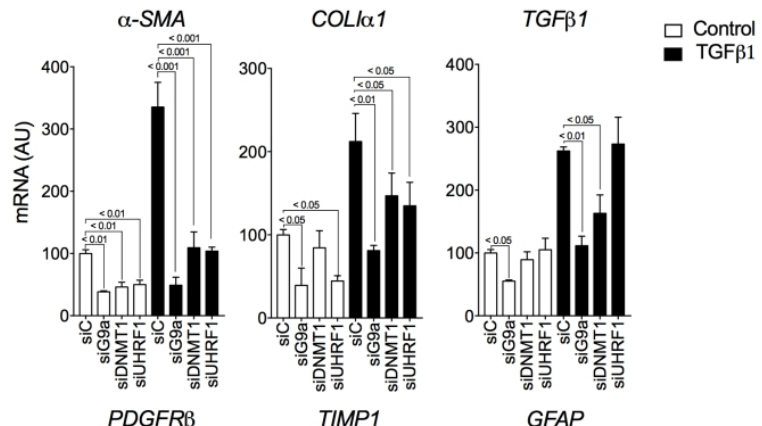

Figure 2

$187 \times 272 \mathrm{~mm}(300 \times 300 \mathrm{DPI})$ 


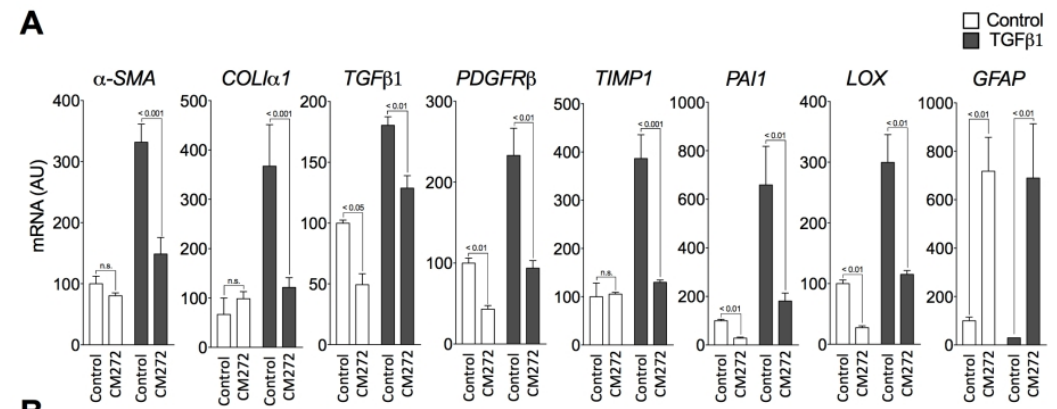

B
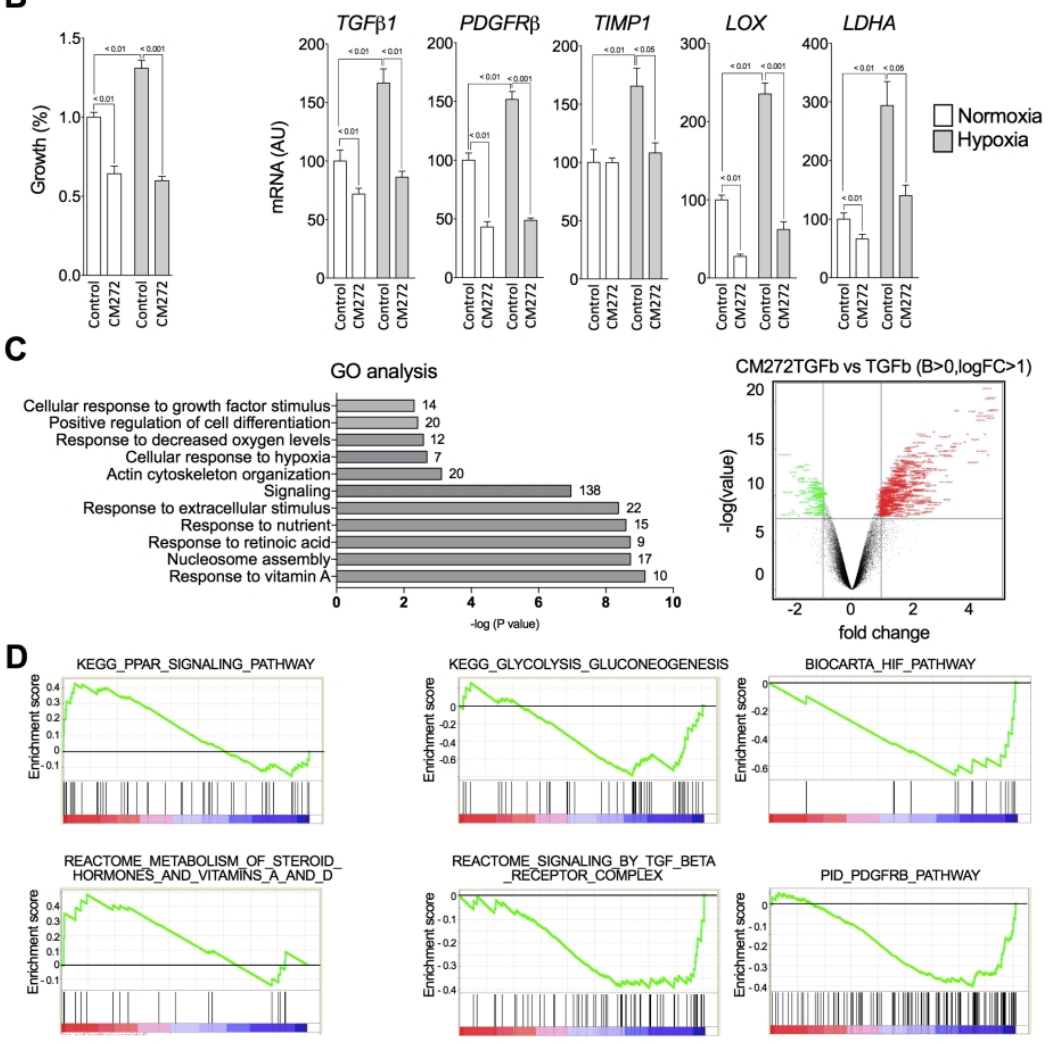

Figure 3

Figure 3

$182 \times 269 \mathrm{~mm}(300 \times 300 \mathrm{DPI})$ 
A

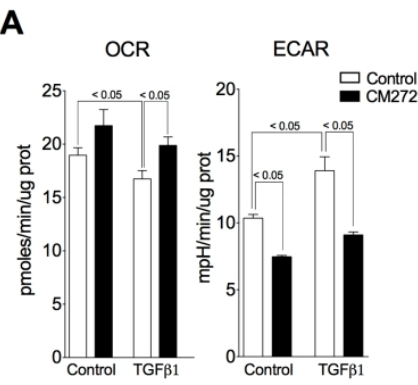

B ATP Production rate

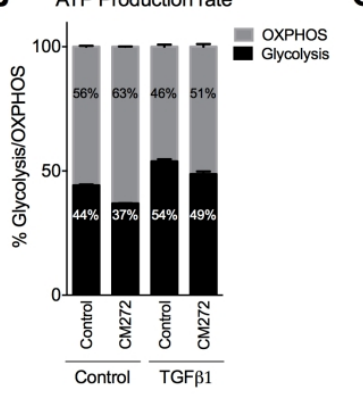

C
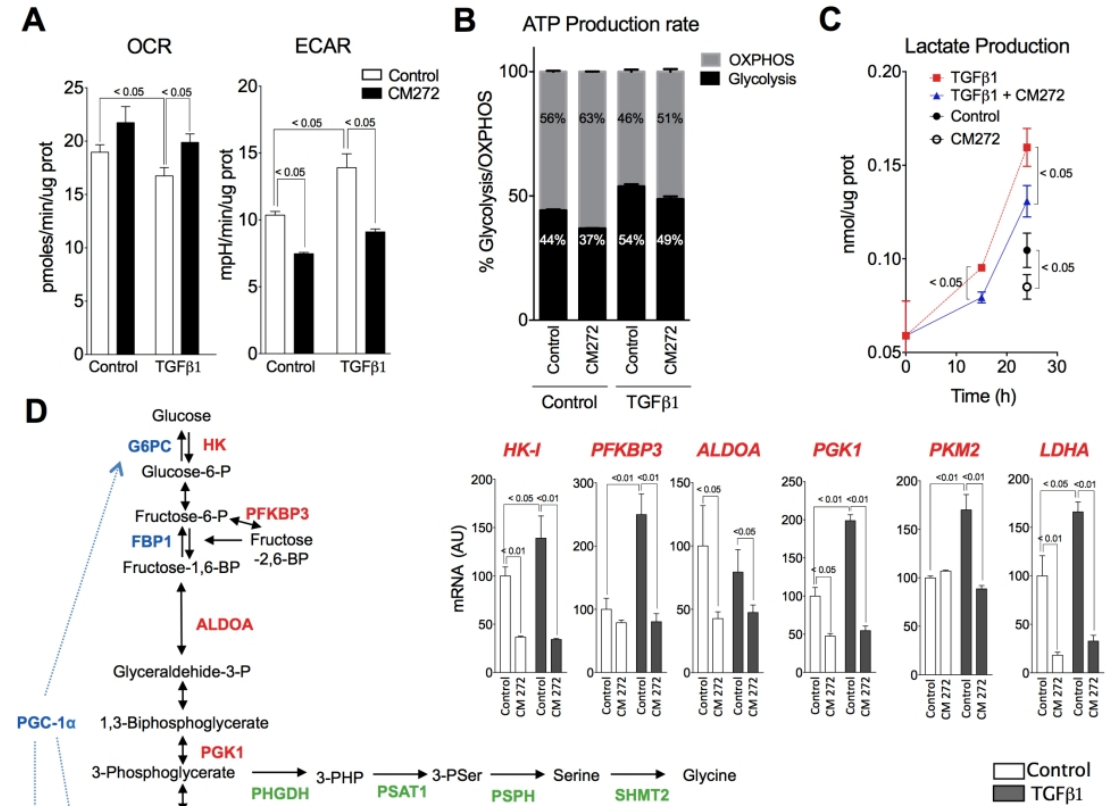

-PHP $\underset{\text { PSAT1 }}{\longrightarrow}$ 3.PSer $\underset{\text { PSPH }}{\longrightarrow}$ Serine $\underset{\text { SHMT2 }}{\longrightarrow}$ Glycine

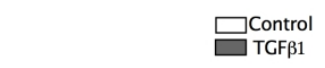

Figure 4

Figure 4

$192 \times 266 \mathrm{~mm}(300 \times 300$ DPI) 
A
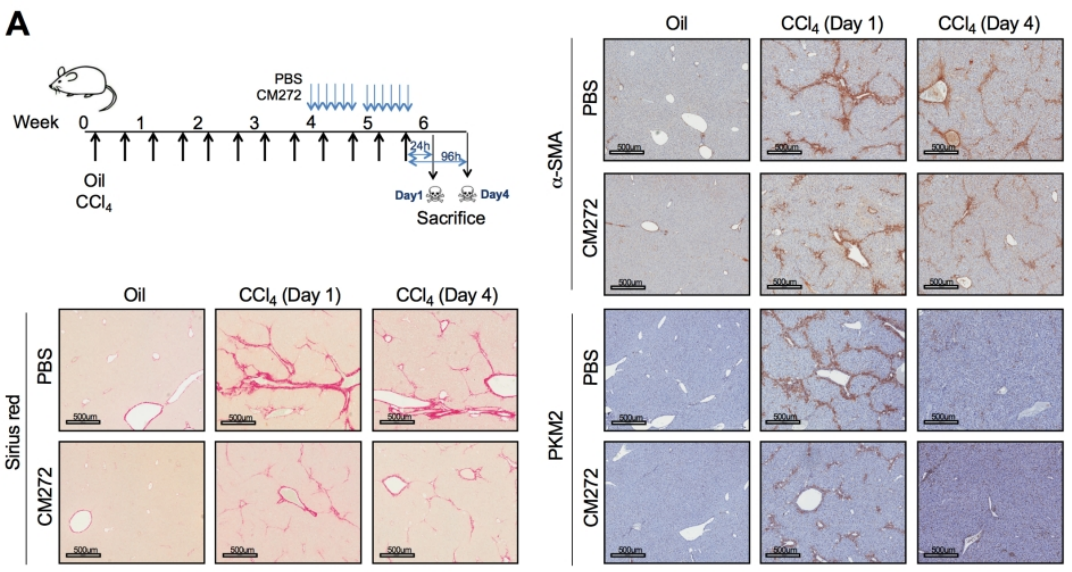

\section{B}
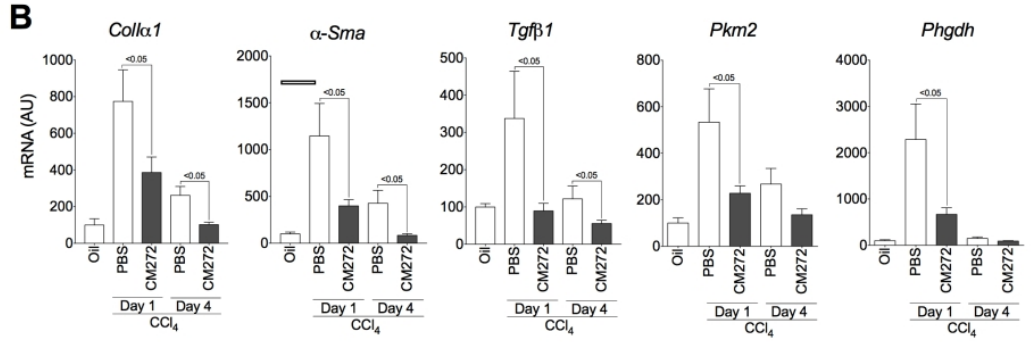

C
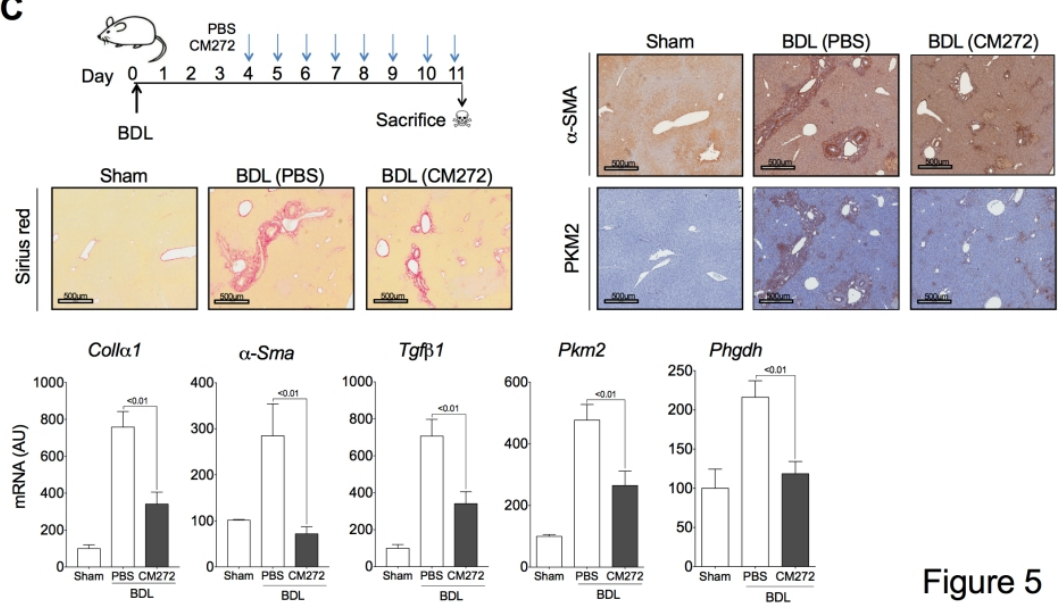

Figure 5

Figure 5

$180 \times 262 \mathrm{~mm}(300 \times 300 \mathrm{DPI})$ 
A
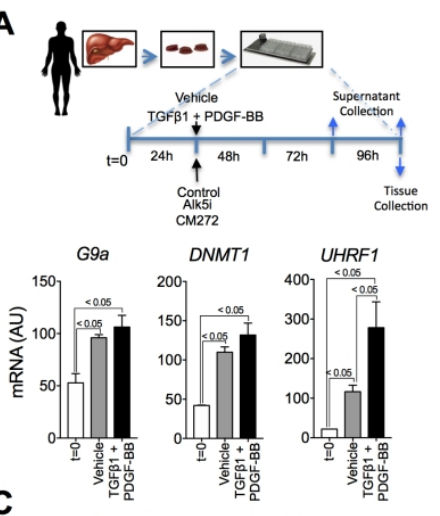

B $\quad \mathrm{t}=0 \quad$ vehicle

Vehicle TGF $\beta 1$

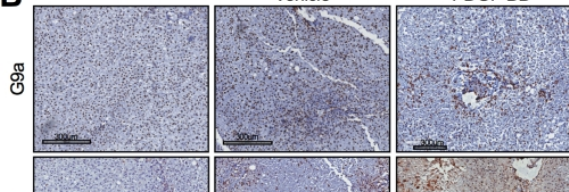

COLlal $\alpha$-SMA PDGFR

点
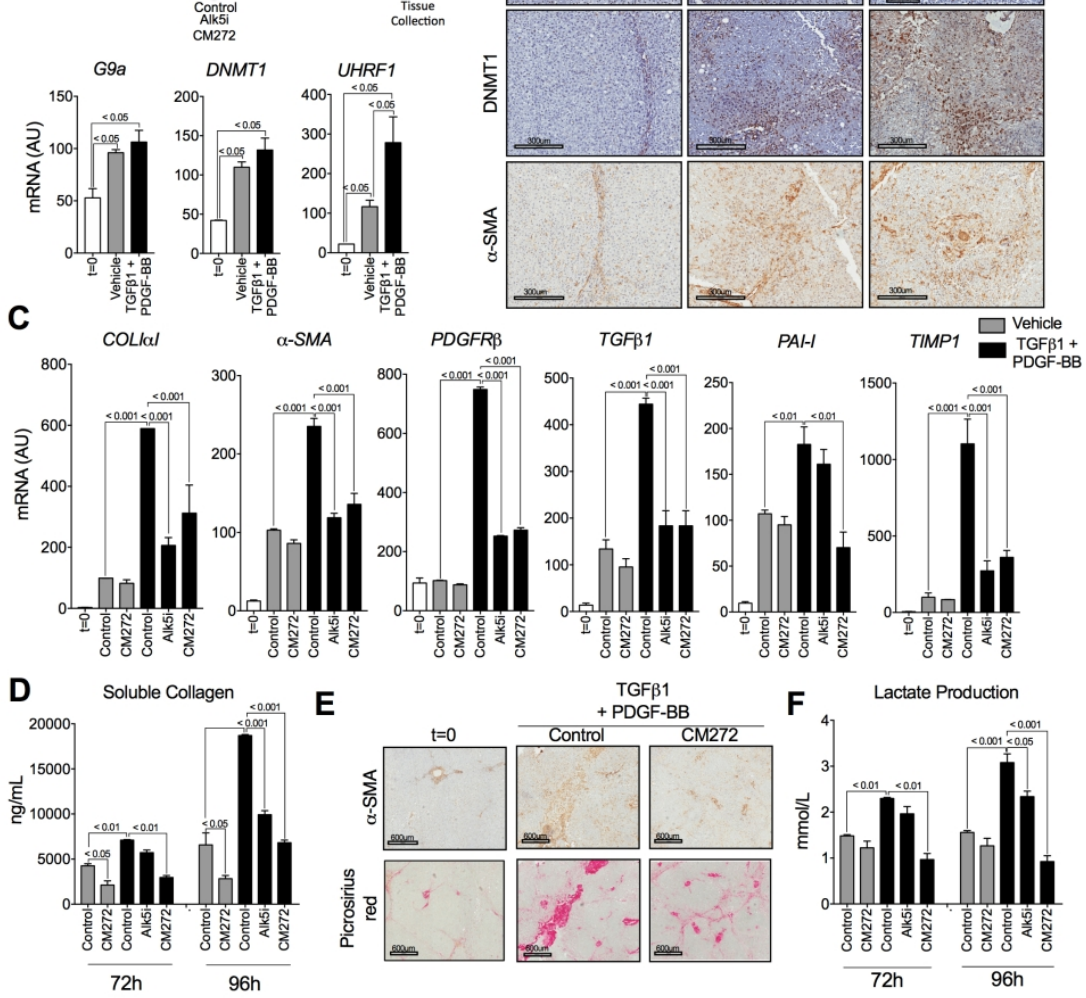

E
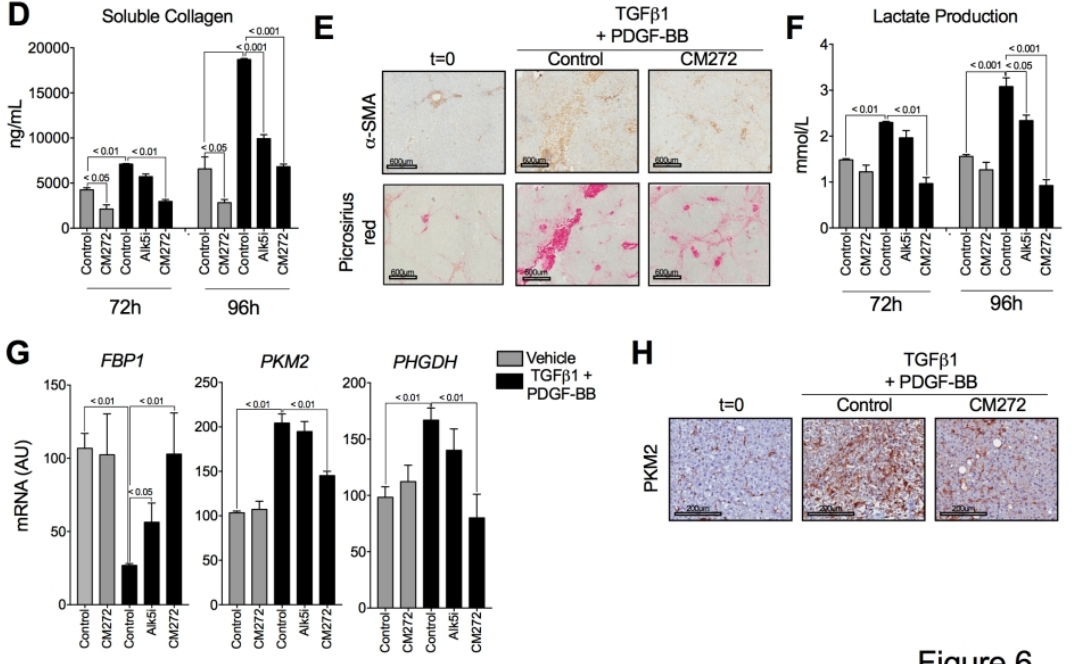

Figure 6

$191 \times 272 \mathrm{~mm}(300 \times 300 \mathrm{DPI})$

Figure 6 


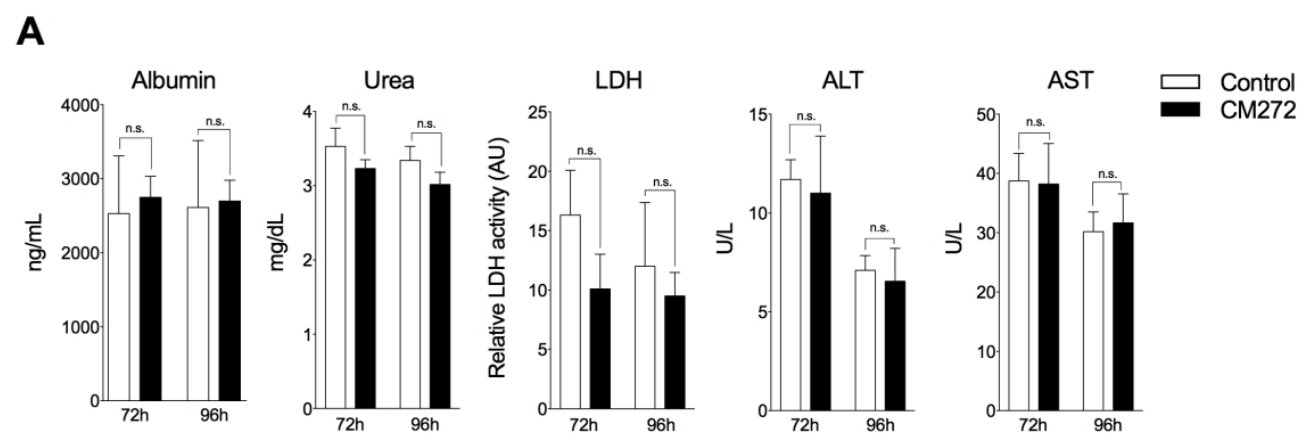

B

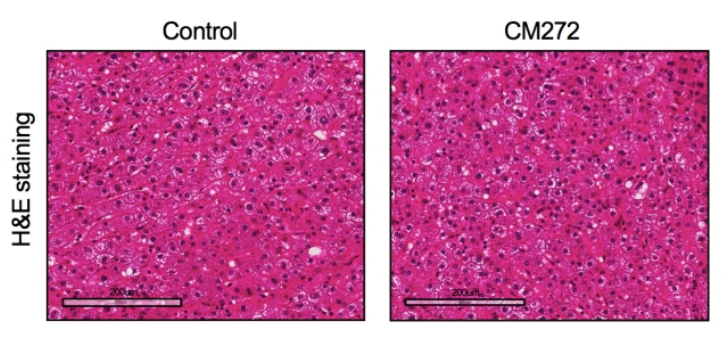

Figure 7

Figure 7

$188 \times 133 \mathrm{~mm}(300 \times 300 \mathrm{DPI})$ 


\section{SUPPLEMENTARY MATERIALS AND METHODS \\ Immunohistochemistry, immunofluorescence and tissue staining}

Immunohistochemical detection of G9a (antibody ab185050, Abcam, Cambridge, UK), DNMT1 (antibody ab188453, Abcam), a-SMA (antibody A2547, Sigma Aldrich, St. Louis, MO, USA), and PKM2 (antibody 3198S, Cell Signaling Technology, Beverly, MA, USA) was performed on $3 \mu \mathrm{m}$ thick formalin-fixed paraffin embedded mouse or human liver tissues following standard protocols as we described before.[1] Paraffin was removed and the tissues rehydrated using a slide wash/incubation sequence with Histo-Clear II (National Diagnostics, Nottingham, UK), ethanol 10\%, 90\%, 70\% and $\mathrm{ddH}_{2} 0$. Antigen retrieval was performed with Tris-EDTA Buffer (Dako, Glostrup, Denmark) and sections were incubated with primary antibodies diluted in blocking solution (1\% BSA in PBS) overnight at $4^{\circ} \mathrm{C}$. After washing, sections were incubated with secondary antibodies diluted in $1 \%$ BSA in PBS for another $1 \mathrm{~h}$ at room temperature and then washed and visualized with 3,3'-diaminobenzidine tetrahydrochloride (DAB) (Dako) counterstained with haematoxylin. The primary antibody for G9a detection was diluted 1:500, DNMT1 1:100, $\alpha-S M A ~ 1: 100$, PKM2 1:100 and the secondary antibody was anti-rabbit Envision + System-HRP (Dako). For immunofluorescent stainings, tissue preparation and immunofluorescence detection have been described previously [2]. The following antibodies were used: rabbit-anti-G9a (ab185050, Abcam, 1:100), rabbit-anti-DNMT1 (ab188453, Abcam, 1:100), mouse anti- $\alpha$-SMA (ab7817, Abcam, 1:100). Appropriate $\underline{\text { secondary antibodies used were from Life Technologies' Alexa Fluor series (488; A21202, }}$ 594; A21207, 1:300). For microscopy and image analyses tissues were viewed under a 
Zeiss LSM 800 confocal microscope (Zeiss). Images were processed and analyzed using ImageJ (NIH) and Adobe Photoshop Creative Suite 5 (Adobe).

\section{Cell culture and treatments}

The human HSC line LX2,[3] obtained from Millipore-Merck (Darmstadt, Germany), was cultured in Dulbecco's Modified Eagle Medium (DMEM) supplemented with 2\% FBS and 100U/ml penicillin-streptomycin. Primary hHSCs were isolated from resected livers wedges obtained from patients undergoing surgery at the Royal Free Hospital (London, UK) after giving informed consent. The study was approved by the ethics committee the Royal Free Hospital (protocol \#NC2015.020-RF). Cells were isolated and their purity was assessed as published,[4] with modifications for human liver, [5]. hHSCs were cultured in Iscove's Modified DMEM (IMDM), supplemented with 20\% FBS, 2.0 mM glutamine, nonessential amino acids, $1.0 \mathrm{mM}$ sodium pyruvate, antibiotic-antimycotic mix (Life Technologies, Paisley, UK). Experiments described herein were performed on hHSCs from at least three independent cell preparations, used between passage 3 and 8 . Primary mouse hepatic stellate cells (mHSCs) were isolated from 12 to 14 weeks-old C57BL/6 male mice using sequential pronase (Roche, Barcelona, Spain) and collagenase (Life Technologies, Carlsbad, CA, USA) digestion followed by density-gradient centrifugation with Nycodenz AG (Accurate Chemical, Westbury, NY, USA) as previously described.[6] Six livers were pooled for each HSC isolation and cell viability was measured by trypan blue exclusion and exceeded $90 \%$. Purity of mHSC preparations was assessed by autofluorescence of retinoid-containing vacuoles 1 day after isolation and was found to be $>99 \%$. mHSCs were cultured on plastic in Gibco Dulbecco's Modified Eagle Medium Nutrient Mixture F-12 (DMEM/F-12) supplemented with 10\% FBS and 
$100 \mathrm{U} / \mathrm{ml}$ penicillin-streptomycin. Freshly isolated HSCs (day 0) were considered quiescent and were cultured in plastic dishes to transdifferentiate into activated HSC (from day 4 onwards).

All cell cultures were maintained under standard conditions in a humidified incubator under $5 \% \mathrm{CO}_{2}$ in air at $37^{\circ} \mathrm{C}$. For hypoxic culture conditions cells were incubated under 1\% $\mathrm{O}_{2}$ atmosphere in the $\mathrm{H} 35$ Hypoxystation incubator (Don Whitley Scientific Ltd., Shipley, UK). TGFß1 stimulation of LX2 and hHSC cells was performed at $5 \mathrm{ng} / \mathrm{mL}$ at indicated times using recombinant human TGF $\beta 1$ protein from R\&D Systems (Minneapolis, MN, USA). CM272 was prepared according to the synthetic protocol recently reported,[7]. Purity for the used compound was $>95 \%$. Decitabine and BIX01294 were both from Sigma and were resuspended in dimethyl sulfoxide (DMSO). The PHGDH inhibitor NCT503 and the glucose analog 2-deoxy-D-glucose (2DG) were both from Sigma Aldrich. In vitro treatments were performed at indicated times and doses, and controls received the same concentrations of DMSO (always $\leq 0.1 \%$ of final volume).

\section{Cells transfection with siRNAs}

Human G9a, DNMT1 and UHRF1-specific siRNAs and control siRNA (siC) were from Santa Cruz Biotechnology (Santa Cruz, CA, USA). Transfections were performed with $75 \mathrm{nM}$ of each siRNA using Lipofectamine RNAiMAX reagent (Invitrogen, Grand Island, NY, USA) as we previously described, [8] and following the manufacturer's instructions. Cells were harvested $48 \mathrm{~h}$ after transfection. Gene expression was confirmed by qPCR and western blotting after transfections. 


\section{Western blotting}

Cells and tissues were lysed in RIPA buffer. Histones were extracted as described below. Samples were subjected to western blot analysis as reported,[9,10]. Antibodies used are listed in supplementary table 1 . The densitometric analysis of all Western blot signals are shown in Supporting Fig. S11.

\section{Subcellular protein extraction}

Subcellular cell fractionation and separation of nuclear chromatin-bound protein extracts from LX2 cells was done with the Subcellular Protein Fractionation Kit for Cultured Cells from Thermo Fisher Scientific (Waltham, MA, USA) following manufacturer's instructions. LX2 cells $\left(10^{6}\right)$ were stimulated either with vehicle or TGF $\beta 1$ $(5 \mathrm{ng} / \mathrm{mL})$ during $3 \mathrm{~h}$ prior to protein fractionation.

\section{Gene expression and microarray analyses}

RNA was extracted using the automated Maxwell system from Promega (Madison, WI, USA) according to the manufacturer's instructions. For retro-transcription RNA samples were exposed for $1 \mathrm{~min}$ at $90^{\circ} \mathrm{C}$ for denaturalization followed by $1 \mathrm{~h}$ at $37^{\circ} \mathrm{C}$ using a mix containing: $50 \mathrm{mM}$ Tris- $\mathrm{HCl} \mathrm{pH}$ 8.3, $75 \mathrm{mM} \mathrm{KCl}$ and $3 \mathrm{mM} \mathrm{MgCl}, 10 \mathrm{ng} / \mathrm{uL}$ of random primers, $0.5 \mathrm{mM}$ of each deoxyribonucleic triphosphate (dNTP), $5 \mathrm{mM}$ of dithiothreitol (DTT), $1.2 \mathrm{U} / \mathrm{uL}$ RNase inhibitors (RNase out) and $6 \mathrm{U} / \mathrm{uL}$ of M-MLV inverse transcriptase enzyme. All reagents from Invitrogen (Carlsbad, CA, USA), except dNTPs that were from Roche Diagnostics (Mannheim, Germany). Resulting complementary DNA (cDNA) were 
used to measure differences among genic expression levels. With the resulting cDNAs qPCR reactions were performed in a Bio-Rad CFX96 Real-Time System thermal cycler using iQ SYBR Green Supermix reagent from Bio-Rad (Hercules, CA, USA) following manufacturer's instructions. Primers are described in supplementary table 2 . Relative quantification of mRNA was calculated with the $-\Delta \Delta C T$ method using the reference gene of constitutive expression $H 3 F 3 A$ as we described, [9].

For microarray analyses, RNA integrity from each sample was confirmed prior to cDNA synthesis on Agilent RNA Nano LabChips (Agilent Technologies, Santa Clara, CA, USA). The sense cDNA was prepared from $200 \mathrm{ng}$ of total RNA and then fragmented and biotinylated using Affymetrix GeneChip ${ }^{\circledR}$ WT PLUS Reagent Kit. Labeled sense cDNA was hybridized to the Affymetrix Human Gene 2.0 ST microarray according to the manufacturer protocols and using GeneChip ${ }^{\circledR}$ Hybridization, Wash and Stain Kit. Genechips were scanned with the Affymetrix GeneChip ${ }^{\circledR}$ Scanner 3000. Both background correction and normalization were done using RMA (Robust Multichip Average) algorithm. After quality assessment, a filtering process was performed to eliminate low expression probe sets. Applying the criterion of an expression value greater than 16 in 2 samples for each experimental condition (TGF $\beta 1+$ Control and TGF $\beta 1+C M-272$ treatment), 29762 probe sets were selected for statistical analysis. $R$ and Bioconductor,[11] were used for preprocessing and statistical analysis. LIMMA (Linear Models for Microarray Data) was used to find out the probe sets that showed significant differential expression between experimental conditions.[12] Genes were selected as significant using a criterion of $\mathrm{B}>0$ and $|\operatorname{logFC}|>1$. 
Functional enrichment analysis of Gene Ontology (GO) categories,[13] was carried out using standard hypergeometric test and the gene list ranked by logFC was also analyzed with Gene Set Enrichment Analysis (GSEA),[14]. Microarray data can be downloaded from Gene Expression Omnibus (GEO) public functional genomics data repository under the accession number GSE139504.

\section{Metabolic flux analysis}

The oxygen consumption rate (OCR) and extracellular acidification rate (ECAR) were measured in LX2 cells using a Seahorse XFp extracellular flux analyzer (Seahorse Bioscience, Billerica, MA, USA). In brief, LX2 were seeded on Seahorse XFp plates at a final confluence of $85-90 \%$ in Gibco DMEM $10 \%$ medium. Cells were pre-treated with CM272 (200nM) during 24h. The medium was then replaced with Seahorse XF DMEM medium pH 7.4 supplemented with $10 \mathrm{mM}$ glucose (Sigma), $2 \mathrm{mM}$ glutamine (Gibco, Fisher Scientific) and $1 \mathrm{mM}$ pyruvate (Sigma) and stimulated with TGFß1 (5ng/uL) during 3h. Cells were then incubated for $45 \mathrm{~min}$ (in the case of no TGF 31 stimulation) or $3 \mathrm{~h}$ (when TGF $\beta 1$ stimulation) at $37^{\circ} \mathrm{C}$ and $0 \% \mathrm{CO}_{2}$. Basal levels of $\mathrm{OCR}$ and $\mathrm{ECAR}$ were then recorded. ATP production rate was measured according to the manufacturer's instructions, using $1.5 \mu \mathrm{M}$ oligomycin and $0.5 \mu \mathrm{M}$ rotenone/antimycin $\mathrm{A}$, all from Sigma. OCR and ECAR data were normalized to the protein content as assessed by Bradford assay from Bio-Rad.

\section{Global and gene-specific DNA methylation analyses}


Genomic DNA was extracted using a DNA kit (Maxwell 16 LEV Blood DNA Kit, Promega) following the manufacturer's instructions. DNA purity and concentration were measured using a NanoDrop spectrophotometer (Thermo Fisher Scientific). LX2 cells were treated with vehicle (DMSO) or $\mathrm{CM} 272(400 \mathrm{nM})$ during $48 \mathrm{~h}$ for global DNA methylation studies. This was measured using the MethylFlash Global DNA Methylation (5-mC) ELISA Easy kit from EpiGentek (Farmingdale, NY, USA) following the manufacturer's instructions.

LX2 cells were also treated with vehicle (DMSO), decitabine (5 $\mu \mathrm{M})$ or CM272 (100nM) for 4 days, with daily medium change. DNA methylation status of the FBP1 and PGC-1 $\alpha$ promoters were analyzed by methylation-specific PCR (MSP). To this end $1 \mu \mathrm{g}$ of genomic DNA was treated and modified using the EZ DNA methylation gold kit from Zymo Research (Irvine, CA, USA) following the manufacturer's instructions. MSP was performed on bisulfite-modified DNA using a set of primers for $F B P 1$ and $P G C-1 \alpha$ designed using MethPrimer software (The Li Lab, www.urogene.org) and are listed in supplementary table 2. MSP reaction was performed using Phusion U Hot Start DNA Polymerase kit (F-555S, Thermo Fisher Scientific) and PCR products were electrophoresed and visualized in GelRed Nucleic Acid (41003, Biotium, Fremont, CA, USA)-stained $2 \%$ agarose gels under UV light.

\section{Histone extraction}

Histones were isolated as previously described,[15]. Briefly, cells were lysed in a buffer containing $10 \mathrm{mM}$ Tris- $\mathrm{HCl} \mathrm{pH} 7.4,10 \mathrm{mM} \mathrm{NaCl}$ and $3 \mathrm{mM} \mathrm{MgCl}$. After centrifugation at $2500 \mathrm{rpm}$ for $10 \mathrm{~min}$ at $4^{\circ} \mathrm{C}$ supernatants were removed, and pellets were lysed in the 
previous buffer but containing $0.5 \%$ NP40 on ice for 10 min with gentle stirring. Nuclei were pelleted by centrifugation at $2500 \mathrm{rpm}$ for $10 \mathrm{~min}$ at $4^{\circ} \mathrm{C}$ and resuspended in $5 \mathrm{mM}$ $\mathrm{MgCl}_{2}$ and $0.8 \mathrm{M} \mathrm{HCl}$. Nuclei were incubated in this buffer during $30 \mathrm{~min}$ at $4{ }^{\circ} \mathrm{C}$ to extract the histones. Samples were then centrifuged at $14000 \mathrm{rpm}$ for $10 \mathrm{~min}$ at $4^{\circ} \mathrm{C}$ to pellet debris and supernatants were transferred to a clean tube where TCA 50\% was added to precipitate the histones. After washing the pellets with acetone they were air-dried and resuspended in $100 \mathrm{mM}$ Tris- $\mathrm{HCl} \mathrm{pH} 7.5,1 \mathrm{mM}$ EDTA and 1\% SDS. The histone concentration in the extract was measured using the BCA assay (Pierce Technologies, Rockford, IL, USA) according to manufacturer's specifications.

\section{Quantitative chromatin immunoprecipitation (Q-ChIP)}

Q-ChIP assays were performed in LX2 cells treated with vehicle or CM272 (48h, $200 \mathrm{nM}$ ), as previously described,[16]. Briefly, for crosslinking of DNA and proteins cells were treated with $1 \%$ formaldehyde for 10 min before quenching with $0.125 \mathrm{M}$ glycine. Cells were harvested in ice-cold PBS with proteases inhibitors. Samples were incubated with lysis buffer (10 mM EDTA, $50 \mathrm{mM}$ Tris- $\mathrm{HCl}$ pH 8.1, $1 \%$ SDS and proteases inhibitor mixture) and sonicated on ice to yield $200-800$ bp DNA fragments. After centrifugation at $14000 \mathrm{rpm}$ for $10 \mathrm{~min}$, supernatant was collected and frozen at $-80^{\circ} \mathrm{C}$ to obtain the chromatin. $100 \mu \mathrm{g}$ of DNA was used per immunoprecipitation (IP). Chromatin was precleared with protein A-agarose/salmon sperm DNA (Upstate Biotechnology, Merck, Darmstadt, Germany), then diluted 1/4 in IP dilution buffer (0.01\% SDS, $1.1 \%$ TritonX100, 1.2 mM EDTA, 16.7 mM Tris- $\mathrm{HCl}$ pH 8.1, $167 \mathrm{mM} \mathrm{NaCl}$ ) and incubated overnight at $4^{\circ} \mathrm{C}$ with $5 \mu \mathrm{g}$ of ab1220 anti-H3K9me2 antibody (Abcam, UK), 17-680 anti-H3K9me antibody (Millipore-Merck, Germany) or 07-690 anti-total H3 total antibody (Millipore- 
Merck, Germany) or nonspecific 2729 IgG (Cell Signalling Technology, The Netherlands). Immuno-complexes were precipitated by incubation for $1 \mathrm{~h}$ with protein Aagarose/salmon sperm DNA. Bound DNA-protein complexes were eluted and cross-links were reversed after a series of washes. Purified DNA was resuspended in TE buffer for PCR. The specific PCR primers used were described previously for FBP1,[17], for PGC1$\alpha,[18]$ and for $P H G D H,[19]$ and are listed in supplementary table 2 . Independent Q-ChIP assays were performed at least twice in duplicates. The proportion of H3K9me2 of each gene was normalized with total $\mathrm{H} 3$ and quantified calculating [(2(- $\Delta \Delta \mathrm{Ct}) \mathrm{CM}-272$ sample / 2(- $\Delta \Delta \mathrm{Ct})$ control $\left.)^{*} 100\right]$ as described.[20]

\section{Serum and conditioned media biochemical determinations}

Blood obtained from mice was preserved at $4^{\circ} \mathrm{C}$ overnight to allow complete formation of the blood clot. Supernatants were then centrifuged at $2500 \mathrm{rpm}$ for $10 \mathrm{~min}$ at $4^{\circ} \mathrm{C}$ to obtain serum. Alanine aminotransferase (ALT), Aspartate aminotransferase (AST), urea, creatinine and bilirubin levels were measured where indicated in serum and conditioned media from PCLSs using a C311 Cobas Analyzer (Roche Diagnostics) following manufacturer's instructions. Lactate levels in conditioned media from LX2 cells were also measured with the C311 Cobas Analyzer. Albumin and collagen levels in PCLSs conditioned media were measured using the human (E88-129) albumin ELISA kit (Bethyl laboratories, Cambridge, UK) and the human collagen Ia1 ELISA kit (DY6220-05, R\&D systems, Abingdon, UK) respectively as per manufacturer's instructions. Lactate dehydrogenase (LDH) assay was performed on culture media from PCLSs using the Pierce LDH cytotoxicity Assay Kit (Thermo Scientific) following manufacturer's instructions. 


\section{RNA isolation from PCLSs}

Between 2 to 4 PCLSs per condition were placed in QIAzol, disrupted in a Qiagen Tissue Lyser II and passed through a Qiashredder (Qiagen, Manchester, UK). Chloroform was added, the sample vortexed and centrifuged at $12,000 \mathrm{~g}$ for $15 \mathrm{~min}$. The aqueous layer was collected and added to $70 \%$ ethanol. Total RNA was purified using the RNeasy Micro Kit (Qiagen, Manchester, UK).

\section{Picrosirius red staining and immunohistochemical analyses in PCLSs}

5- $\mu$ m-thick formalin-fixed paraffin-embedded PCLSs sections were processed for Picrosirius Red staining as previously reported,[21]. Immunohistochemical staining for G9a (ab185050, Abcam) DNMT1 (ab188453, Abcam), aSMA (A2547, Sigma) and PKM2 (3198S, Cell Signaling Technology) were performed as described above for liver tissues.

\section{Statistical analyses}

If not stated in the legend, each result shown represents the mean \pm SEM of at least $n=3$ independent experiments. Data were compared using the Student $t$ test. A $P$ value of $<0.05$ was considered significant. Data analyses were performed using GraphPad Prism software version 7.0 (GraphPad Software Inc., San Diego, CA). 


\section{References}

1 Santamaría E, Rodríguez-Ortigosa CM, Uriarte I, et al. The Epidermal Growth Factor Receptor Ligand Amphiregulin Protects From Cholestatic Liver Injury and Regulates Bile Acids Synthesis. Hepatology 2019;69:1632-47.

doi:10.1002/hep.30348

2 Pardo-Saganta A, Law BM, Gonzalez-Celeiro M, et al. Ciliated cells of pseudostratified airway epithelium do not become mucous cells after ovalbumin challenge. Am J Respir Cell Mol Biol 2013;48:364-73. doi:10.1165/rcmb.2012$01460 \mathrm{C}$

3 Xu L, Hui AY, Albanis E, et al. Human hepatic stellate cell lines, LX-1 and LX-2: new tools for analysis of hepatic fibrosis. Gut 2005;54:142-51. doi:10.1136/gut.2004.042127

4 Mederacke I, Dapito DH, Affò S, et al. High-yield and high-purity isolation of hepatic stellate cells from normal and fibrotic mouse livers. Nat Protoc 2015;10:305-15. doi:10.1038/nprot.2015.017

5 Rombouts K, Carloni V. Determination and Characterization of TetraspaninAssociated Phosphoinositide-4 Kinases in Primary and Neoplastic Liver Cells. In: Methods in molecular biology (Clifton, N.J.). 2016. 203-12. doi:10.1007/978-14939-3170-5_17

6 Perugorria MJ, Latasa MU, Nicou A, et al. The epidermal growth factor receptor ligand amphiregulin participates in the development of mouse liver fibrosis. Hepatology 2008;48:1251-61. doi:10.1002/hep.22437

7 San José-Enériz E, Agirre X, Rabal O, et al. Discovery of first-in-class reversible dual small molecule inhibitors against G9a and DNMTs in hematological malignancies. Nat Commun 2017;8:15424. doi:10.1038/ncomms15424

8 Urtasun R, Elizalde M, Azkona M, et al. Splicing regulator SLU7 preserves survival of hepatocellular carcinoma cells and other solid tumors via oncogenic miR-1792 cluster expression. Oncogene 2016;35:4719-29. doi:10.1038/onc.2015.517

9 Elizalde M, Urtasun R, Azkona M, et al. Splicing regulator SLU7 is essential for maintaining liver homeostasis. J Clin Invest 2014;124:2909-20. doi:10.1172/JCI74382

10 Alvarez-Sola G, Uriarte I, Latasa MU, et al. Fibroblast growth factor 15/19 (FGF15/19) protects from diet-induced hepatic steatosis: development of an FGF19-based chimeric molecule to promote fatty liver regeneration. Gut 2017;66:1818-28. doi:10.1136/gutjnl-2016-312975

11 Gentleman RC, Carey VJ, Bates DM, et al. Bioconductor: open software development for computational biology and bioinformatics. Genome Biol 2004;5:R80. doi:10.1186/gb-2004-5-10-r80

12 Smyth GK. Linear Models and Empirical Bayes Methods for Assessing Differential Expression in Microarray Experiments. Stat Appl Genet Mol Biol 2004;3:1-25. doi:10.2202/1544-6115.1027

13 Gene Ontology Consortium, Blake JA, Dolan M, et al. Gene Ontology Annotations and Resources. Nucleic Acids Res 2012;41:D530-5. doi:10.1093/nar/gks1050

14 Subramanian A, Tamayo P, Mootha VK, et al. Gene set enrichment analysis: A knowledge-based approach for interpreting genome-wide expression profiles. 
Proc Natl Acad Sci 2005;102:15545-50. doi:10.1073/pnas.0506580102

15 Rodriguez-Collazo P, Leuba SH, Zlatanova J. Robust methods for purification of histones from cultured mammalian cells with the preservation of their native modifications. Nucleic Acids Res 2009;37:e81. doi:10.1093/nar/gkp273 Bárcena-Varela M, Caruso S, Llerena S, et al. Dual Targeting of Histone Methyltransferase G9a and DNA-Methyltransferase 1 for the Treatment of Experimental Hepatocellular Carcinoma. Hepatology 2019;69:587-603. doi:10.1002/hep.30168

17 Dong C, Yuan T, Wu Y, et al. Loss of FBP1 by Snail-mediated repression provides metabolic advantages in basal-like breast cancer. Cancer Cell 2013;23:316-31. doi:10.1016/j.ccr.2013.01.022

18 Ligresti G, Caporarello N, Meridew JA, et al. CBX5/G9a/H3K9me-mediated gene repression is essential to fibroblast activation during lung fibrosis. JCl Insight 2019;4:e127111. doi:10.1172/jci.insight.127111

19 Ding J, Li T, Wang X, et al. The histone H3 methyltransferase G9A epigenetically activates the serine-glycine synthesis pathway to sustain cancer cell survival and proliferation. Cell Metab 2013;18:896-907. doi:10.1016/j.cmet.2013.11.004

20 Nye MD, Almada LL, Fernandez-Barrena MG, et al. The transcription factor GLI1 interacts with SMAD proteins to modulate transforming growth factor $\beta$ induced gene expression in a p300/CREB-binding protein-associated factor (PCAF)-dependent manner. J Biol Chem 2014;289:15495-506. doi:10.1074/jbc.M113.545194

21 Paish HL, Reed LH, Brown H, et al. A Bioreactor Technology for Modeling Fibrosis in Human and Rodent Precision-Cut Liver Slices. Hepatology 2019;: hep.30651. doi:10.1002/hep.30651 


\section{Supplementary Table 1.}

Antibodies used for western blotting.

\begin{tabular}{|c|c|}
\hline Antibodies & Reference \& Supplier \\
\hline \multicolumn{2}{|l|}{ Primary antibodies } \\
\hline anti- $\alpha-S M A$ & A2547, Sigma Aldrich, St. Louis, MO, USA. \\
\hline anti- $\alpha$-TUBULIN & 2144S, Cell Signalling Technology, Leiden, The Netherlands. \\
\hline anti-DNMT1 & 5032S, Cell Signalling Technology, Leiden, The Netherlands. \\
\hline anti-FBP1 & HPA005857, Sigma Aldrich, St. Louis, MO, USA. \\
\hline 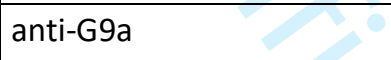 & 3306S, Cell Signalling Technology, Leiden, The Netherlands. \\
\hline anti-total H3 & 07-690, Millipore-Merck, Darmstadt, Germany. \\
\hline anti-H3K9me2 & 07-212, Millipore-Merck, Darmstadt, Germany. \\
\hline anti-PGC-1 $\alpha$ & sc-13067, Santa Cruz Biotechnology, CA, USA. \\
\hline anti-UHRF1 & ab57083, Abcam, Cambridge, UK. \\
\hline anti-collagen & ab138492, Abcam, Cambridge, UK. \\
\hline anti-BAMBI & sc-100681, Santa Cruz Biotechnology, CA, USA. \\
\hline anti-SMAD3 & 9523S, Cell Signalling Technology, Leiden, The Netherlands. \\
\hline anti-pSMAD3, Ser423/425 & 9520S, Cell Signalling Technology, Leiden, The Netherlands. \\
\hline anti- $\beta$-actin & ab6276, Abcam, Cambridge, UK. \\
\hline \multicolumn{2}{|l|}{ Secondary antibodies } \\
\hline $\begin{array}{l}\text { anti-rabbit IgG HRP-linked } \\
\text { antibody }\end{array}$ & 7074S, Cell Signalling Technology, Leiden, The Netherlands. \\
\hline $\begin{array}{l}\text { Goat anti-mouse } \\
\text { IgG:HRPO }\end{array}$ & M15345, Transduction Laboratories, USA. \\
\hline
\end{tabular}


Supplementary Table 2.

List of primers sequences

\begin{tabular}{|c|c|c|}
\hline \multicolumn{3}{|r|}{ Primers used for qRT-PCR } \\
\hline Gene & \multicolumn{2}{|c|}{ Sequence } \\
\hline \multirow{2}{*}{$\begin{array}{c}\alpha S M A, \alpha S m a \\
\text { (human, mouse) }\end{array}$} & Fw & 5' - CCAGGGCTGTTTTTCCCATCC -3' \\
\hline & Rev & 5' - GTCATTTTCTCCCGGTTGGCC -3' \\
\hline \multirow{2}{*}{$\begin{array}{l}\text { ALDOA } \\
\text { (human) }\end{array}$} & Fw & 5' - AGTCCATTGGCACCGAGAAC - $3^{\prime}$ \\
\hline & Rev & 5'- AACATTGGCATTTTCCATGA -3' \\
\hline \multirow{2}{*}{$\begin{array}{c}\text { BAMBI } \\
\text { (human) }\end{array}$} & Fw & 5'- TGGATCGCCACTCCAGCTA -3' \\
\hline & Rev & 5' - TGTCTTCATGACAGCATTCCA -3' \\
\hline \multirow{2}{*}{$\begin{array}{l}\text { COLIA1 } \\
\text { (human) }\end{array}$} & Fw & 5'- GGCTCCTGCTCCTCTTAGCGG -3' \\
\hline & $\operatorname{Rev}$ & 5'- CGGGACAGCACTCGCCCTCGG -3' \\
\hline \multirow{2}{*}{$\begin{array}{l}\text { Coll } \alpha 1 \\
\text { (mouse) }\end{array}$} & Fw & 5' - CAGATTGAGAACATCCGCAG -3' \\
\hline & Rev & 5' - GAATCCATCGGTCATGCTCTC - $3^{\prime}$ \\
\hline \multirow{2}{*}{$\begin{array}{l}\text { DNMT1 } \\
\text { (human) }\end{array}$} & Fw & 5'- GAGGCCCGAAGAAAAAGAAC - $3^{\prime}$ \\
\hline & Rev & 5'- TGAAGCAGGTCAGTTTGTGC -3' \\
\hline \multirow{2}{*}{$\begin{array}{l}\text { Dnmt1 } \\
\text { (mouse) }\end{array}$} & Fw & 5'- CTTCGACGTCACACCAGAGA -3' \\
\hline & $\operatorname{Rev}$ & 5' - CGGGATCACACTTTTGCTTT -3' \\
\hline \multirow{2}{*}{$\begin{array}{c}\text { FBP1 } \\
\text { (human) }\end{array}$} & Fw & 5'- ACATCGATTGCCTTGTGTCC - $3^{\prime}$ \\
\hline & Rev & 5' - CATGAAGCAGTTGACCCCAC - $3^{\prime}$ \\
\hline \multirow{2}{*}{$\begin{array}{c}G 9 a \\
\text { (human) }\end{array}$} & Fw & 5'- GCAGCACTGCACGTGTGTGGA -3' \\
\hline & Rev & 5'- ACATCAGCCTCAGCATCAGA - $3^{\prime}$ \\
\hline \multirow{2}{*}{$\begin{array}{c}G 9 a \\
\text { (mouse) }\end{array}$} & Fw & 5'- GCAGCACTGCACGTGTGTGGA -3' \\
\hline & Rev & 5' - ACATCAGCCTCGGCATCAGA -3' \\
\hline \multirow{2}{*}{$\begin{array}{c}\text { GFAP } \\
\text { (human) }\end{array}$} & Fw & 5'- GAGATGATGGAGCTCAATGAC - $3^{\prime}$ \\
\hline & Rev & 5' - TCCAGCCTCAGGTTGGTTTC -3' \\
\hline \multirow{2}{*}{$\begin{array}{c}\text { H3F3A, H3f3a } \\
\text { (human, mouse) }\end{array}$} & Fw & 5'- AAAGCCGCTCGCAAGAGTGCG -3' \\
\hline & Rev & 5' - ACTTGCCTCCTGCAAAGCAC - $3^{\prime}$ \\
\hline \multirow{2}{*}{$\begin{array}{c}H K 1 \\
\text { (human) }\end{array}$} & Fw & 5'- GAGATGAAGAATGGCCTCTCCCG -3' \\
\hline & Rev & 5' - TCTTGTCCTTGATCTTCCTTTTCTCC - $3^{\prime}$ \\
\hline \multirow{2}{*}{$\begin{array}{c}\text { IL-1b } \\
\text { (mouse) }\end{array}$} & Fw & 5' - CATTGTGGCTGTGGAGAAGC - $3^{\prime}$ \\
\hline & Rev & 5'- CCTTGTACAAAGCTCATGGAG -3' \\
\hline \multirow{2}{*}{$\begin{array}{c}\angle D H A \\
\text { (human) }\end{array}$} & Fw & 5'- GTTGGTGCTGTTGGCATGGC -3' \\
\hline & $\operatorname{Rev}$ & 5'- GTGATAATGACCAGCTTGGAG -3' \\
\hline \multirow{2}{*}{$\begin{array}{c}\text { LOX } \\
\text { (human) }\end{array}$} & Fw & 5' - CCCCAAAGAGTGAAAAACCA - $3^{\prime}$ \\
\hline & Rev & 5' - CCAGGACTCAATCCCTGTGT -3' \\
\hline
\end{tabular}




\begin{tabular}{|c|c|c|}
\hline \multirow{2}{*}{$\begin{array}{c}\text { Lrat } \\
\text { (mouse) }\end{array}$} & Fw & 5'- CAGAAGGTGGTCTCCAACAA -3' \\
\hline & Rev & $5^{\prime}-$ TAATCCCAAGACAGCCGAAG -3' \\
\hline \multirow{2}{*}{$\begin{array}{c}\text { Mcp-1 } \\
\text { (mouse) }\end{array}$} & Fw & $5^{\prime}$ - CAGCGCAACCACGAGAC - $3^{\prime}$ \\
\hline & Rev & 5'- AGAACTCCACAAACCCATC -3' \\
\hline \multirow{2}{*}{$\begin{array}{c}P A 11 \\
\text { (human) }\end{array}$} & Fw & 5'- CTTCATGCCCCACTTCTTCA -3' \\
\hline & Rev & 5'- GGGCGTGGTGAACTCAGTAT -3' \\
\hline \multirow{2}{*}{$\begin{array}{l}\text { PDGFRB } \\
\text { (human) }\end{array}$} & Fw & 5'- GTGGTGTGGGAACGGATGTCC - $3^{\prime}$ \\
\hline & Rev & $5^{\prime}-$ GAGGAAGCCCACGGTGGGATC - $3^{\prime}$ \\
\hline \multirow{2}{*}{$\begin{array}{c}\text { PEPCK } \\
\text { (human) }\end{array}$} & Fw & 5'- CAAGTGTTCCCAAATTGACGCCACC - $3^{\prime}$ \\
\hline & Rev & 5'- GCCTGAGTAACCTTAAATTTGAAC -3' \\
\hline \multirow{2}{*}{$\begin{array}{l}\text { PFKBP3 } \\
\text { (human) }\end{array}$} & Fw & 5'- GAGAGATGTCAAAAGCTACCTG -3' \\
\hline & Rev & 5'- CAGTCTTTGTAATCCGGGCTGG -3' \\
\hline \multirow{2}{*}{$\begin{array}{l}P G C-1 \alpha \\
\text { (human) }\end{array}$} & Fw & 5'- GCTGACAGATGGAGACGTGA -3' \\
\hline & Rev & 5'- GTGTGAGGAGGGTCATCGTT -3' \\
\hline \multirow{2}{*}{$\begin{array}{c}P G K 1 \\
\text { (human) }\end{array}$} & Fw & 5'-GTTCCTATGAAGAACAACCAG-3' \\
\hline & Rev & 5'-САТСТTТТСССТTСССТТСТTСС-3' \\
\hline \multirow{2}{*}{$\begin{array}{l}\text { PHGDH, Phgdh } \\
\text { (human, mouse) }\end{array}$} & Fw & 5'- GAGGAGATCTGGCCTCTCTGTG -3' \\
\hline & Rev & 5'- GATTTCCCCTTCACCATGTC -3' \\
\hline \multirow{2}{*}{$\begin{array}{c}\text { PKM2, Pkm2 } \\
\text { (human, mouse) }\end{array}$} & Fw & 5'- GAACATCCTGTGGCTGGACTA -3' \\
\hline & Rev & 5'- CCTTCTTGCTGCCCAAGG -3' \\
\hline \multirow{2}{*}{$\begin{array}{c}\text { PSAT1 } \\
\text { (human) }\end{array}$} & Fw & $5^{\prime}$ - CCAAGCACCTGGAACCTCA -3' \\
\hline & Rev & $5^{\prime}$ - CCCATGACGTAGATGCTGAA - $3^{\prime}$ \\
\hline \multirow{2}{*}{$\begin{array}{c}P S P H \\
\text { (human) }\end{array}$} & Fw & 5'- GTCATCAGAGAAGAAGGAATCG - $3^{\prime}$ \\
\hline & Rev & 5'- GTTGCTGGGATATTGAGCTTTG -3' \\
\hline \multirow{2}{*}{$\begin{array}{l}\text { SHMT2 } \\
\text { (human) }\end{array}$} & Fw & 5'- CTGCAGAGGGAGAAGGACAG -3' \\
\hline & Rev & 5'- GATCCAGGTCAAAGGCTTCC -3' \\
\hline \multirow{2}{*}{$\begin{array}{c}\text { TGF } \beta 1 \\
\text { (human) }\end{array}$} & Fw & 5'- TGGTGGAAACCCACAACGAA - $3^{\prime}$ \\
\hline & Rev & 5'- GGCCATGAGAAGCAGGAAAG -3' \\
\hline \multirow{2}{*}{$\begin{array}{c}\operatorname{Tgf} \beta 1 \\
\text { (mouse) }\end{array}$} & Fw & $5^{\prime}$ - TGGTGGACCGCAACAACGCC - $3^{\prime}$ \\
\hline & Rev & 5'- GGCCATGAGGAGCAGGAAGG -3' \\
\hline \multirow{2}{*}{$\begin{array}{c}\text { TIMP1, Timp1 } \\
\text { (human, mouse) }\end{array}$} & Fw & 5'- AGACCACCTTATACCAGCG -3' \\
\hline & Rev & 5' - AACAGGGAAACACTGTGCA -3' \\
\hline \multirow{2}{*}{$\begin{array}{l}\text { UHRF1 } \\
\text { (human) }\end{array}$} & Fw & 5'- CAAGAAGAAGGCGAAGATGG -3' \\
\hline & Rev & 5' - AAAAATTCCCATGGTCCACA -3' \\
\hline \multirow{2}{*}{$\begin{array}{l}\operatorname{Tnf} \alpha \\
\text { (mouse) }\end{array}$} & Fw & 5'- GAGTGACAAGCCTGTAGCCC -3' \\
\hline & Rev & $5^{\prime}$ - CCCTTCTCCAGCTGGAAGAC - $3^{\prime}$ \\
\hline
\end{tabular}




\begin{tabular}{|c|c|c|}
\hline \multirow{2}{*}{$\begin{array}{c}\text { Uhrf1 } \\
\text { (mouse) }\end{array}$} & Fw & 5'- CGAACTATGGATGGGAAGGA -3' \\
\hline & Rev & 5'- ATTCACTGTGACCCACACCA -3' \\
\hline \multicolumn{3}{|r|}{ MSP primer sequences } \\
\hline Gene & \multicolumn{2}{|r|}{ Sequence } \\
\hline \multirow{2}{*}{$\begin{array}{l}\text { M-FBP1 } \\
\text { (human) }\end{array}$} & Fw & 5'- GTTAGTTTTTTTCGTTAGGTTTCGC -3' \\
\hline & Rev & 5'- AATCAAAATATTAACGTCCGTATCG -3' \\
\hline \multirow{2}{*}{5} & Fw & 5'- TTAGTTTTTTTTGTTAGGTTTTGTGG -3' \\
\hline & $\operatorname{Rev}$ & 5' - TCAAAATATTAACATCCATATCAAA -3' \\
\hline \multirow{2}{*}{$\begin{array}{c}\text { M-PGC-1 } \alpha \\
\text { (human) }\end{array}$} & Fw & 5' - ATTTTAAGGTAGTTAGGGAGGAAAC - $3^{\prime}$ \\
\hline & Rev & 5' - AACAAATATTAATAAATACAATCGCT -3' \\
\hline \multirow{2}{*}{$\begin{array}{c}U-P G C-1 \alpha \\
\text { (human) }\end{array}$} & Fw & 5' - TTTAAGGTAGTTAGGGAGGAAATGT -3' \\
\hline & Rev & 5' - CCAAAAAACAAATATTAATAAATACAATCA -3' \\
\hline \multicolumn{3}{|r|}{ ChIP primer sequences } \\
\hline Gene & & 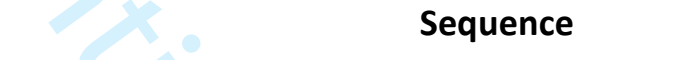 \\
\hline \multirow{2}{*}{$\begin{array}{c}\text { FBP1 } \\
\text { (human) }\end{array}$} & Fw & 5'- GACAGAAGGGCCAGGTGA -3' \\
\hline & $\operatorname{Rev}$ & 5'- GCCAGAGAGAAAGCTATGACTG -3' \\
\hline \multirow{2}{*}{$\begin{array}{l}P G C-1 \alpha \\
\text { (human) }\end{array}$} & Fw & 5'- GGGCACTAGGGTTGGAATTCAATG -3' \\
\hline & $\operatorname{Rev}$ & 5'- CAGATCAGCTTTGATTCCCGGCTCC - $3^{\prime}$ \\
\hline \multirow{2}{*}{$\begin{array}{c}\text { PHGDH } \\
\text { (human) }\end{array}$} & Fw & 5'- GAGCTTTGGCTGAGATGGAGA-3' \\
\hline & Rev & 5' - CTCAAACTCTCCGCGACTCC-3' \\
\hline
\end{tabular}


Supporting Figure S1. G9a, DNMT1 and $\alpha$-SMA immunostainings on sections from normal and diseased human liver tissues. Higher magnification images of the immunostainings showing G9a and DNMT1 detection in myofibroblasts (arrows) in human liver tissues presented in Fig. $1 \mathrm{~A}$.

Supporting Figure S2. Co-immunofluorescent stainings of G9a (green) and $\alpha$-SMA (red), and of DNMT1 (green) and $\alpha$-SMA (red) in fibrotic lesions from diseased human livers. White arrowheads point to positive myofibroblasts.

Supporting Figure S3. G9a, DNMT1 and $\alpha$-SMA immunostainings on sections from normal and diseased mouse liver tissues. Higher magnification images of the immunostainings showing G9a and DNMT1 detection (arrows) in mouse liver tissues presented in Fig. 1 B. Representative images are shown.

Supporting Figure S4. Validation of G9a, DNMT1 and UHRF1 gene expression knockdown in LX2 cells transfected with the respective siRNAs or a control siRNA (siC). The expression of each gene was measured by $\mathrm{qPCR}$ and western blotting $48 \mathrm{~h}$ after siRNA transfection. Representative blots are shown. Blots were probed for $\alpha$-tubulin ( $\alpha$ TUB) to show specificity of siRNAs and equal loading of the gels.

Supporting Figure S5. (A) Analysis of total DNA methylation (5meC levels) in LX2 and hHSCs treated with CM272 (400 nM) for $48 \mathrm{~h}$ and $72 \mathrm{~h}$ respectively. Values in CM272 treated cells are compared to controls (normalized to 100\%). (B) Western blot analysis of H3K9me2 levels in control and CM272 treated ( $400 \mathrm{nM}, 48 \mathrm{~h}$ ) LX2 and human primary hepatic stellate cells (hHSCs). Ponceau staining of total histones isolated from both cell types are shown to demonstrate equal loading. (C) Effect of CM272 on basal and TGF $\beta 1$ $\underline{\text { stimulated collagen protein levels. LX2 cells were pre-treated or not with CM272 (400 }}$

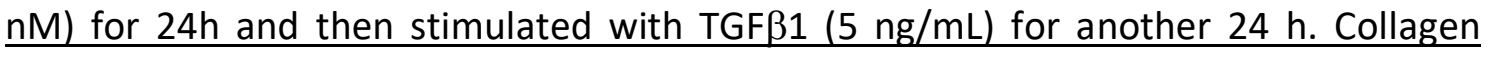


protein levels were analyzed by western blotting. Representative blots are shown. (D) Effect of CM272 on the TGF $\beta 1$-induced expression of fibrogenesis-related genes in hHSCs cells. Cells were treated with CM272 (400 nM) or vehicle (control) for $24 \mathrm{~h}$ and then stimulated with TGF $\beta 1(5 \mathrm{ng} / \mathrm{mL})$ for another $24 \mathrm{~h}$. Gene expression was analyzed by qPCR. (E) Effect of $\mathrm{CM} 272$ on culture activation in primary mouse HSC. Cells were $\underline{\text { isolated and after } 4 \text { days in culture were treated or not with } \mathrm{CM} 272(400 \mathrm{nM}) \text { for another }}$ 3 days. The expression of the indicated genes was analyzed by qPCR. (F) Expression of the indicated fibrogenesis-related genes in LX2 cells treated with the G9a inhibitor BIX01294 (BIX) and/or the DNMT inhibitor decitabine (Dec) and TGF $\beta 1$. Cells were treated with Dec $(5 \mu \mathrm{M})$ for $72 \mathrm{~h}$, and where indicated BIX01294 (5 $\mu \mathrm{M})$ was added for the last 24h. Treatments with BIX01294 alone were performed for $24 \mathrm{~h}$. Where indicated cells were also stimulated with TGF $31(5 \mathrm{ng} / \mathrm{mL})$ for the last $24 \mathrm{~h}$ of Dec treatment or together with BIX. Gene expression was measured by qPCR.

Supporting Figure S6. (A) Western blot analysis of SMAD3 phosphorylation (pSMAD3, Ser423/425) levels in control LX2 cells and in cells pretreated with or not with CM272 (200 nM, 48h) and then stimulated with TGF $\beta 1(5 \mathrm{ng} / \mathrm{mL})$ for $30 \mathrm{~min}$. (B) Expression of BAMBI in control and CM272 treated ( $200 \mathrm{nM}, 48 \mathrm{~h}) \mathrm{LX} 2$ cells analyzed by GPCR and $\underline{\text { western blot. Representative blots are shown. (C) LX2 cells were treated as indicated }}$ with $\mathrm{CM} 272(400 \mathrm{nM})$ and/or the TGF $\beta 1 \mathrm{R}$ inhibitor (Alk5i) $(2.5 \mu \mathrm{M})$ fro $24 \mathrm{~h}$ and then stimulated or not with TGF $\beta 1(5 \mathrm{ng} / \mathrm{mL})$ for another $24 \mathrm{~h}$. The expression of the indicated genes was measured at the end of treatments by PPCR.

Supporting Figure S7. (A) Effect of 2-deoxy-D-glucose (2DG) on glycolytic metabolism in control and TGF $\beta 1$ treated LX2 cells. Cells were incubated or not with 2DG (5 mM) for $\underline{24 \mathrm{~h} \text { and then where indicated were treated with TGF } \beta 1(5 \mathrm{ng} / \mathrm{mL}) \text { for another } 24 \mathrm{~h}}$. 
Lactate concentrations were measured in culture media at the end of treatments. (B) Expression of COL1 $\alpha 1$ and $\alpha$-SMA in LX2 cells treated as described above. Gene expression was analyzed by qPCR. (C) Analysis of H3K9me levels by qChIP assay in the proximal promoter region of $P H G D H$ gene in LX2 cells treated with CM272 (200nM) for $\underline{48 h}$.

Supportting Figure S8. (A) Effect of CM272 on hypoxia-stimulated serine-glycine pathway genes expression. LX2 cells were treated or not with CM272 (400 nM) for $24 \mathrm{~h}$ and then grown under normoxic $\left(20 \% \mathrm{O}_{2}\right)$ or hypoxic $\left(1 \% \mathrm{O}_{2}\right)$ conditions for a further 24 h. Gene expression was analyzed by qPCR. (B) Left panel: effect of PHGDH enzymatic inhibition with NTC503 on basal and hypoxia-stimulated growth of LX2 cells. Cells were pre-treated or not with the indicated concentrations of NTC503 for $2 \mathrm{~h}$ and then were grown for $24 \mathrm{~h}$ under normoxic or hypoxic conditions. Right panel: Effect of PHGDH enzymatic inhibition with NTC503 on basal and TGF $\beta 1$ stimulated collagen protein levels. LX2 cells were pre-treated or not with NTC503 $(30 \mu \mathrm{M})$ for $2 \mathrm{~h}$ and then stimulated with TGF $\beta 1(5 \mathrm{ng} / \mathrm{mL})$ for $24 \mathrm{~h}$. Collagen protein levels were analyzed by western blotting. Representative blots are shown.

Supporting Figure S9. (A) Expression of metabolic genes in primary hHSCs. Cells were treated with CM272 (400 nM) or vehicle (control) for $24 \mathrm{~h}$ and then stimulated with TGF $\beta 1$ ( $5 \mathrm{ng} / \mathrm{mL}$ ) for another $24 \mathrm{~h}$. Gene expression was analyzed by qPCR. (B) Expression of FBP1 and PGC-1 $\alpha$ in LX2 cells treated with the G9a inhibitor BIX01294 and/or the DNMT inhibitor decitabine. Cells were treated with decitabine $(5 \mu \mathrm{M})$ for $72 \mathrm{~h}$, and where indicated BIX01294 (5 $\mu \mathrm{M})$ was added for another 24h. Treatments with BIX01294 alone were performed for $24 \mathrm{~h}$. Gene expression was analyzed by qPCR. 
Supporting Figure S10. (A) Effect of $\mathrm{CM} 272$ on the acute liver fibrogenic response elicited by $\mathrm{CCl}_{4}$ in mice. As shown in the diagram, mice received a single $\mathrm{CCl}_{4}$ injection (i.p.), or its vehicle (oil) and $24 \mathrm{~h}$ later were treated with CM272 $(2.5 \mathrm{mg} / \mathrm{kg}$ body weight, i.p.) or vehicle and were humanely killed $24 \mathrm{~h}$ later. Representative immunohistochemical staining of $\alpha-S M A$ in vehicle and $\mathrm{CM} 272$ treated animals are shown. $\alpha$-SMA protein levels were also determined by western blotting in liver tissue extracts. A representative western blot is shown. (B) Body weights and serum levels of creatinine, $\mathrm{ALT}$ and $\mathrm{AST}$ in mice from the chronic $\mathrm{CCl}_{4}$ administration and BDL models. (C) Analysis of cytokine gene expression in liver tissues from the chronic $\mathrm{CCl}_{4}$ administration and BDL models. Gene expression was analyzed by qPCR.

Supporting Figure S11. Quantification of western blots shown in main and supporting figures after densitometric analysis of images. 

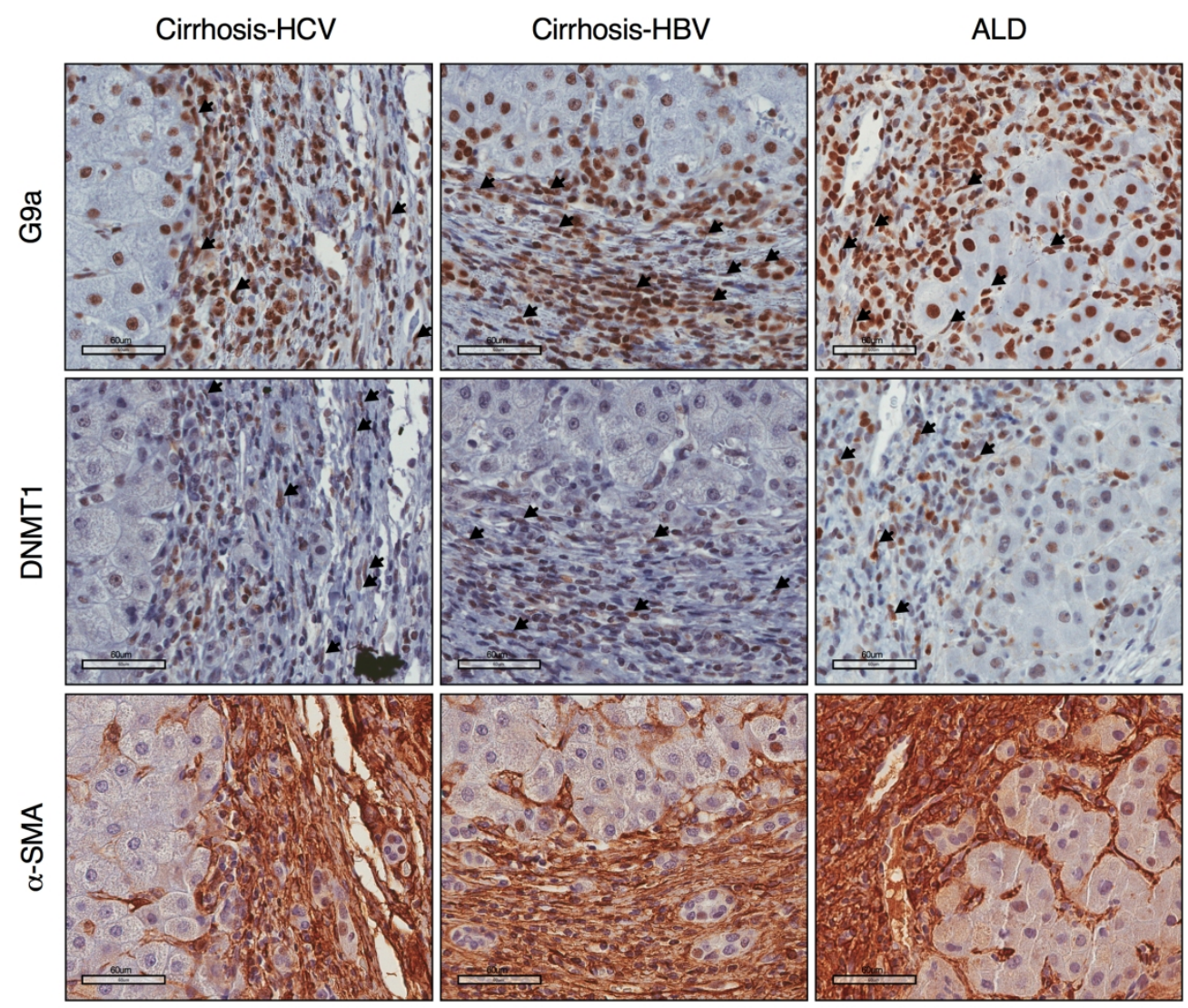

Supporting Fig S1

$186 \times 190 \mathrm{~mm}(300 \times 300$ DPI $)$ 

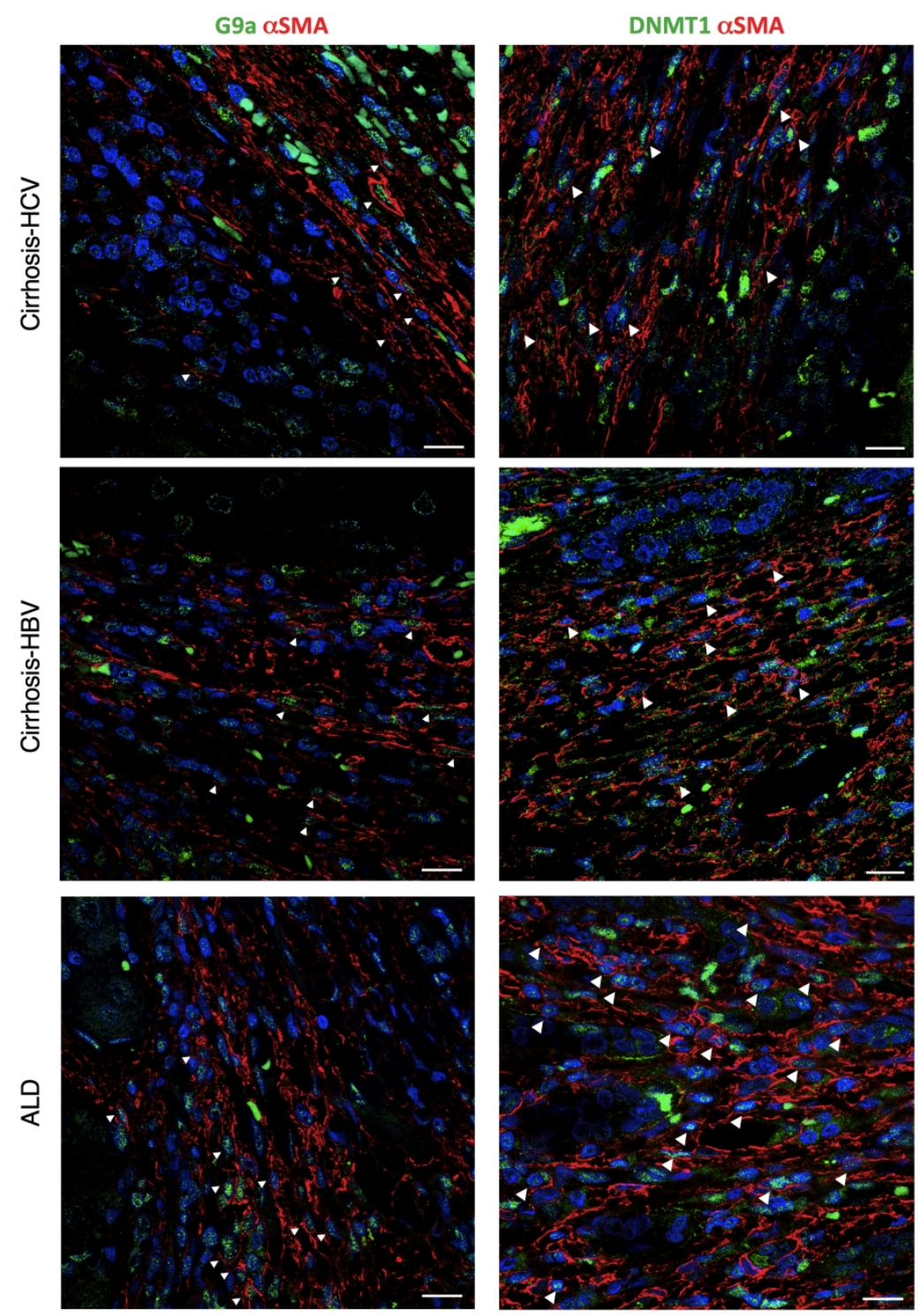

Supporting Fig S2

$167 \times 254 \mathrm{~mm}(300 \times 300 \mathrm{DPI})$ 

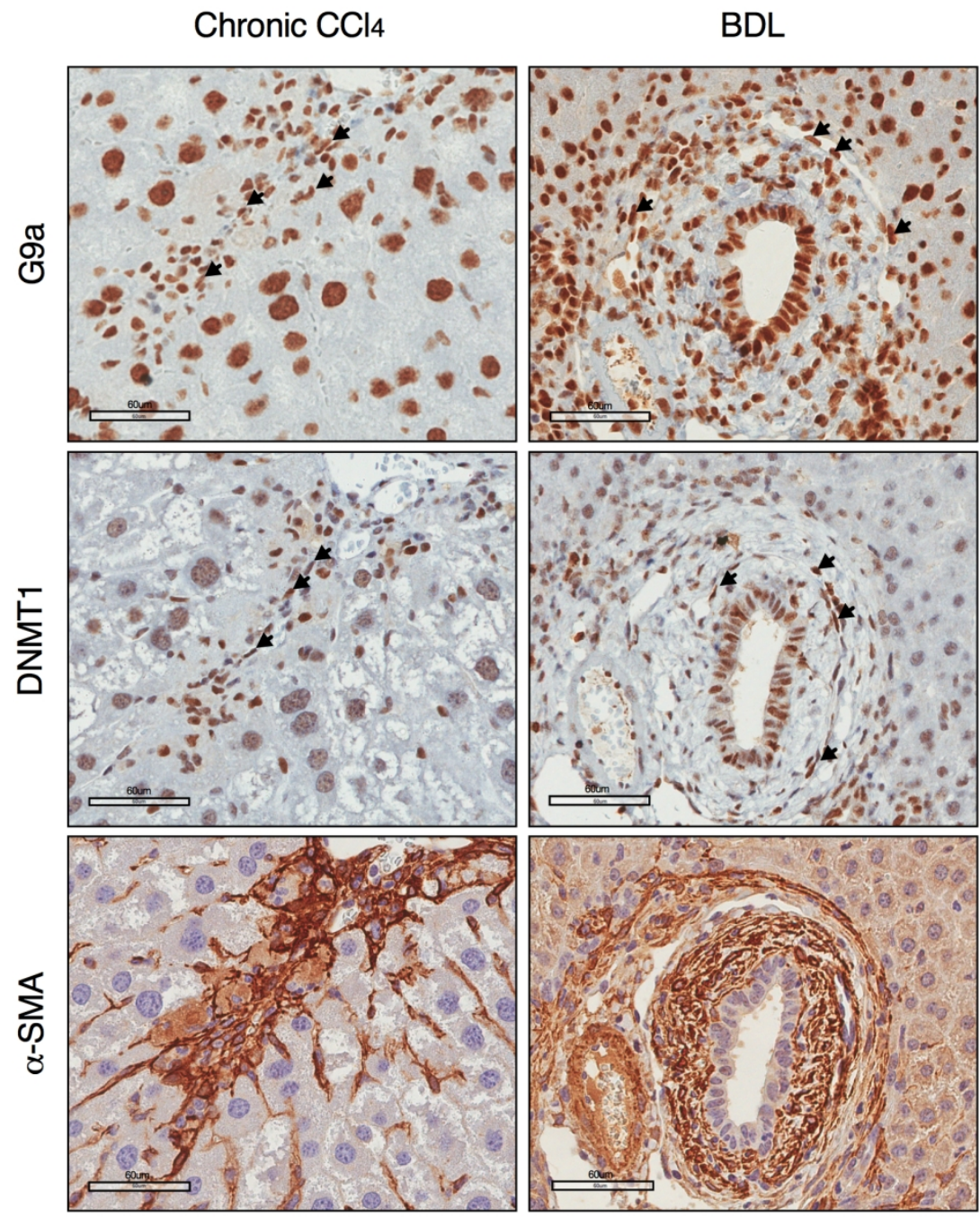

\section{Supporting Fig S3}

$133 \times 190 \mathrm{~mm}(300 \times 300 \mathrm{DPI})$ 

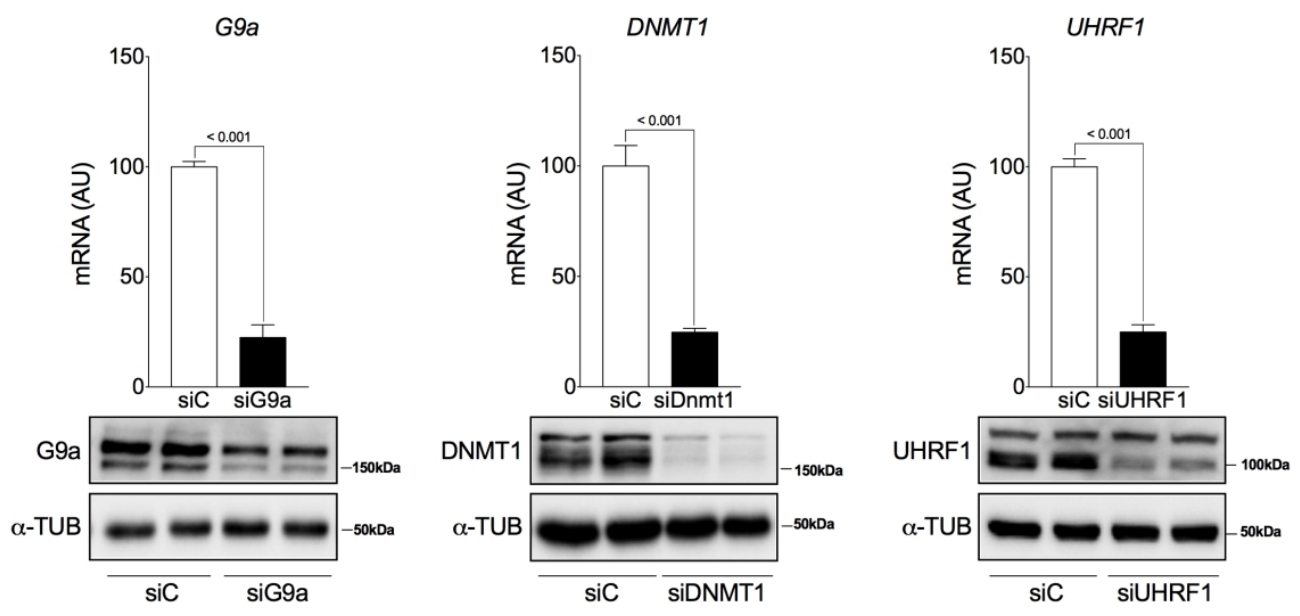

Supporting Fig S4

$188 \times 101 \mathrm{~mm}(300 \times 300$ DPI $)$ 
A

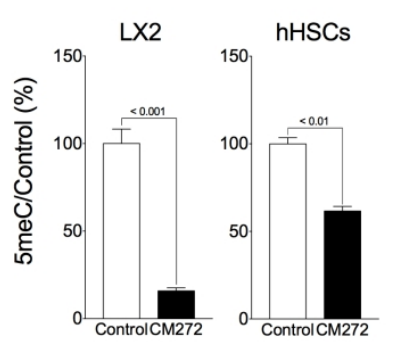

C
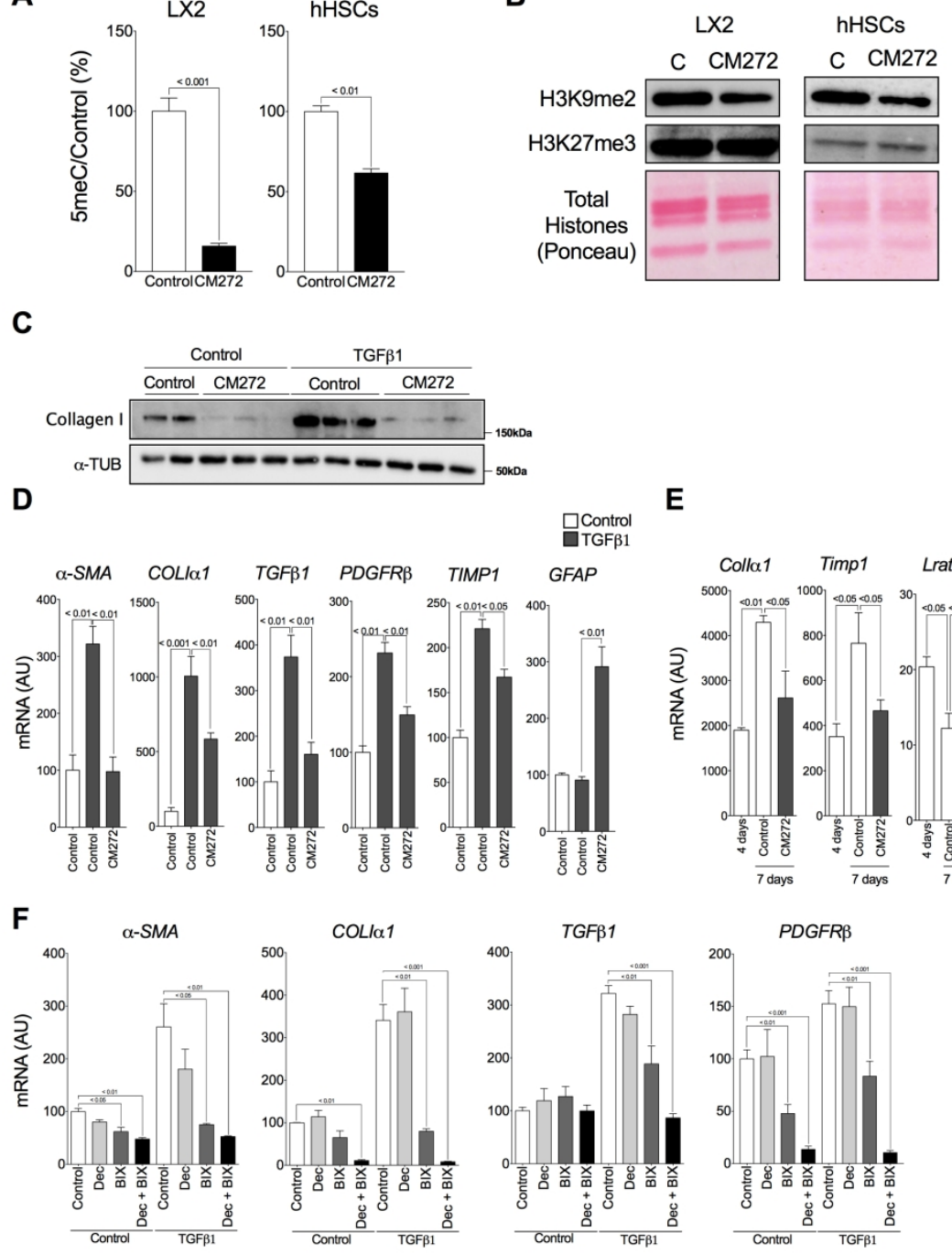

15

17
E
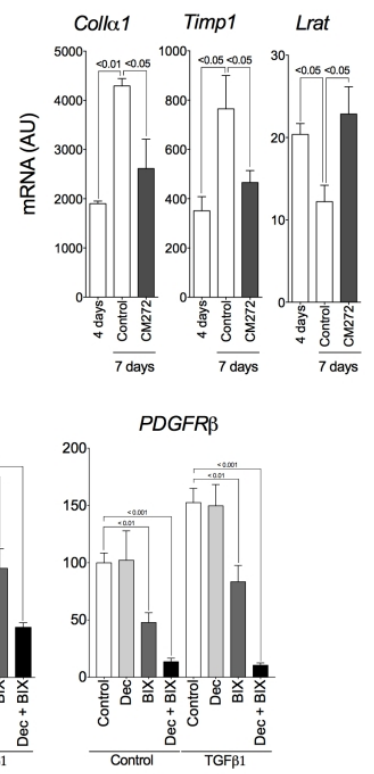

Supporting Fig S5

$189 \times 272 \mathrm{~mm}(300 \times 300 \mathrm{DPI})$ 
A

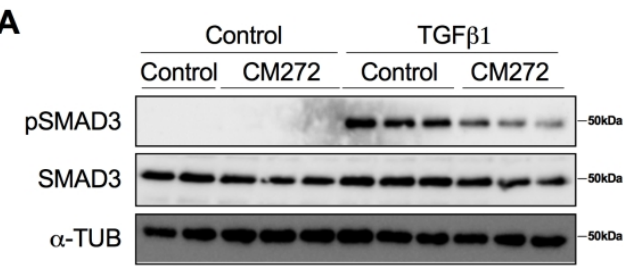

B

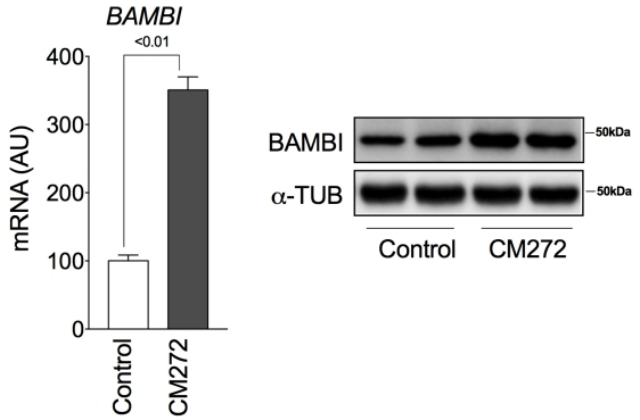

C
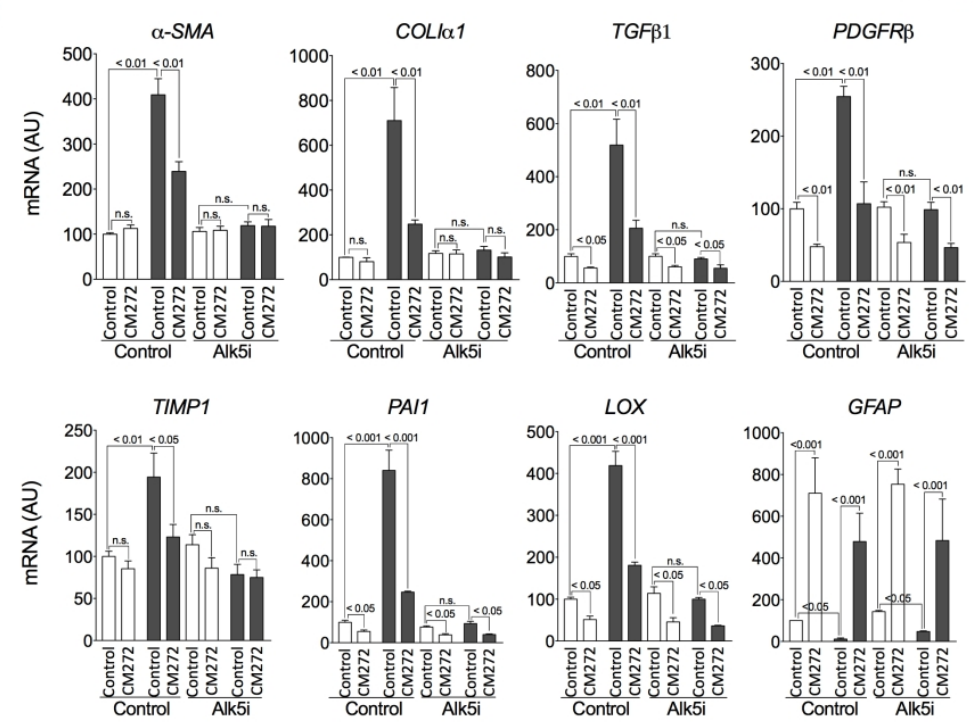

Supporting Fig S6

$174 \times 266 \mathrm{~mm}(300 \times 300 \mathrm{DPI})$ 
A

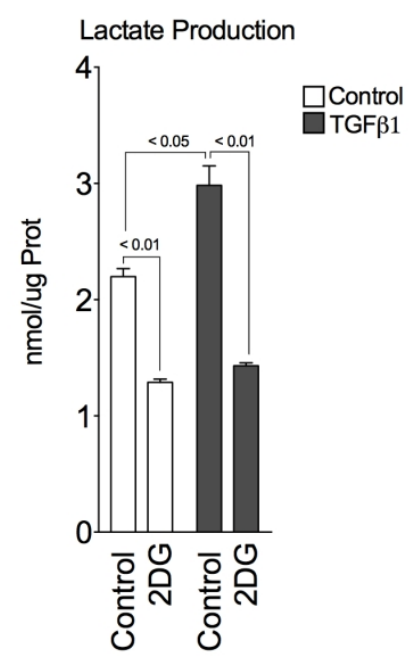

C

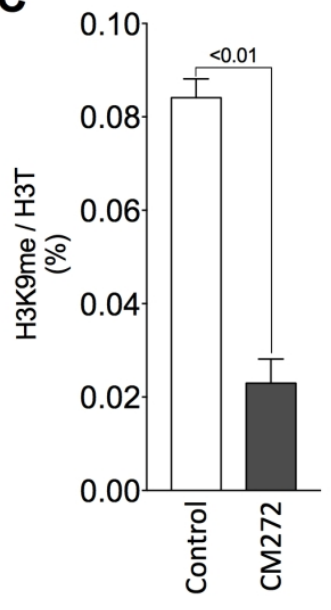

B

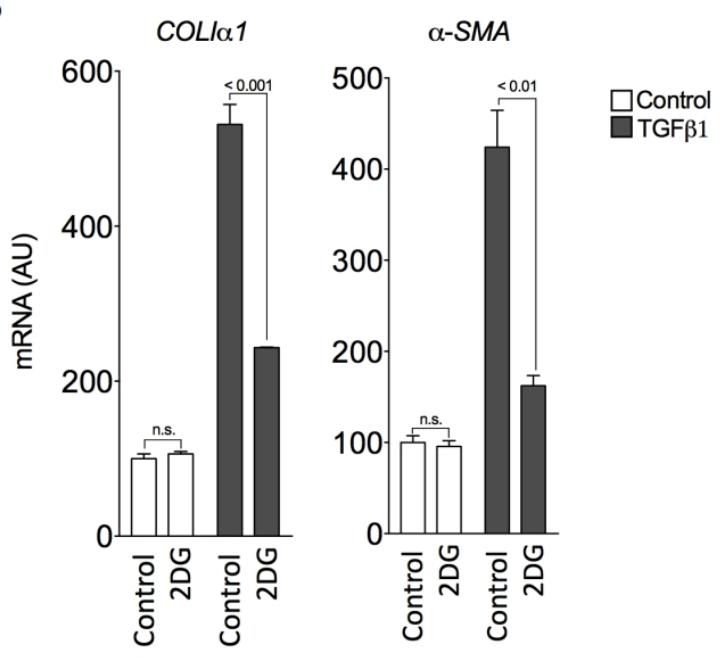

Supporting Fig S7

$169 \times 188 \mathrm{~mm}(300 \times 300 \mathrm{DPI})$

https://mc.manuscriptcentral.com/gut 

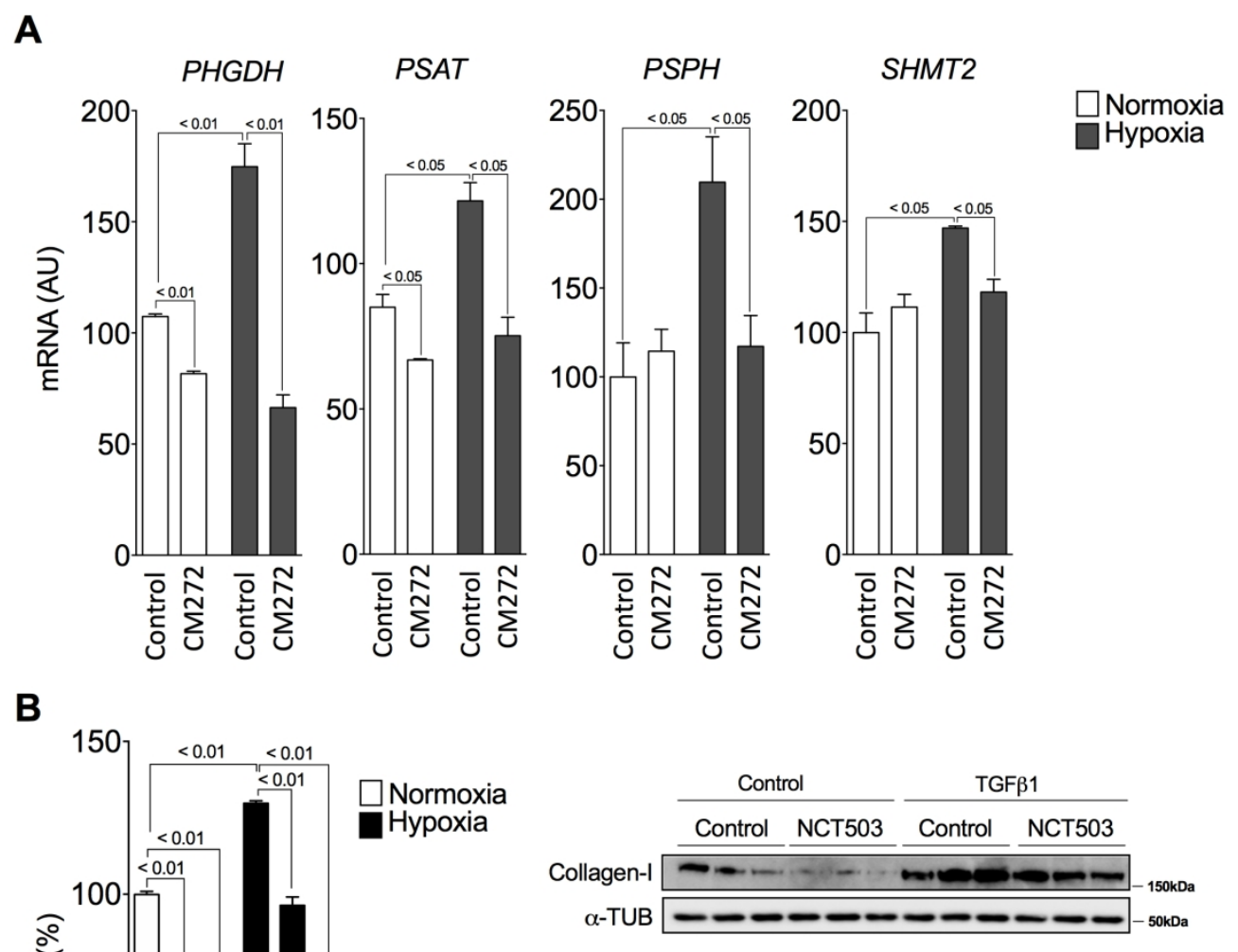

Supporting Fig S8

$182 \times 203 \mathrm{~mm}(300 \times 300$ DPI $)$ 
A
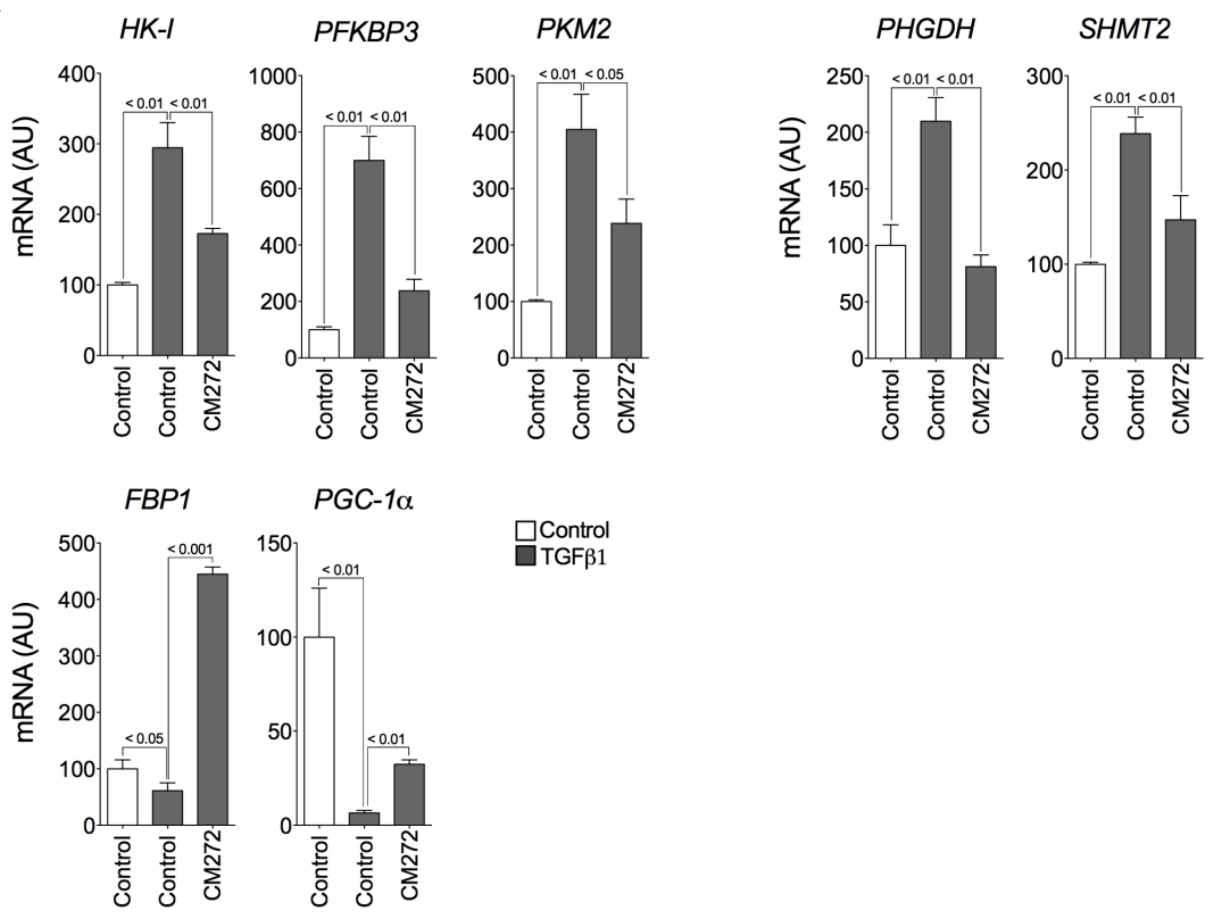

믐ontrol

B

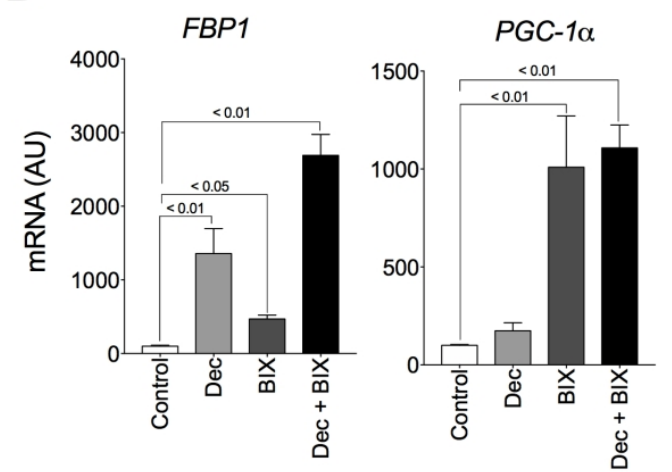

Supporting Fig S9

$176 \times 217 \mathrm{~mm}(300 \times 300$ DPI $)$ 
A

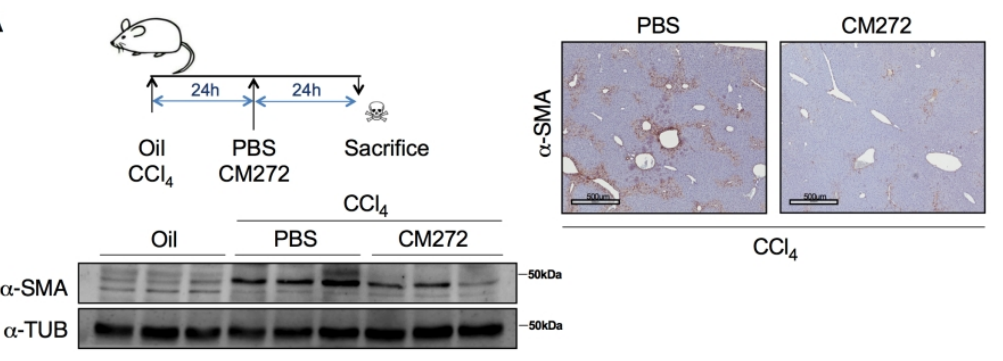

B

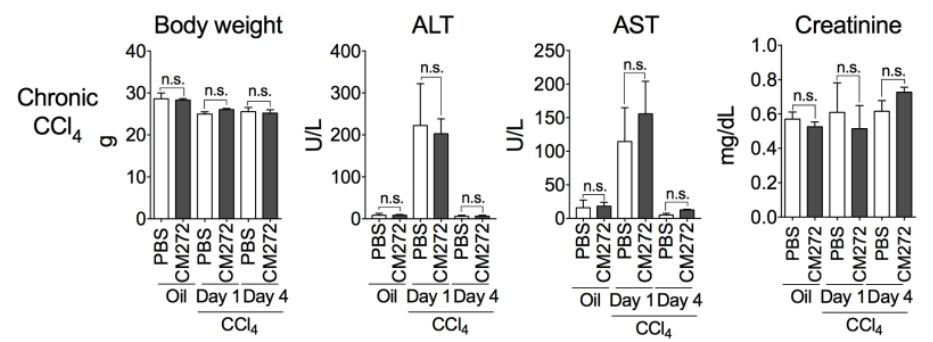

C
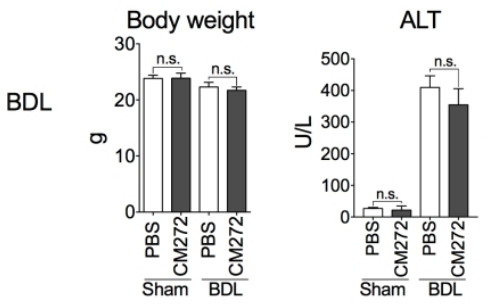

AST

Creatinine
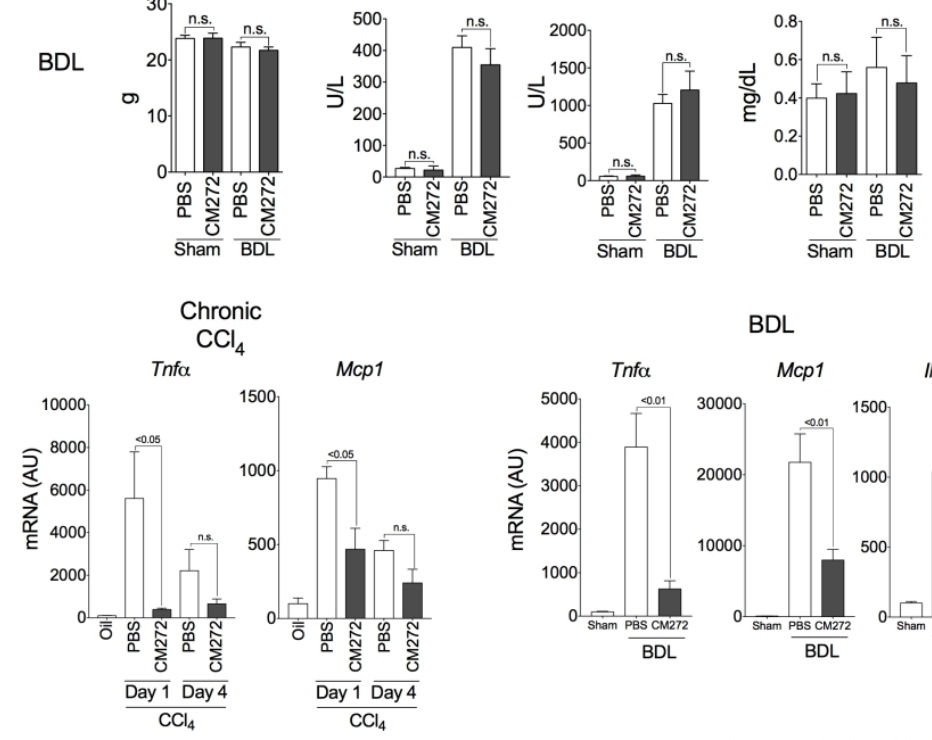

BDL

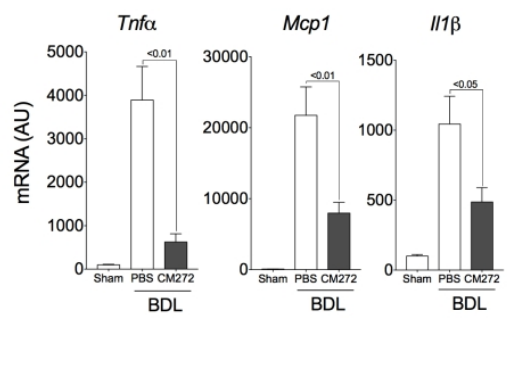

Supporting Fig S10

$186 \times 272 \mathrm{~mm}(300 \times 300$ DPI $)$ 

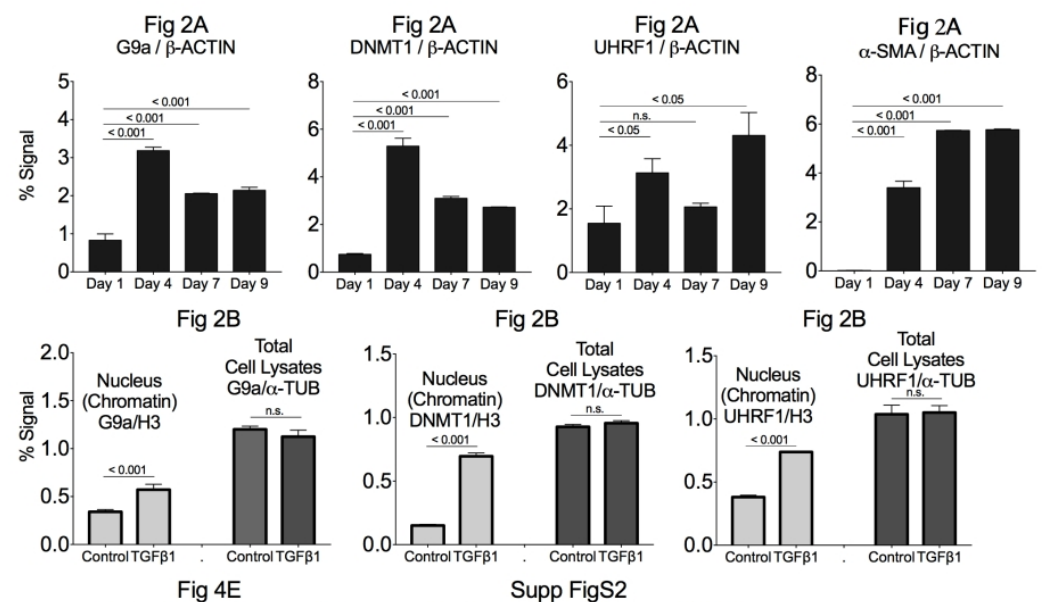

Fig 2B
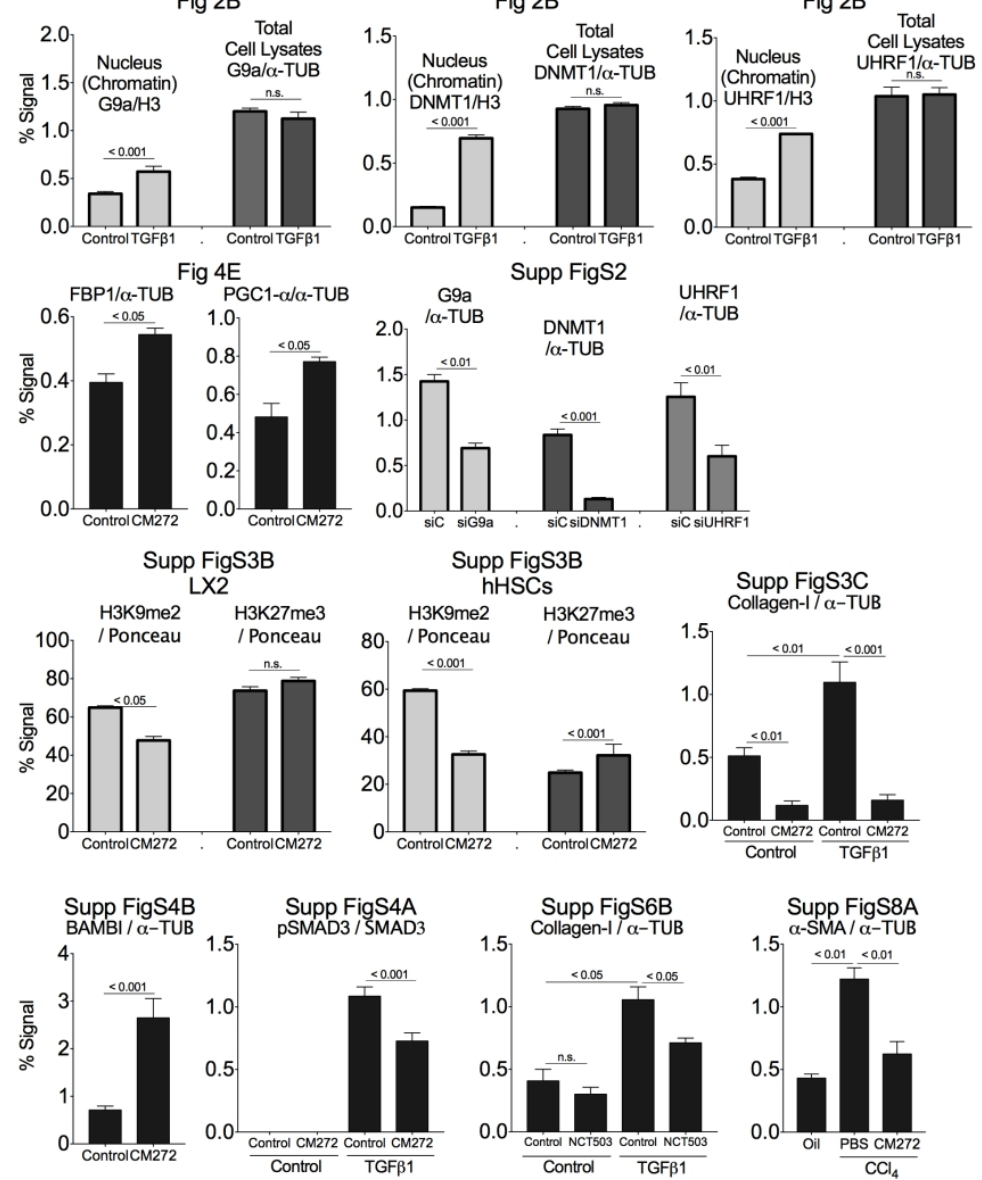

Supporting Fig S11

$181 \times 263 \mathrm{~mm}(300 \times 300 \mathrm{DPI})$ 